\title{
Working with Mandatory and Negotiable Aspects of Personal Codes: Implications of the Narratives of Rural Men for Social Work Practice.
}

\author{
by \\ Gary Glover, BSW, RSW, Carleton University
}

\begin{abstract}
A Thesis submitted to the Faculty of Graduate Studies and Research In partial fulfillment of the requirements for the degree of

Master of Social Work

in

School of Social Work

Carleton University

Ottawa, Ontario
\end{abstract}

November 2012

(C) 2012

Gary Glover 
Library and Archives

Canada

Published Heritage

Branch

395 Wellington Street

Ottawa ON K1A ON4

Canada
Bibliothèque et

Archives Canada

Direction du

Patrimoine de l'édition

395 , rue Wellington

Ottawa ON K1A ON4

Canada
Your file Votre référence

ISBN: 978-0-494-94336-6

Our file Notre référence

ISBN: $978-0-494-94336-6$
NOTICE:

The author has granted a nonexclusive license allowing Library and Archives Canada to reproduce, publish, archive, preserve, conserve, communicate to the public by telecommunication or on the Internet, loan, distrbute and sell theses worldwide, for commercial or noncommercial purposes, in microform, paper, electronic and/or any other formats.

The author retains copyright ownership and moral rights in this thesis. Neither the thesis nor substantial extracts from it may be printed or otherwise reproduced without the author's permission.
AVIS:

L'auteur a accordé une licence non exclusive permettant à la Bibliothèque et Archives Canada de reproduire, publier, archiver, sauvegarder, conserver, transmettre au public par télécommunication ou par l'Internet, prêter, distribuer et vendre des thèses partout dans le monde, à des fins commerciales ou autres, sur support microforme, papier, électronique et/ou autres formats.

L'auteur conserve la propriété du droit d'auteur et des droits moraux qui protege cette thèse. $\mathrm{Ni}$ la thèse ni des extraits substantiels de celle-ci ne doivent être imprimés ou autrement reproduits sans son autorisation.
In compliance with the Canadian Privacy Act some supporting forms may have been removed from this thesis.

While these forms may be included in the document page count, their removal does not represent any loss of content from the thesis.
Conformément à la loi canadienne sur la protection de la vie privée, quelques formulaires secondaires ont été enlevés de cette thèse.

Bien que ces formulaires aient inclus dans la pagination, il n'y aura aucun contenu manquant. 
The undersigned recommends to

The Faculty of Graduate and Postdoctoral Affairs

acceptance of the thesis

"Working with Mandatory and Negotiable Aspects of Personal Codes: Implications of the Narratives of Rural Men for Social Work Practice"

submitted by Gary Glover, B.S.W.

in partial fulfillment of the requirements for

the degree of Master of Social Work

Dr. Michel-Andre Beauvolsk

Thesis Supervisor

Dr. Adje vandeSande

Thesis Supervisor

Dr. Hugh Shewell

Director, School of Social Work

Carleton University

2012 


\section{Abstract}

This exploratory research suggests that social work practice with men would benefit from attending to men's core values, or "code" and the reality that men need to meet a personal and societal performative standard to have a sense of integrity. Two of the core values identified as mandatory to meeting the performative, are 'Connection' (to self, others, and 'something larger'), and 'Purpose', with a particular attention being given to the rural performative standard of 'Instrumental Purpose', the production of something concrete, measurable and useful. 


\section{Acknowledgements}

I would like to acknowledge the support of Cindy, Cedar, Bob, Maggie, Jack, Melissa, Fraser and Mac. They have been patiently supporting me through this long process and picking up the slack at home, as well as providing the constant reminder that there is beauty and goodness in this world. Thanks family...you're the best. A heart felt thanks to the men and women who gave their thought and time to this project and pushed me to do this when I wondered if it was worth it. I hope I have done your stories some justice. Thanks to all the social worker types who encouraged me and are out there every day at the coal face in the misery industry...you're my heroes. Finally, I raise my glass in a toast to Michel Andre and Adje, two of the smartest, nicest people I ever met. 


\section{Table of Contents}

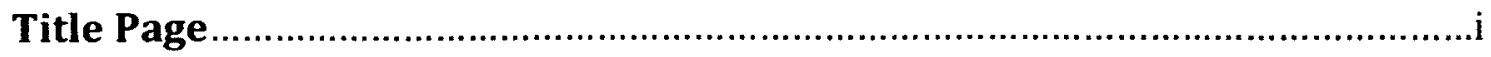

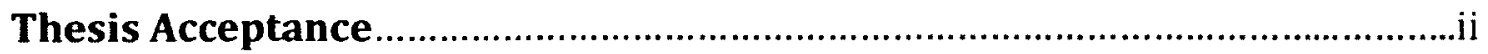

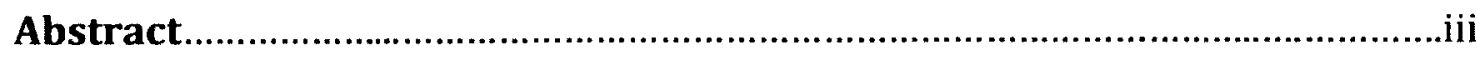

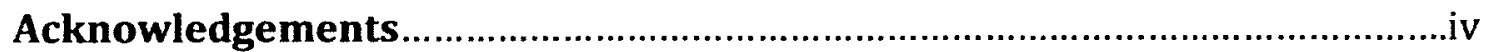

Table of Contents...........................................................................................

Chapter One: Introduction

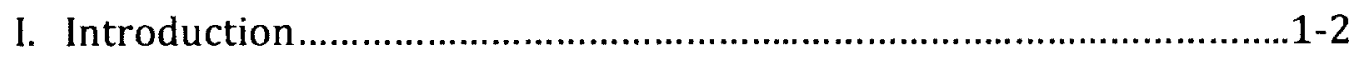

II. Theoretical Perspective.................................................................... $2-6$

\section{Chapter Two: Literature Review}

I. Literature Review............................................................................

\section{Chapter Three: Methodology}

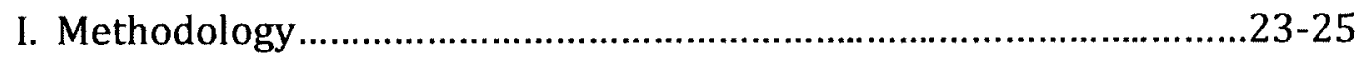

Chapter Four: Findings and Discussion ....................................................26

I. The Major Theme: The Code...........................................................26-28

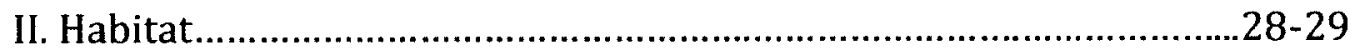

III. Niche

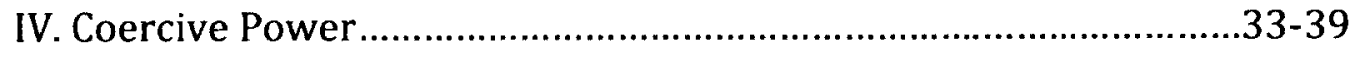

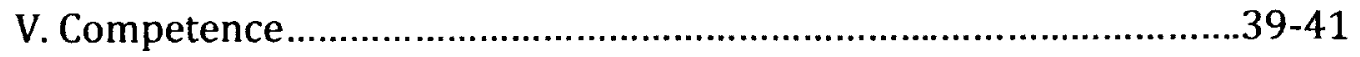

VI. Life Course-Historical Time............................................................41-50

VII. Life Course-Social Time..........................................................50-60

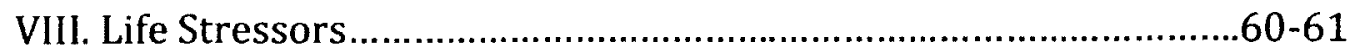

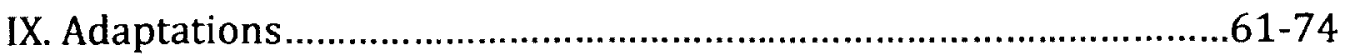




\section{Table of Contents...continued}

$\mathrm{X}$. Adaptations-meeting the rural male performative................................74-80

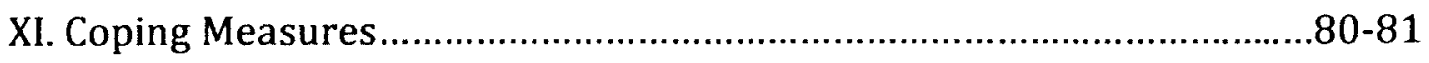

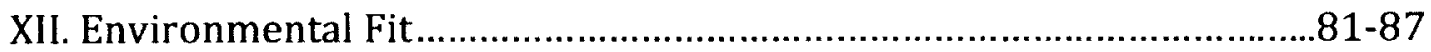

\section{Chapter Five-The Code-Imperative/Negotiable}

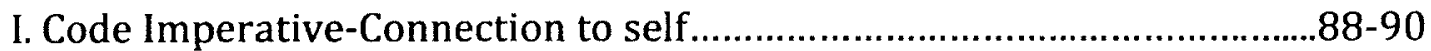

II. Code Imperative-Connection to Social Environment................................90-94

III. Code Imperative- Connection to 'Something larger than myself' .........95-96

IV. Code Imperative- Connection to past and future...................................96-97

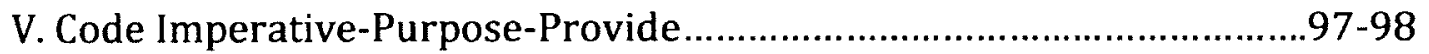

V (i)-Instrumental Purpose .....................................................99-100

VI. Code negotiable- Instrumental purpose ..............................................100

VII. Code Imperative- The Purpose- Protect..........................................101-102

VII. Code Imperative-The Purpose- Nurture ..............................................102

VIII. Code Imperative-The Purpose- Role Model..................................103-105

XI. Code Negotiable- Control over social environment..........................105-106

X. Code Negotiable- Stoicism............................................................106-108

XI. Code Negotiable- Sexuality: 'Not Gay" ..................................................108

XII. Social Value of the Code..............................................................108-109

XIII. Consequence of not meeting the Code...........................................109-111

\section{Chapter Six-Conclusions}

I. Implications for Social Work 
1I. Conclusion \& Future directions for research...................................119-122

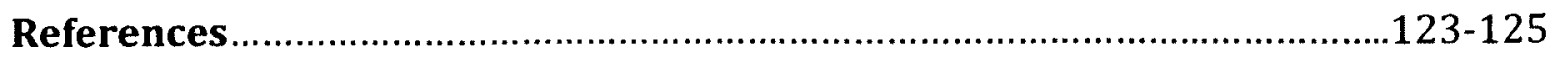

\section{Appendices}

I. Local Demographics ......................................................................126-131

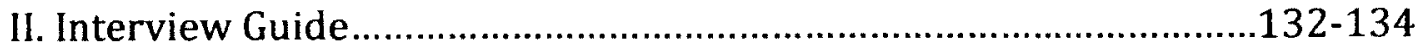

III. Individual Time, excerpts from Transcripts....................................135-195 
Working with Mandatory and Negotiable Aspects of Personal Codes: Implications of the Narratives of Rural Men for Social Work Practice

\section{Chapter One (1): Introduction}

The last three decades have seen enormous change in gendered construction of roles in the personal, family and societal spheres in Canada. Women have led the way in demanding equality in all these areas and men are often perceived to be either resistant and resentful or left behind and confused. At the same time there has been a major shift away from economies of production to economies of service and information. This has had a major impact on men in rural eastern Ontario who had previously found reasonably well paid and satisfying work in farming, forestry and factories. There has been no exploration of the lived experience of these men.

This study intends to begin the process of exploring that narrative in the hope that by extracting themes from their lived experience, men can be engaged in addressing current social and personal issues. The research question is, "What are the implications of rural men's personal narratives to the practice of social work?" This is an intensely personal issue for me. I have farmed and worked at various jobs in forestry and factories to support my family and my increasingly unprofitable farming habit for over thirty years and I enrolled in the school of Social Work at Carleton University because I wanted the words to describe what I saw happening to men and families.

In 2005, I was hired to "Do something about Dads" in a rural eastern Ontario setting. In partnership with another man from the local Children's Mental Health program, I explored various program designs. The program which evolved to meet 
the identified needs of the men was a bi-monthly peer support group which everyone referred to as the "Dad's Group". Despite encouraging anecdotal results, community support, and a provincial award for excellence in Father Involvement programming, it continuously struggled to find stable funding and my position was terminated in June 2011.

One of the men involved in the Dad's Group had been ordered to take the Partner Assault Response (PAR) program after being convicted of domestic assault and suggested that I should apply for the facilitator job with this program. I facilitated the PAR program for five years. Both of these experiences confirmed that there are issues that need to be addressed and gave me confidence that engaging men in the conversation can address some of our persistent and emerging social and individual issues.

I am in a unique position to do this exploratory research because of my age (57), embeddedness in the community (farmer, school-bus driver, musician, former municipal councilor, former summer camp director, etc.), existing relationships of trust, formal education as a social worker, and collegial relationships with local social workers. These are strengths in terms of gaining rich and detailed narrative but it also removes any pretence of objectivity from this research.

\section{Chapter One (II): Theoretical Perspective}

In order to create as comprehensive a picture as possible, I used Ecological Theory as developed by Germain and Gitterman (Germain 1996) Ecological Theory is concerned with determining Person:Environment fit by 
examining a comprehensive set of domains(Gitterman 2008). I believe the textual mapping of a complete ecology of relationships provides the best analytical framework for extracting themes.

The domains of the ecological model were applied to construction of the interview guide, as well as to analysis of the data. This provides a rich and detailed picture of their social ecology through examination of the places they feel comfortable (Habitat), perception of social status, (Niche), connection to people and the natural world, perceived self-efficacy (Competence), experience of injustice, (Coercive Power), major life stressors and coping behaviours. A key concept of the ecological model is "Person:Environmental Fit" which examines participants perception of whether their physical and social environment is seen as favourable or unfavourable to meeting their needs and goals. "Adaptations" examines strategies for improving environmental fit. This model is ideal for this inquiry because it examines "Life Course" of the individual, without trying to mold it into any predetermined set of stages. This is done by inquiry into "Individual time", defined as the person's own narrative of their life, "Historical time", or the experience of the individuals birth and social cohort, and "Social time", the individual's experience of broad societal change within their life.

Life Modeled Practice grew out of the need to apply ecological theory to social work practice and move from the traditional social work model of treatment of deficits towards a practice that focuses on strengths and movement toward environmental fit and health (Germain \& Gitterman 1980). 
Gitterman and Germain (2008) also reference “Deep Ecology” as an

extension of their theory and this is very useful in making sense of the rich and confusing data collected in this study.

"Deep ecology enhances our understanding that all phenomena are interconnected and interdependent as well as dependent on the cyclical processes of nature (Naess, 1989; Reed \& Rothenberg, 1993). Living systems are viewed as networks with other systems of networks nesting within larger networks - "in intricate patterns of intertwined webs, networks nesting within larger networks (Capra, 1996, p. 82). The intertwined, interdependent networks - the web of life have certain common properties (Capra, 1996). Their intricate patterns are nonlinear - they go in all directions and develop feedback loops, which allow them to self-regulate by learning from and correcting mistakes." (Gitterman, 2008, pp. 6667).

These perspectives are ideally suited to encouraging and interpreting men's experience as the strengths based approach and lack of labeling seems to be congruent with identified masculine role definitions (Morgan, 2010 pp. 12-13, Glicken, 2005, p. 288). The focus on growth and ecological function sets the tone for movement forward in a positive direction. The worker/researcher in this model is an agent of client empowerment rather than social control and this is a realistic and desirable stance for this research.

The questions were phrased from a strengths based perspective and roughly ordered from the general to the specific in an attempt to obtain the greatest detail and follow a natural flow. The interview process remained open to diversion and participant interpretation of significant themes.

In addition to questions designed to elicit information on the life model categories listed above, I added a question at the end relating to core values as it seemed to flow naturally from the line of questioning and It has been my experience 
that life choices are made in relative compliance to a personal code. This intuition was supported by the research.

Another theoretical concept which was quite useful is Judith Butler's idea of the Performative. I will not pretend to be familiar with her larger body of work but the idea that there is a performative standard created by social discourse is very useful to beginning to tease out how we can go about negotiating change in personal codes and roles (Butler, 1993, p. 125)

The search for the research question has been an interesting journey that leads after all in a circle. I started this educational adventure in an attempt to find out what is happening for men in my community and I find myself back to the same point, despite one of my trusted and esteemed academic mentors advising me to narrow the scope of the question to a program evaluation of the Dad's Group and another advisor urging me to expand the question. After reviewing the scant literature on the subject of rural masculinities it struck me that what is missing is an understanding of the day-to-day lived realities of men. 1 stumbled on to Gerald de Montigny's discussion of applying ethnomethodology [EM], to social work and realized that this approach could take advantage of my embeddedness (unique adequacy in EM terms) (De Montigny, 2007) and allow the narrative to emerge, "indifferent to, or refusing to contribute to the development of a fund of formal, universal, analytic theory, as such, to shift attention back onto the practical and mundane work whereby the fund of formal, academic, and analytic theories come to be produced." (De Montigny, 2007, p. 104).

Further along in the paper, he links EM to the ecological approach, stating, "Similar to an ecological approach, which asks, 'What is going on?'(Germain and 
Gitterman, 1996, p. 7), EM leads social workers to explicate how it is that people in interaction make that which goes on, appear to go on." (de Montigny, 2007, p. 110). The fog of theory was dispelled by his assertion that, "Perhaps more radically, EM provides tools for fulfilling Marx and Engel's methodological demand that enquiry must not begin with 'men as narrated, thought of, imagined, conceived', but must examine 'real, active men' and 'their real life process' (de Montigny, 2007), quoting Marx and Engels, 1976, p. 36). This was a welcome way through the precious post modern muddle of academic research on male masculinities. The notion that EM was concerned with discovering and honouring the way that people make 'good enough' sense and order in their daily lives to carry on resonated with my experience that the men I live among and work with are doing, "the level best they can with the little the lord gave 'em", as my friend Kenny Blair used to tell me, whenever I would get impatient with somebody. 


\section{Chapter Two: Literature Review}

Rural and Masculine as Pathology

There is not a large academic literature on the effect on rural men of the economic and social transformations of the late twentieth century. However, some work has examined rural and masculine meaning making from American, Irish, English and Scandinavian perspectives, usually through feminist and post positivist lenses. These lenses largely treat rural masculinity as problematic and pathological. One paper published in Scotland takes an auto-ethnographic look at rural resource extraction truck drivers in Canada and one very recent paper examines gender contradiction in Canadian resource extraction industries. A paper that I prepared for another course examined specific local impacts and aspects of these changes. This paper is appended to give local demograhics and context.

Barlett and Conger (2004) looked at definitions of masculine success on American farms and found two definitions of success in their sample. In the "agrarian" perspective, the men valued family partnership in a multi generational farming lifestyle, and in a "industrial" perspective, men defined success as provision of an adequate standard of living to maintain traditional gender roles of the husband as provider and the wife as homemaker. They found that the economic downturn of the 1980's had a more profound emotional toll on the "industrial" farmers, particularly when their wives were forced to obtain off-farm employment, and that these farmers tended to feel less sense of mastery, personal control and optimism, but that the emotional effect of loss of farm was more severe on the men who held "agrarian" values because they viewed it as the betrayal of an inter-generational 
trust. One interesting observation is that distress in the male farmer did not appear in forms easily codified as depression and there was considerable unwillingness to share symptoms of distress. They do note the emergence of a third 'masculine ideal' among those practicing more sustainable agriculture and found success was defined in terms of relationships to the earth, family and community but that there were stresses for these farm families in terms of acceptance into traditional farm communities. They tie this new rural masculinity to the observation that urban men were moving towards a masculinity that could encompass attention to fathering, compassion, accountability and egalitarianism and away from instrumental and power dominance. However they note that while the urban workplace has 'collapsed' as a central locus for performing masculinity, the rural agricultural workplace is still very much the male arena for, "contested meanings and practices" (Barlett, 2004, p. 222).

An examination of American urban/rural social and spatial boundaries in 2011 notes that the 'vertical integration' brought about by trans-national economies, the Reagan era shift away from government support and the transition from a production to a consumption economy have resulted in "rural ghettos", that are ,"spatially concentrated, geographically isolated, and seemingly resistant to effective policy interventions" (Lichter, 2011, p. 578). At the same time Americans hold fast to the stereotype of rural dwellers as the archetypal American; hardworking and loyal to family, community and country. The authors point to Sarah Palin's appeal to 'real Americans' in her 2008 bid for vice president and also note that the decline in family farms is strongly linked to the rise in right wing militia 
groups and that these, "reactive movements are a response to threats to traditional lifestyles and values." (Lichter, 2011, p. 571). They also note that the majority of fruits, vegetables, direct to consumer food sales and organic products, originate on metropolitan area farms, and that poor rural areas are particularly vulnerable to become sites for socially and environmentally undesireable land uses such as 'fracking' for gas, toxic dumpsites, prisons, and agro/industrial feedlots and slaughter operations (Lichter, 2011).

An examination of masculinity in Alaska points to the use of historic and constructed nostalgia to maintain a reassuring construction of frontier masculinity that is tough, self-reliant, heterosexual, rural and white and able to marginalize the feminine, aboriginal and urban(Hogan, 2008). The authors posit that this "nature state narrative" is necessary for the economic and social identity of Alaskans. The social construction of the rugged, nature battling, hegemonic Alaskan Man is necessary to offset the media predominance of the urban hegemonic male, who is classed as vain, materialist, physically and morally weak. This helps establish the identity of Alaska as unique, although the authors point out that many of the narratives used to bolster this identity are Canadian in origin. This may increase relevance of this work to my study area, as identity formative texts such as the works of Robert Service and Jack London were standard reading for Ontario schoolchildren of my generation.

The pathology of nostalgia is seen as a tendency to, "downplay or even erase unresolved traumas from the past, as well as complicate current and future environmental, economic and social problems." (Hogan, 2008, p. 70). The authors 
point to ongoing devaluation of aboriginal worldview and worth, celebration of prostitution, high rates of suicide, sexual assault and domestic violence as a concomitant to the "Real Alaskan" masculine ideals of physical and sexual freedom, danger, autonomy, and self-reliance. The authors note that they find themselves, as transplanted Alaskans, "buying into' the "nature state" mentality and recommend further ethnographic research to examine the lived lives of men in Alaska and the connection to white male privilege and, "the complex social and environmental problems that Alaska faces in an age of the new colonizer: late capitalism." (Hogan, 2008, p. 83).

Another American study looked at the "redneck" hegemonic construction of masculinity in a rural school as a contributing factor in poor academic outcomes for boys. The author identifies the behavioural requirement and the negative outcome; "for working class boys "being a man" meant resisting school, engaging in risky, physically challenging behaviours such as fighting or drug use, and embracing manual or illegal labour. Such constructions of masculinity promoted opposition to school and other institutions. This only calcified the boys working class position, hindering their chances for upward mobility and greater social and economic power."(Morris, 2008, p. 733)

Morris concludes that the economic transition from 'blue collar' breadwinner to tough, rebellious, 'redneck', may produce poor school performance for boys as a, "latent, localized cost(s) of maintaining the broader power of masculinity." (Morris, 2008, p. 747).

The final American paper reviewed takes an ecofeminist and ethnographic approach to studying expressions of masculinity in a deer hunting subculture. Instead of a monolithic male hegemonic ideal, the author found a range of negotiable 
and acceptable male behaviours in this small sample. Littlefield details the ecofeminist linkage between patriarchal oppression of women and the environment and also suggests including the view that masculinity is "an internal struggle between the varying forces that society places on men" and endorses the idea that men should, "fuse the collectivist narrative of breadwinner with the individualist narrative of the rebel to create a man-of action hero who works towards socially redeeming goals."(Littlefield, 2010, p. 103).

Littlefield identifies several acceptable constructs of masculinity within this sub-culture. The 'Efficient 'Traditionalist' adheres to a strict personal code of hunting for harvest to feed his family and strong attention to family, community (including hunting club) and ecological systems. The 'Rational gearhead 'expresses his masculinity by performing "control, order, precision and accuracy." The "Eco-buddy " demonstrates his masculinity by finding his place in nature and the 'Compassionate Transcendental' is an older man for whom the entire hunting experience is about connection with nature through his dogs and their trained abilities and his personal relationships of trust through the hunting subculture that enable his financial success as an automobile dealer (Littlefield, 2010).

He concludes that; "violence towards animals and domination over the natural world and women were not major themes in the hunting subculture" and that what he found was, "men expressing a variety of masculinities that often include aspects of traditional, family-related values, mastery of technology, connection and deep immersion in nature, connection with and care for, the environment, social 
connection with other humans, and even connection with the animals they may end up killing."(Littlefield, 2010, p. 113).

The Scandinavian literature looks at performance of masculinity as it transitions from rural work activity requirements in forestry. Brandth examines the definition of 'masculine' as a social construction as well as a response to a social condition in which "young men who cannot expect to practice their masculinity locally in the image of their fathers and their grandfathers but need to find new ways of being rural men in a late modern age." (Brandth, 2005, p. 149). These researchers note the transition from hegemonic 'tough man' required by traditional logging and characterized as tough, calm, steady and modest, through the transitional representation of the efficient machine operator to the current hegemonic ideal of the: 'powerful man', more skilled in managerial and organizational work.

They also note the tension between the requirement for the modern ideal of men representing themselves as 'powerful' to have some ideological identification with the physical and machine based work valued by the disempowered blue collar forestry workers. The pressure on the blue collar workers is in the other direction. In order to perform rural masculinity and maintain identity and status it is necessary to maintain a separation from the intellectuals and an allegiance to common sense, largely encapsulated in the protestant work ethic of humility, hard work, stoicism and practicality (Brandth, 2005).

A Norwegian study looks specifically at the construction of masculinity for young rural men, noting that the dominant public portrayal of a rural male is as a 
"marginalized loser" (Bye, 2009, p. 278). The researcher found that the majority of these young men were able to find employment in a rural job market that valued practical knowledge and a willingness to work over formal training and certification and that their choice to remain in a rural environment could be seen as a lifestyle choice of "'peace and quiet', 'safety and security' and being 'close to nature"' (Bye, 2009, p. 279) that also avoids the excessive marginalization that they would face in an urban environment. Most of the participants had grown up on small farms with a traditional masculine hegemony of breadwinning and hard physical labour performed in the work place but the loss of jobs in farming, forestry and other resource extraction industry has led to a de-valuing of work as a necessary stage for the performance of masculinity. The choice to 'stay' for these young men necessitated encompassing alternative understandings of masculinity, typically played out more in choice of leisure activities than in increasingly service oriented and part time employment. They were able to add the new traits of caregiving (involved fathering), home-making (especially if it involves use of tools such as in the provision of firewood and snowplowing) , egalitarian intimate relationships (including sharing outdoor interests such as hunting and snowmobiling with their partners), and academic achievement; to the repertoire of acceptable masculine behaviours as long as they were also able to maintain the instrumental hegemonic values of mastering nature and machines in their leisure activities. In this environment a man is expected to be able to fix his own snowmobile and be prepared to engage in risky and illegal behaviour on it, participate in hunting, subscribe to the idea that carnivores should be killed to protect livestock and game 
animals, dress as a 'local' and not in a vain and urban manner, and be able to outperform women in hunting, fixing things and drinking. Although this demonstrates an unwillingness to let go of traditional aspects of masculinity it does represent "a mobilization of strategic identities in order for young men to stay in the rural community and as a way to transform local discourses of rural masculinity into something flexible"(Bye, 2009, p. 280).

An analysis of Swedish media portrayals of rural men found that they are portrayed as "unequal, incapable and deviant" objects, which elevates the urban masculine ideal to the opposite qualities of "Equal, capable and constituting the norm" (Stenbacka, 2011, p. 243). This is based on analysis of several television programs, one of which has been franchised to the North American market (The Week the Women Went), and other programs which have corollaries here. The author argues that these demonstrate "that a hegemonic masculinity today does not involve the rural but to a greater extent sees the rural as deviant"(Stenbacka, 2011, p. 237) and this "othering" of the rural male positions him as a problem, "traditional, unequal and in need of help" (Stenbacka, 2011, p. 243) and, "may have an impact on national politics, on expectations and financial support...Support for something strong, viable and positive is different from subsidies and support for what is perceived as stagnant and backward." (Stenbacka, 2011, p. 243).

A British writer reviews the scarce international literature to examine rural masculinity, referencing Brandth's early work (Brandth, 2005, as referenced in Little 2002) on changing performance of rural masculinity as seen through media portrayals of men's relationships to their tractors. Notice is also taken of Campbell's 
seminal work on the performance of masculinity in pub culture, which requires 'conversational cock-fighting' and 'disciplines of drinking' and serves to reproduce it's own particular version of masculinity. (Campbell, 2000, as referenced in Little, 2002). This writer also points to the essential heteronormativity of rural masculinity, noting that despite homo-erotic portrayals of rural life in various media, rural gay men are often marginalized and experience prejudice and exclusion. The author calls for more examination of the way that rural gender is performed in actual bodily functions in order to get beyond the tendency of socialconstructivist discourse to focus on performance to the exclusion of performativity, ${ }^{1}$ due to the essentially irrational, emotional and animal function of the body. Little argues that the body is not, "a natural entity onto which gendered characteristics are mapped but as part of the production, performance and fluidity of gendered subjectivities" (Little, 2003, p. 260) and traces the transition of the rural body from a traditional ideal of competence and fitness within nature, as opposed to the urban body which was seen as, "defensive, passive and sensually deprived" (Little, 2003, p. 262). Note is made of the modern enactment of the rural body as highly traditional, almost exclusively heterosexual and embodied sexually by both male and female as, "benign, amusing, comfortable and unsurprising" (Little, 2003, p. 269).

A British academic journal editorial examines the construction of the British countryside as exclusively white and notes that this trope of the 'privileged idyl' was exported throughout the British Empire, despite the presence of aboriginal populations and is still used to preserve the sense of 'non-rural other' along racial and ethnic lines and also serves to suppress aboriginal claims-making. They note 
that most academic discussion of rurality suffers this blindness and efforts to address this will entail further re-imagining of "the rural" as we move through a, “multi-functional transition" (Panelli, 2009, p. 361).

${ }^{1}$ Performativity is defined by Judith Butler as, "that reiterative power of discourse to produce the phenomena that it regulates and constrains" (Butler, 1993)

An Irish study examined the degree to which young people see themselves as embedded in their rural context despite immersion in global political, technologic and cultural elements, and a rapid cultural, economic and social transition to a post modern society. They found that all the children exhibited a strong embeddedness within local landscape and culture but that this dropped off among the 14 to 17 year olds and themes of leaving appeared in a substantial proportion of the accounts. Gender differences appeared with the girls typically acquiring a broader range of options for "doing girl" from global media, despite the fact that exposure for both genders was primarily accessed in a way that reinforced gender patterns (the girls accessed popular music and teen drama shows and the boys used computers and accessed sports coverage) (O'Connor, 2005).

An interesting 'auto-ethnographic' approach to examining performance of masculinity and the underlying performativity was undertaken by Rhys Evans (2000). He analyzed his experience as a truck driver in a rural 'staples' (resource extraction) economy in western Canada. He uses this analyses to make the point that masculinity includes a large number of competing and value laden discourses 
and that performance of masculine activities which have a high value in a given time and place allows men to engage in 'un-manly' activities without loss of status or selfrespect. The 'given time and place' he explores is the traditionally rural masculine working-class world of the 'staples' economy, in which skilled labourers were able to make a good wage as long as they were able to 'get the job done', and the respected traits were endurance, skill, humility, humour and independence. This respect was rarely shown by verbal confirmation but by acceptance into the community and absence of ridicule. Physical appearance, intellectual capacity, ethnic origin or politics did not matter as long as 'you could get the job done'. Despite the need to constantly 'do' gender, again and again within a social space, a history of 'getting the job done', provides a good enough view of masculine self to allow defence against the "ambiguous nature of performativity itself" (Evans, 2000, p. 22).

He concludes,

"Performing work offers rural men ways of incorporating behaviours, feelings and tendencies which confound the stereotypes through the use of work performance to occupy an unchangeable position of masculinity which remains undiminished by tenderness, gentleness, confusion and insecurity-in other words, the whole range of human feelings and emotions...A...question which requires more enquiry is whether these masculinities can survive the transition from a rural staples economy to the post-production, rural service economy which seems to be ascendant."(Evans, 2000, p. 24).

A recent Canadian paper proposes that research into this subject would benefit from examination of gender contradictions at the level of material consequences, as well as the performative/discursive level and the intersection of the two. This paper primarily focuses on the negative effect of gender role on 
women but notes that one study found female support for traditional masculine performativity that resulted in the women's own marginalization. In another situation, adherence to traditional masculine definition in a situation of financial stress and reduced employment opportunities, "resulted in an institutional practice of working in unpleasant and risky conditions and neglecting safety standards." (0’Shaughnessy, 2011, p. 139).

This paper supports the idea of the workplace as the arena for performing masculinity and notes that while job performance allows men to access multiple discourses of masculinity, they are ill-equipped to deal with challenge to their occupational identities and established gendered division of labour. Women, on the other hand, are more able to "move between different feminine identities and subject positions" ( 0 'Shaughnessy, 2011, p. 141), although there is some evidence that this increases alienation between men and women, with women coming "to view men as a liability rather than an asset to family finances" ( 0 'Shaughnessy, 2011, p. 141), and men viewing women as dangerous 'sex objects', rather than dependable spouses or family members .

Evans et al propose using the Health, Illness, Men and Masculinities (HIMM) theoretical framework to address the overall lower health status of men in Canada by increasing understanding of the intersection between life course masculinities and other social determinants of health. In comparison with young women, "young men are three times more likely to die from accidental death; four times more likely to die from suicide; and half as likely to seek out health care services." (Evans, 2009, p. 10). 
Men account for $90 \%$ of workplace fatalities, and suffer twice the rate of lost years of life, primarily due to diabetes, vehicle accidents, arterial and heart disease. The authors note that being a woman is the strongest predictor of preventative and health promoting behaviour and that there are systemic barriers to men accessing health care services. An example they use is that typical screening tools for depression are biased "towards capturing traditional 'feminine' signs of depression...rather than the anger, emotional numbing, substance abuse and impoverished relationships that typically emerge in and around men's depression." (Evans, 2009, p. 12) They also note that the "Canadian health care system monitors girls and young women's bodies to a far greater extent than those of young men." (Evans, 2009, p. 12), and that elderly men are virtually invisible in today's society. These authors state that "hegemonic masculinity and traditional beliefs about manhood are the strongest predictors of individual risk behaviour over the lifecourse" (Evans, 2009, p. 13) and recommend using the HIMM framework to develop interventions that address these tremendous health disparities (Evans, 2009). The prime initiative they introduce is the Australian social movement of “Men's Sheds" (Evans, 2009). These sheds provide men with an inclusive and nonjudgmental meeting place where they can work on projects in company with other men and in the process, build self respect and self care abilities. "The number of sheds has been doubling every year for approximately ten years" (Morgan, 2010, p. 12) and is slowly gathering support of more traditional mental health services. The movement has also spread to Great Britain. In Canada, there is one Men's Shed that 
has been operating in Winnipeg for four years now and interest in the model from men in several other provinces (Mackie, 2012).

As can be seen by this literature review, most of the academic discourse sets male masculinity as problematic and pathological. This has largely been true in writings on therapy for men as well, although some therapists such as Carl Whitaker and Paul Glicken, have developed methods which are more inclusive of male sensibilities. Some of the primary aspects of both approaches are use of a collaborative, strengths-based approach and the use of humour and metaphor to provide objectification of personal issues and reduce men's defensive reaction to labeling .

A study of use of support groups for older men produced recommendations that are similar to the approaches of both of the above named therapists; use of a strengths based approach, focus on task, provision of clear structure, building reciprocity into the exchange, specific inclusion of men in advertising and images, respect and accommodation of power challenges and the tendency for men to rely on women for emotional and practical care giving (Smith, 1997).

There is also some reference in this literature review to ways in which men have accommodated to change with positive re-negotiations of the masculine enactment. One of the key themes that emerges is the embodiment of the 'caring father' as an acceptable masculine performative discourse.

The body of academic work on father involvement is relatively new and social work has been slow to incorporate any consideration of fathering, perhaps because it is only within the last decade that this has come into the public 
consciousness as an emerging issue. In 2009 , a review of the educational preparation for working with fathers in Canadian Bachelor of Social Work programs found that there were almost no references to fathers in the programs they surveyed (Walmsley, 2009, pp. 78-79). In the very few instances where there was any reference to fathers, the source material was usually American. The authors point out that there are significant statistical differences in family structure between the two countries. Canada has seen a boom in same sex marriage, father led single parent families, and joint custody settlement in family court and also has a lower recommendations divorce rate than the United States ${ }^{2}$ (Walmsley, 2009, p. 85). This lack of attention to fathering in the Social Work curriculum is linked to an observed invisibility of fathers in child protection and family service settings (Walmsley, 2009, p. 75-77).

The Canadian Father Involvement Research Alliance (FIRA) arose out of a partnership between the Community Action Program for Children (CAPC) and the Canada Prenatal Nutrition Project (CPNP) of Health Canada and has produced a number of research projects specific to fathering in Canada. The bulk of this research has been from a population health perspective, examining benefits to children, mothers, fathers and communities and there has been very limited financial support for community based programs or attention to the lived experience of fathers (Lero, 2006).

In an assessment of the state of Father Involvement programs in English speaking Canada, John Hoffman speaks to 'best practice' for these programs. While 
there is no attention given to viewing participation in these programs through the lens of performativity, it can be seen to underlie most, if not all, of his

${ }^{2}$ In Canada the number of same sex couples grew 32.6 per cent between 2001 and 2006. Common Law family couples increased 18.9 percent, and father led single parent families increased by 14.6 per cent while mother led single parent families increased by 6.3 per cent. $51 \%$ of family court judgements award sole or joint custody to fathers. This does not always mean custody in terms of living arrangements but refers to shared decision making for the child.

recommendations. Key factors for program success include working from a strengths based approach, developing specifically masculine (and culturally sensitive) program elements and role models in consultation with fathers, and developing a community narrative of the importance of men-as-fathers (Hoffman, 2011).

The conclusion I draw from this review of the academic literature, as well as my previous academic enquiries, is that the critical and largely unexplored element required to engage men in addressing personal and social issues is to gain an understanding through their own narrative of how they live their lives as men. This research is designed to do that for a specific sample of men in a rural locale in Ontario that has undergone considerable economic and social change. 


\section{Chapter Three: Methodology}

There has been no study or application of the lived experience of rural Canadian men in social work research and practice. This exploratory research uses qualitative methods to extract themes from taped interviews that were conducted using an interview guide based on the domains of the Life Model of Social Work (Gitterman, 2008) practice. The aim is to identify themes for clinical use, further discussion and research.

The sample is composed of ten adult (over $18 \mathrm{yrs}$.) men from rural and small town eastern Ontario, ranging in age from late 20 's to early 80 's. Additionally three women contributed their thoughts. The participants were selected on an availability basis from existing community contacts and an attempt was made to include men of different ages, socioeconomic status, occupational backgrounds and political leanings.

Interviews were conducted and recorded with eight individuals and one small group of two men and one woman. An interview guide was used (appendix 2), but participants were not constrained to the interview guide questions and topics of individual concern and insight were explored, sometimes in great depth and detail.

The interviews were transcribed and made available to the participants who had requested this option. It was understood that the participants had seven days to withdraw from the research from receipt of transcription or from the date of the interview if they chose not to review their transcript. None of the participants withdrew. 
The transcripts were reviewed several times to strip out identifying information and to divide the narrative into the domains of the Life Model. New categories were created for narrative which did not fit into any of the Life Model domains and some domains were seen to be absorbed within existing categories. The material was reviewed three times and I felt that by this point all of the narrative had been grouped into like categories (theoretical sufficiency). Themes, connections and contrasts were emerging by this point as well and the first draft was constructed by selecting quotes or groups of quotes which conveyed the patterns emerging.

The entire body of transcript was provided to first reader Dr. Beauvolsk, to provide triangulation on my effort to construct categories and themes from the deep and rich data. I then wrote the second draft with further refinements of the themes, connections and contrasts and provided this to Dr. Beauvolsk for his comments. I was particularly concerned that the quotes were longer than is normal in academic work, but felt that reducing them to even these lengths was removing valuable context. I proposed including an appendix of selected passages to convey more of the linguistic and narrative context and have included this as appendix 3.

Dr. Beauvolsk supported my proposal to maintain the integrity of the data within its context, suggested structural and formatting changes and provided assistance on these changes. This has been extremely useful given the depth and complexity of data provided and my own embeddedness in the culture. It is impossible for me to draw objective conclusions and this necessitates presentation of a thesis that includes as much detail as possible and points to as many 
connections as I can find so that readers can contribute their own perspective to this exploratory dialogue. 


\section{Chapter Four: Findings and Discussions}

The intent of this research was to use the Life Model (Gitterman, 2008) as a guide to ensure that a relatively complete ecology of these men's lives would be explored in the interviews. I have also used it as an analytical tool to organize the material into an ecological system. The focus was on understanding how they see themselves as adapting to changes in the world in the hope that their adaptive strategies could inform social work practice with men.

The depth and complexity of material produced was frankly overwhelming, enmeshed as it was in personal narratives that defy neat categorization. During the analyses phase of this research I heard someone on the radio say that chaos is a pattern that appears random and that certainly resonates strongly with my experience of trying to reduce this material to simple themes and also mirrors the principles of deep ecology. Out of all the material I have chosen to highlight "The Code" as the main theme that has significance to social work practice. This reductive process leaves me with a profound sense of regret for the loss of the cultural context and complex interconnection that the narratives demonstrated. In order to address this loss, I have included an appendix of transcript passages which I hope will help situate the shorter quotes within their context.

\section{The Major Theme: The Code}

The performative code was supported as the way that these men make sense of their life. This code is not spoken but was clearly understood by all the participants when it was named. They also understood how it is reproduced and enforced by social discourse and see both the value and some of the problems that 
the code creates. The Code conforms to the basic principles of Deep Ecology. It is based on interdependence of networks, re-occurring natural patterns and self correcting feedback loops which provide flexibility as long as diversity is respected and change is negotiated within the tolerance levels of the ecosystem.

As I have come to understand that these men order their lives by a comprehensible, although unspoken, set of personal rules, I have begun speaking to male and female clients about this in my clinical practice and I am finding that it gives them a way to objectify "who they are" and negotiate flexibility in their performative as they come to understand that this flexibility is not only possible but sometimes necessary to accommodate to changing life circumstances while still honouring aspects of their code that are functional. This has provided valuable triangulation on the findings.

The prime aspect of the code is "Connection" and this emerged as "Connection to Self", " Social Connection ", and "Connection to Something Bigger". The second main code performative is "Purpose"; the need to Provide, Produce and Protect, preferably in an instrumental, concrete, 'hands-on' way (instrumental purpose). The code requirement of Producer/Provider serves as a means of Connection and could be negotiated as long as Connection is maintained. Other performative requirements that are commonly understood such as Instrumental Purpose, Stoicism, and "Not Feminine/Gay", were also secondary to "Connection" and therefore negotiable.

In these findings I will describe the ecology of these men using the Life Model domains of Habitat, Niche, Coercive Power, Competence, Life Course, Coping 
measures, Environmental Fit and Adaptations. As a specific aspect of Adaptations I will look specifically at rural masculine communication and the differences these men identified between urban and rural men. Once the context is set I will look more closely at the performative "Code" and it's mandatory and negotiable elements and examine some of the implications for social work practice and directions for future research.

\section{II-Habitat-where they feel comfortable}

Within the Life Model, Habitat refers to the places where the organism can be found, such as nesting places, home ranges, and territory. The participants were from Eastern Ontario rural and small town locations, concentrated in the County of Lanark, and including participants from Leeds- Grenville and Frontenac Counties. They expressed a range of comfort in different habitats. One man said,

"I have very little contact with urban, by choice...I just want to stay out here and look at the world... you know I go into town, I'm an observer not a participant... I go into town I see third-generation welfare people, I see people haven't got a job and never ever plan to get a job... you don't see that out here as much. I go in with my friends... scurry back to my little sanctuary here."

Other men spoke of escaping, "I moved away up here... just to be that far away from her", and,

"I'm a transplanted urban person to the country and the origins of my family are from rural but then the generation before me became urban and then professional which gave me my advantage and choices and then when I saw the world laid out before me with the permanent job in the government right out of school and all that, I tried it and I hated it and I couldn't work there, it'd be a living death." 
Typically men that were more educated or who had grown up in an urban environment, were more comfortable moving between urban and rural environments,

"I don't have any trouble really going between them because I'm pretty much myself in both worlds ...the city people love to be outraged by... talk of shooting squirrels and things."

A young man noted,

"If you're a product of a family who is from this area then you're going to grow up with a certain outlook... I had the city influence as well as the country influence and still to this day I'm attached to both. I love the city and I love the country, each for each reason...I love the country for it's...quaintness and it's 'naturalishness', ....and I love the city for ... it's cultural vibrancy ... but I think if you only grow up with a country sort of background you're scared of the city."

Another man who said he had lived in the city and "hated it" objected to this classification of the country dweller as 'quaint', saying that he found this did not recognize the amount of effort required to make a living in the country.

\section{III-Niche-perception of social status:}

Within the Life Model, Niche refers to the position occupied by a species of organisms within a symbiotic community, that is, their place in a community's web of life. The participants were overwhelmingly of British (primarily Scottish/Irish) descent, with some German heritage and some undeclared First Nations heritage, and ranged in age from late twenties to early eighties. This is a restricted demographic but largely representative of the intended study population and suits the narrow and deep exploratory nature of this research. There may be a tendency 
to view this as a dominant cultural norm but the participants sense of environmental fit indicated that they felt this was no longer the case in society and for those most enmeshed in this culture, they readily endorsed the idea that they were 'dinosaurs', preserving their culture in the face of implacable change and hoping to pass on what they see as valuable in their world view and experience.

One participant analyzed the political disenfranchisement of those of British descent as a clash between the French and English cultures. "That's why, at this point in time, we're having so much trouble with the French, they were taught to be bureaucrats, we were taught to be tradesmen". I have appended narratives that demonstrate a manner of speaking that is characteristic of the Ottawa Valley Scots/Irish brogue and I believe that this is a relevant part of the rural culture in this area, particularly informing the valuing of stoicism, work ethic, community, family and individual choice.

In general, those who had cultural experience outside their local rural community (more urban experience, more education), were able to express the social devaluation of the rural culture.

"I would work on my uncles farm... and hay and that kind of thing...it imprints that...thing of...pride...to me...farming and rural people always had a place of honour...a place of dignity...I always had an admiration for that... it's not honoured, but it deserves to be."

Another man said,

"We're in a new age... and we're leaving the one behind and the one behind had a lot of good in it... just like contact sports has gone stupid cuz money got involved in it so it's not even about team work or play". 
There was a clear sense of division between different cultures within the larger rural culture, with the most obvious being the "newcomer", or in some cases, "the hippy" or "back to the lander",

'I've been here for comin' on 43 years so...I've been adopted...I'm an outsider in one sense but the community's put me through the fuckin' screen many times and tested my mettle and I end up still here so they've just given up and accepted and I'm one of them, you know what I mean? I'm Bi...I can go either way (laughs). So...the outsider is my...stance."

In general, these "outsiders" showed a greater self-awareness on this topic and attributed that to more "triangulation on the rest of the universe". In describing a local "hippy" music festival which has been run by volunteers for over thirty years one of the participants described the niche it occupies as, "one of the few places on the planet where you can't buy a coke".

Cocaine is noted as a major issue by several participants, oxycotin by one and alcohol and marijuana are accepted as common social intoxicants Two of the older and more socially conservative participants consider marijuana destructive and said they have never seen drugs, although they both consider the use of drugs to be widespread, "Over $90 \%$ of the people in this neighbourhood smoke pot".

The theme of societal devaluation of rural values emerged for all those who had migrated from the city, as well as an ability to more clearly identify the differences between the urban and rural culture and an articulate defence of rural values,

"That's the culture then, right there, and the culture that I took on when I got here was... the people that we connected with were not the local people, they were all going to the factories. It was the old people that were still on the farm that took us in and we could relate to...not their kids, they were... somewhere else." 
It is fairly obvious to everybody in the broader rural culture who belongs to which subculture but there are overlapping sets of values and allegiances, "He's just like you or me, but he's a redneck and he thought I was a greenie and his buddy even more redneck". One man identified that some people might label him "one of the old boys" but rejected that label and asserted that he was, "A generally caring, supportive fellow". The appreciation and respect of the "newcomers" for what they learned from the older generation was a repetitive theme,

"Not warm and fuzzy but he's coverin' your back ..that's the old way...and he would never thank you for anything you ever did for him...the most awesome intelligent fuckin' neighbour I ever met...he is a walking computer...every little story in his head, he is an egomaniac when he's running his (machinery)...he is king ...and he can do no wrong, and he is 80 some fuckin' years old".

One participant who had grown up within the child welfare system said he,

"considered myself the same level as a dog, because dogs come into your family...they're either shot, they're kicked...or given away...well, hey...that's exactly what happens to me, I'm either kicked or given away...haven't been shot yet but had almost my face ripped off."

Within the rural culture, it was expressed that these men still felt that they enjoy high status, “We're still allowed to be men here ...it's diminishing...there're a lot of rules but we still rock here man...we own it, so things are good."

The oldest participant (early 80's), who has farmed all his life, stated,

'The man livin' in the country has so much advantage over the man livin' in the city, it's not funny...well, like us here you know, and we're not able to do much anymore ...I don't work...my shoulders and arms are done and my hearts no hell but it don't bother me too bad as long as I behave but we have a good garden and we've 12 hens ...you know what I mean and up until 2 years ago I had a good team of horses to go out and drive, you know what I mean...and work, and out and ahead of that I'd use them in the bush...

and, oh so far ahead...you burn your wood instead of burnin oil...now, a year ago...I was 79 years livin' in a house that burnt wood and last year I had trouble pilin' it...when we were done putting in the oil I had spent over 3000 dollars ...you 
know what l'm comin' at...no sense...but....we're comfortable with the oil...brand new oil furnace sittin' beside a brand new wood furnace, you know, but, oh shit, there's no difference between the wood heat....it's twice the heat and everything's warm and comfortable, you know...oh, miss it , I sure do...turrible but ...you get over 80 ...you just gotta...start turning...you know what I mean and try to get another few years in, we'll have to sell this and move to town cuz they'll take my license."

\section{IV-Coercive Power:social exclusion from power and experience of injustice:}

Within the Life Model, Coercive Power refers to withholding of power by dominant groups from other groups on the basis of personal or culture features. In general, experience of coercive power seemed to make it more difficult to negotiate change in the performative code and increased the mandatory nature of protective purpose. The man who had grown up within the foster child system said that while experts have told him he cannot possibly hold a memory from before his second birthday, he still recalls,

"I can still see myself with my arms stretched out to that woman, being torn away from her, who I thought could be my mother and the children's aid worker pulling me away and me just bawling my eyes out and my arms being stretched like that...I still see that today, that very picture. It's so vivid, it's incredible and I know from that point on, for sure, at age 20 months, I built this huge wall around me cuz after that, when I went to the next place, I vowed they would never hurt me again, speaking of the children's aid of course....at that time I didn't know who they were...they were my enemy."

He recounted,

"Besides the sexual abuse, emotional abuse...one day...he took one of those...big swede saw(s) with the big bow...about four feet long...he took that right across my face...I don't know how he didn't take my eye out cuz I still have the scar from my eye here...underneath my brow here, and the scar across my nose here where he nearly ripped my nose off."

He experienced injustice as he tried to locate his birth family,

"I literally grew up thinking that they were the enemy...they hid...your history more than anything...that's what burns me up...my family history...they have no right to keep my family from me...my birth family...nobody has any right...we are born on this earth to a family and we have the right to know who they are." 
He also experienced coercive power within the education system,

"it's funny how the teachers ...assess that...it's very strange because they always thought that I was bullying the big bullies...I was sticking up for my peers but their assessment to me was..no, ...you're the bully ...and I could never understand that... I had some very very prejudiced teachers,..I was a childrens aid...and these remarks would have been in writing... a teacher...wrote, "I guess he's ok for a children's aid kid"...what kind of a remark is that?"

One participant who had grown marijuana for a living described his experience of coercive power from what he describes as "the seamy underbelly" and "the moral authority". From the "seamy underbelly" he experienced theft and nonrepayment of debt but other than commenting on it he did not reference his dealings with this as traumatic, it was more expected and part of the reason he quit growing marijuana.

"How do you choose to communicate? Are you gonna go shoot them now? Or, whaddaya you...burn his house? Those are hateful things...l've had them myself... and I've done some of this shit but the thing is, hey you're not going to get the results you want, but then this new urbanism's not the answer either. It's the other side of sneaky, you know...having one word meaning two things to two different people... it's obfuscation... and there's too much of that going on and we're teaching it in school just like the manipulation game commercial. That fuckin' MIT business school, that's all it is."

From the "moral authority" he experienced arrest and harassment which led to him feeling permanently labeled as a criminal. He sees this same criminalization and marginalization happening to other men.

"I'm a target because I'm overt, I'm not clandestine and secretive..l'm in your face and l've got a history and it's in the system so all they have to do is punch in and it's "Ooooh...two other charges"...don't look at his age or when they were...don't look at that he was out of the country for five months and he's just back....There's no traffic...there's no trading...there's no....nothing and when they had all this list ...guns....money ... drugs ...packaging...scales ...cellphones , and...nothing, they had absolutely nothing. It was a fishing trip for trout...big fuckin trout...picture this...big fish (fuck off gesture). I'm fuckin lucky but it isn't so lucky for these guys. The system...is lazy. The system works 9 to $5 . "$ 
He said,

"I don't understand the psychology and I don't understand what they're trying to do to create embitteredness, like...look what they've done to the old guys up here. We're embittered towards the police because of the behaviour of the police and their attitude. There's no respect, there's just an assumption and then an aggressive response. The assumption is that they're better than we are and that we need to be straightened out and they're the ones to do it."

He feels that he has been harassed on an ongoing basis because of previous

unsuccessful charges against him in court, and he draws parallels from his

experience to other marginalized and criminalized men,

"all they say about, oh, he's...that's why I get...I'm easy for that, for them, authorities to come on me, just like these kids are because they've got charges and they're in the system so they gang up on people, you see they didn't do any homework for that, they took it from a oxycontin ho... and then they jump on that and they can get a search warrant immediately...".

He follows his logic and notes the outcome,

"There's also stereotypical behaviour taking place with the authorities right now where they're just knee jerk reaction stuff where they've tarred them with the brush and so forever they're going to be that so the part that I don't like is that once there's been an (in)discretion, like family dispute or theft or drugs or automobile shit where they lose their license or whatever, then they just predator them. They just look for the next one and the next one and just pile the charges up till they're so blocked into a corner that there's no escape and that's when you create crazy stuff where people act out, like they'll go on a rampage...because it's easy.

It serves the purpose of the guy in the suit because it's easy...he can go for longer coffee breaks because you don't have to do much work. You can pretty well predict the outcome because you've created...it's sort of like the way casino's work. You know the house always wins. It's tilted. It's just like the best t-shirt from the occupy movement that I like is, "the system's not broke...it's fixed"...cuz they baited them, so now they love it, now they got a response. Now you're in the ring...let's have it out. OK, you think you've got that...you don't have fuck all, what's your education or what're you bringing to the table, oh, and then you yelled at your wife or she said you slapped her in the face. You're not seeing her and you're not allowed anywhere near her and you can't see your kids and you're not in your home and now you're on the fuckin' street cuz you don't have shelters cuz the girls have 'em and now you're on the street and you don't have a home and you don't have a job and you're fuckin' frustrated like...hell. 
And then you either act on your own or you find like mindeds and you act out together and create a solidarity of bad behaviour because you feel victimized and so, nobody understands me but your bro cuz he's been down that same road and it's happening to him so that's who you trust and then you start losing trust and faith in the institutions that you were born in under.

So now we've got a real crisis, eh, cuz it cuts across the whole thing now, so it's sort of like the environment. When you start polluting or manipulating genes or whatever, you've gotta be at it all the time. Like nature does it all the time but it does it benignly , but we gotta be active, science has to get better, you gotta put more money and more energy, if you hadn't gone there in the first place, it wouldn't be that way and it's the same with society.

If you'd have shown any respect and inclusiveness and seen the changes are coming and nurtured the transition instead of damage control and this is basically what society is, but they only work 9 to 5 , like they don't give a fuck, they want to know when their holidays are, when the raise is coming and where the benefits are."

Understanding this perspective would allow opportunities for growth and change by recognizing that for every negative sanction enacted, a door towards change could be negotiated by the individual if there isn't foreclosure of change.

The older, life long farmer has managed to negotiate his life without full out confrontation with coercive power but sees it brought to bear against a younger male family member,

"Sittin there, listening to all you know...and a witness that was agin him, a young lad...cuz he was supposed to beat him up or something like that...over dope...tryna get paid l'd imagine...not sure about that but that's about the ghist of it and he was called up to the front and asked, 'well what do you do for a livin' and he said, 'I'm a dope dealer'...told the judge and the rest....'oh, and what do you deal?...'I deal coke' (laugh) and...they said, 'Well how come you're not wrote up for it?'...'Well, cuz I made a deal...if I witness agin him...they said they'd let me off ...and, uh, yah, it proved on my end, whatever he was saying agin...was lies and then...oh, it was something awful, just one after the other up there, you know and one girl's supposed to...supposed to rape one girl...dna 's no proof...no nothing they didn't get that and one girl wasn't sure...you know...she was there or not...she was so out of it ...what a son of a bitch of a rig, I never even seen the like." 
A younger participant spoke about his experience in the job market as "annihilation", identifying that there is a necessary correction happening in his generation to bring more women and visible minorities into an increasingly limited job market. He agrees that,

"I'm a total believer in equality but the problem I have is there's equality...somebody has to suffer for that equality and...myself...a white male who is over -represented in many facets of government...in...police forces...in a lot of things...has been over-represented...so there's a correction happening, within my generation... there's sort of a discrimination...a purposeful discrimination, which 1 understand, which says that we need to lessen this sort of demograph(ic) within society...and...I am in $100 \%$ agreement with that but at the same time, I am now...the discriminated class."

This man went into teaching, enjoyed it and had success, but found,

"I would never want to be a teacher in elementary, because there's this stereotype that if you're a male elementary teacher, you're a pedophile, so I would not want to be that. If you're a male...it's just...who wants to ...even go there?...why would you even want to put yourself in that position?... huge risk to work with children, so it's like, as much as I have really enjoyed it and it's been really fulfilling to me... I'm not going to go there....and that's really heart breaking...I'm at a cusp where it's sort of...there's an attack on the white...male within the workforce."

He also felt that there was injustice in the court system in that he had seen instances where the male parent's adhering to the provider role had been used against him in custody hearings,

"The male has gone with this role, thinking... Being a provider is just as equal as being a nurturer and then, in divorce case hearings, it's thrown against him...they're saying...no,...Billy worked like 60 hours a week so therefore he's an unfit parent to have joint custody."

An older participant challenged him on this, saying that he thought, "the guys generally have the best lawyers", but the younger participant replied,

"that's your generation...it's not today...today it's the other way around... my father had the same lawyer that my mother had and my mom got screwed but today 
my dad would get nothing and my mom would get everything cuz that's the way the judges view things."

Participants generally felt that they had little or no power outside of their private sphere and those who had experienced coercive power felt this injustice most keenly. This participant sums up the anger at the deceptively bland face of coercive power experienced by all the men who described it. He links his experience of injustice to the global political strategy of disguising injustice as justice and pretending to listen and be prepared to negotiate, when in fact the decision is already made,

"It is a headgame cuz they're in control, no you shouldn't trust me because they're manipulating the outcome. Instead of confrontational and authoritarian and right to jail, like in the boardgame...

'No, there's nothing the matter with you, your opinions are as important as ours, your feelings are as important as ours, yours ideas are yayaya', but they're not having any, they're not going to listen to it at all except to have you go through the rote, like do the mantra and get it out, don't you feel better now, you know what I mean and don't respond to change anything.

We're still taking your country and your oil... Like we never said that. We're not going to tell you what we're doing but ...engage in the conversation, and isn't that what all this fuckin' PR shit and everything is all about is making the kettle black or the pot black or just fuckin' around with the optics and the language without any intention of making a change or taking it seriously or being committed to...a growth."

This attitude of mistrust of everything new is endemic in rural communities. It confounded me when I was on the local Municipal Council and couldn't understand why I got such intense push back to initiatives such as setting up recycling at the dump, or a Baseball league for children. Eventually I came to regard the resistance to everything new as a Scots/Irish survival tactic. It seems that historically the best way to survive is to treat everything new and unfamiliar as dangerous. This points to the notion within deep ecology that, "if the system is 
fragmented by the differences among the parts and characterized by prejudice and discrimination, the diversity may decrease the system's resilience and it's chances for survival" (Capra, 1996 in Gitterman, 2008).

\section{V-Competence: perceived self-efficacy, self esteem, self direction:refers to organizational effectiveness in achieving influence.}

All of the participants expressed a high degree of perceived self-efficacy, selfesteem and self direction and a general sense of being able to overcome obstacles in their personal lives, based on past experience of doing so. This was tempered by the realization that,

"I guess what it comes down to is learning to...affect the things that you can, influence the things that you can, accept the things that you can't and recognize the difference between the two...my dad used to have that sitting on his desk on a little cartoon thing ...I sort of half paid attention to it...Sometimes it takes a little more patience to be able to hear and listen to that. When you're younger and you think you have all the answers it's a lot harder to take advice."

The youngest participant expressed the most frustration with self-efficacy in the personal economic sphere, although he had certainly demonstrated ability to live on his own and support himself, contribute to the raising of a child, as well as establish a strong and supportive marital partnership. Performative measures of connection and purpose may be more in need of negotiation for younger men, given some of the current economic challenge to purpose and social challenge to connection highlighted in some of these narratives.

These men were sure of themselves and their opinions but recognized that there are limits to their ability to act. Another participant said that,

"It's about time, at my age ...to have my act all together and to be comfortable with myself to know who I am and I mean, l've known...I've been this way for quite a 
few years now, but... there's times though...I do get loose and this is probably what'll come out... I can still get pretty angry... and I thought I had dealt with that a long time ago, like 1984, and I got a lot of that out... living up here...I call it the way it is and when something happens and if somebody does something wrong I just speak out and say what I'm going to do, you know."

They recognized that not everyone has the ability to be effective in their own life and this is largely a matter of personal history, ability and environmental support,

"The governments change and policy changes...people remain the same and the march of progress is trampling everyone as it goes...either get...in the thing or get trampled,

So the boys don't have...my background, like...of grey matter and exercising it, plus a solid family background, where, not abused and every advantage and allowed to be whoever you wanted to be and given opportunity, like my grandmother or my mother to give me some resources to start up, blow up your balloon a little bit, you know. So I had a lot going for me."

Outside of their personal sphere none of the men expressed any confidence that they could effect change or preserve their culture beyond their own lives, except as a "kernel" in their children. One man talked about being a "culture carrier" and commented on the desperate rage he had witnessed watching the death throes of the farming culture where he had grown up and also the frenzied protection of the French language in the area of Quebec he had worked in. When I asked him why he wasn't frenzied, he said,

"Good call...because the seas change is coming...the only thing that's constant is change...it's a rough reminder of that, you can't stop it...you may not agree with it but you can't stop change.

I'll live in my core and I'll give a little piece, as my grandfather gave to me...a little kernel of where he came from, and I will give a little kernel of where I came from to my son so he will have some old values in him as the world changes around him but there will be a seed that's left over that he will have had from, that I know at a minimum, of three generations... a little kernel of old...how it works.

And he will watch the world swirl around him and just stand in awe with his jaw hanging open now and again and realize that the only thing that doesn't change 
is change itself. So, it's gotta change... us old fucks, we gotta get outa the way so the kids can rule the world and hope they don't fuck it up any worse than we did."

Others expressed disillusion with the political process of change and disagreement with the economic direction of the globalized economy.

"We were once proud and now, I mean, as far as industry goes...and our country...we were once proud, but now everybody is disengaged... disheartened... feel betrayed...

So that's why...what difference does it make if you go out to vote or not...why bother talking to a politician anymore? You press a button and it says...press this, press that...you never get to talk to them anymore and, uh ....and are they ever going to listen to you...no.

Chances are they won't...your local councilor would...yes...for a very local thing ...but nothing as important as that...and are they able to do anything about it anyway. They're getting all of their initiatives and policies and things they can do and can't do from head office in Toronto."

\section{Life Course}

Within the Life Model, Life Course is examined as the person's own narrative of their life, or "Individual Time", their experience of their birth and social cohort, "Historical Time" and their experience of broad social change or "Social Time". The focus of this research is on men's experience of social change so I will move straight into presentation and analysis of those findings. I am appending a selection of the narratives of "Individual Time" because they provide necessary linguistic and cultural context, as well as a basis for understanding behaviours and attitudes. They do this while they are left intact as narrative and fail to do this when they are isolated as meaning units and mixed together as data. 
Historical Time-Changes in this community.

The main changes in community and social cohort were seen as the loss of rural economic and social activity. This was seen by all participants. When asked what changes he had seen in the community, one participant exploded,

"BIG! HUGE! there used to be little farms that operated, little sawmills, little cheese factories that operated and there were stores...TW0 in (local village) , TWO in (village $7 \mathrm{~km}$ away), ONE at (village $4 \mathrm{~km}$ from $2^{\text {nd) }}$, ONE at (village $4 \mathrm{~km}$. from $2^{\text {nd }}$ ), TWO in (village $8 \mathrm{~km}$ from $3^{\text {rd }}$ ) , ONE at (village $6 \mathrm{~km}$ from $2^{\text {nd }}$ ), one at (village $15 \mathrm{~km}$ from $2^{\text {nd }}$ ), there used to be gas at a lot of places, now there's no gas,

It's gonna be the end of ski-dooing...that's what the skidoo club's saying, with no gas around here, they have to carry it, it's gonna be the end of ski-dooing...they've got all this trail shit and all this built up and now they....

And it's the government that's done that and the government that's shut all these stores down cuz now they've got all these...they wanted certain refrigeration and certain health shit and everything and it was gonna be hundreds of thousands of dollars where these fuckin people don't make 10 thousand in a year...

(Village-Municipal Seat), you remember the (community freezer) and all that? Who runs that now? Chinese. Who runs the gas thing?...East Indians...the middle easterns, you know, nobody wants to work...."

He continued to analyze how globalized neo-liberal economics have altered the local social fabric,

"It was marginal as it was but now it's centralized, and now it's so dependant on all the petrochemicals, and the packaging thing.

Stores used to have bulk, they used to have a hundred kilo of beans and brown paper bags and a scale and a counter and a conversation and if it was perishables you'd come every day or other day and now everything is so ultra packaged and frozen and shipped all the way around the world.

Nobody has time, both the people are working and they can't keep the wolf from the door and they have no time to cook or don't even know how anymore and they have no time to socialize, they stick in front of a screen all the time, there's no communication."

He also commented on the effect of technology on the local economy,

"It's the food chain and it's our human nature, we're animals and it takes life to sustain life so we're always...somebody's gonna be in rural, whether it's us, but the thing is... 
Unfortunately is it's "go big or go home" so you have to have highly capitalized endeavours that are totally wired to the fuckin' tax man and the banker and the insurance man and the corporation. Rural survival, if you're gonna be a farmer or a logger or a fisher, you got to be really on the game. That means you gotta have the computerized readers on your sowers and your harvestors to let you know what's going on in the equation. It's all about money and decimal points and it's all about timing, eh? And you can be a winner with nature and a loser at the bank, so I've seen the farmers that are good at this. They offload, through advice from lawyers and accountants."

The oldest participant noted the difference between what he faced as a young man starting out and what a young male farmer would face nowadays,

"I think he's screwed before he starts.

Ok..milking cows...seems to be ...steady...you know what I mean...now what are you gonna do, at 25 thousand dollars a cow for quota, and they've shut it off...

You can't buy quota, unless you're a man now that's milkin and wants to expand more cows ...is the only people that can even apply for quota ...no new starters you know what I mean...

That barn there at (local village)...that big new barn and all that...that's for sale. You can't buy it cuz you can't get any quota ...there's a million dollar barn sittin' there and a set sittin' beside it that he milked all his life in ..you know, it's that...

The same with the hens, you know...pigs...they're tryna get it going that way...you're done...how in the hell could you grow corn...the price of seed and the price of machinery and stuff...you couldn't."

"The farm ...it's stripped down same as the bush...unless you went at it the old fashioned way you wouldn't get very far...there's nobody in the neighbourhood to start with and who the hell's gonna go to a thrashin' or a corn cutting...or a sawin' bee....or put out the shit in the spring.

We used to put out the shit at Joe's today and Mike's tomorrow...about four spreaders come and 5 or 6 men fork shit ...put the whole shit out in a day, you know what I mean?...and they were only putting it out for 20 cows, 25 , there was nobody kept 300 you know..."

This participant went on to list many farmers, almost all of them with Scottish surnames, that had got out of milking in his lifetime, and then proceeded to an insightful analysis of the effect of capital intensive extraction industry.

“I'll tell you what's wrong and I'm old fashioned...don't go by me...I'm old fashioned...but...there's a skidder worth a hundred and some thousand and you 
gotta saw the tree down before it hooks on and all it does is pull the tree out to your truck can get it...

You need your slashing machine to tear it up in pieces and pile it ...you know what I mean, cuz when the truck comes in...the trucks now...the tandem truck is , a .20 foot deck on it, or 22 or something because they use a 12 and a 12, they can use two lengths of logs on the truck...fill the stakes and then the pup behind is a set of wheels at the back end and a set of wheels at the front end so they put on twice as much, as what's on the truck and that's what they go with, what they call a load, but...

Whad'im tryin to tell ya, the man that's in the bush workin' has the skidder and the men fallin, or it's on a big faller-skidder, if you know what I mean, that puts it down...and then there's forwarding machines to put it out, cuz they don't want it drug and all this ...the man...like that's into a million dollars, and everybody you got there...everything they can go to make it pay...

And what happens if they're drunk the night before and never showed up ...every machine has to have a driver or you're DEAD...or one machine breaks...you're DEAD...and the big new half ton truck's gotta sit out there worth 50 thousand...to run for parts...if you know what I mean...or a machine to put a hurt man out of the bush...and, I...

That's what kills it...like a bush might only last a few days...on to the next bush...but..there's no bush left. Now you put a team of horses in there and putt, putt, and worked along ...now ..if you never get there till around 8:30 or 9 and come out and was home for 4 or 5, you'd spend about 6 hours in the bush and it would be a hell of a poor man that wouldn't come out with 3-4 hundred dollars... after you paid for your stuff that you're taking."

Participants noted that it was very difficult for young men to stay in the communities and make any money and the best choice was to "go west".

“Even yet if somebody's workin' and mad...awh...I'm goin west...I can get $\$ 35$ an hour for workin' at Wendy's or someplace...you know...it's stupid...that's what they do." This participant recalled, "You know I worked real hard for $\$ 4$ a day going to the thrashin" “, and "I worked for ... $\$ 32.50$ a week ...and 6 days a week too, hard...turrible, turrible, turrible." .

Now however, "For these guys, yah, they gotta get papered up, whatever, they gotta...whatever it is, whether it's banging nails or welding seams or whatever it is ...there's all kinds of work in fuckin' Canada...all fuckin' kinds of it...it's not here! So you gotta have the courage to get on a bus or hike...drive somewhere and put your fuckin' shingle out and see what can become of it."

In terms of the future of the community, one participant said,

“There are some people like me...there are some dinosaurs out there, young 
dinosaurs... but what I don't so much see is the commitment to, a lifestyle, but we made a commitment to a lifestyle, but when I come out here and live easy on the land and do it together and work hard and I don't see that very much anymore. If I were to sell this place right now would be somebody my age that would buy it. It wouldn't be a young couple that want to come out here and plow the fields and fix the fences."

Another painted a stark picture of increasing marginalization,

“Who's here? Well, I'll tell you who's here...fuckin' drug addicts on welfare that's sprung babies from different men then show them up to the worker then disappear them in anger...once they get more money and that.

So you got the wrong people breeding. They don't know how... I've made an observation ...there's people that want to work and have skills...there's people that want to work, have no skills and no work....there's people that don't want to work that are quite capable of working, it's just that they can not work ...they have no ambition and it's too easy to rub their belly and say please to the government, and then there's those that can't work...the handicapped and ...mental or physically you know and so...this is it , eh...

Well anyway...what's gonna happen here, in the future...it's gonna be a gentrified neighbourhood...there'll be a lot of ... (high end retirement and cottage development)...maybe the little villages might be the thing, but there'll be more built kind of thing. They'll either be finer residences with more gates and locks and property distinctions and group ownerships of common grounds...

And there'll be trails and canoeing and recreation and shit for them or whoever can afford to get out here to use it and the underclass that's here won't be able to afford to live here like you see in California and $\mathrm{BC}$ and all that and the ones that do stay here will be cutting lawns or trimming hedges or moving snow...and the rest of them will either be served by the state in these homes for the kids that don't make it...the losers in society...the victims you know.

So I don't see it as being a vibrant, healthy, integrated community...I don't see manufacturing happening, I don't see the rebirth of artisanal agriculture... This'll get tired, these young people, when they find out how little is going on and how hard it is and they'll start to look for other hobbies... I don't see the resurgence of the lumber...the trees need a rest so they're lucky they're closing all the pulp mills now so the trees are gonna get a rest and the only wood that's worth anything is just firewood and...the wood thing is history"

Other men noted the loss of opportunities for growth and learning within a hands-on skills economy,

"When I was young...you know, finished high school. Do you know, I could go out and find a job within walking distance....an hour or whatever it took me to walk and if I lost that job I could walk around the corner and get another job in two minutes, just like that...can you do that?...nobody can do that... 
So that's how much it's changed and that is awful for a young person...when I was a young person...if the boss didn't like you or you happened to goof up...oh well...I'd go down there and get another one...I'll try to be more careful this time...l'll try to make sure my boss likes me ...or whatever...and you learned, but at least you were able to get another job...just like that,"

"Turrible amount of changes....complete turnaround, absolutely complete turnaround you know...

I remember young lads...likes of (old farmer), just below me ... if there was a thrashin' Wednesday/Thursday and there was a pile of people like that, and they'd give you 2 bucks for goin' to his thrashin' ...you know what I mean...that was the wages they wanted to pay you ...2 dollars...that was your days wages and you'd go to the thrashin' and you'd fork sheaves all day and you carried grain and you worked hard all day and you went in at dinner time and you were fed and you learnt...

You learnt how to work, but the computers come in and everybody wants to start it and go but you can see them goin down the street...all the kids and everybody ...with the phone and textin' you know ...and that's their whole ...thing....that's work, right there."

"There's no jobs in the country...it's a fucking beautiful place to live...low cost of living ...it's great...no jobs... so, what do you do? Who knows?"

Others noted the loss of social interaction,

"People don't communicate with each other anymore, they 'friend' each other, they use their computers, their I-pods, whatever....People are losing their language skills because they're not talking to each other.

Kids now, are afraid of adults other then their parents. They're just afraid of them, they been told they're evil. They want to hurt you. So you say hi to a kid and they... run away, you can't even interact with the kids and if you do run into one, it's like, oh my God I'm surprised this kid will actually speak to an adult."

"It's changed. 40 years ago I was involved with the (agricultural society) and I knew everybody... I still pretty well know everybody but... it's a different community. It was much friendlier.

We used to do bees, we used to do work bees, you know the corn cutting and things like that and... now you could die in your house and nobody would ever know.

People come in here and they live here and sleep here and go to work somewhere else and they're not part of the community and they don't appear to ...want to be part of the community.

I just don't see the kids outside and like I said before you go through the village there and I will see the school bus stop, stop, stop but nobody outside. They 
just disappear indoors...turn on the TV or the computer or the whatever. I guess we were unlucky, we didn't have them, we had to go outside and interact with other people by play... go shoot, fish, whatever..."

Participants ascribed the change to more permissive child raising.

"So you don't ask permission anymore..."Grandma can I have a cookie?"...no, grandma's put in the back, if she catches you she'll rap your knuckles...not there anymore ...there's no rapping the knuckles...oooh, you were caught with a stolen cookie, you little thief. ...l'm sorry...that's ok...don't do it again.

This is the world we got, eh? So have I seen some changes? You wouldn't get that away with my grandmother. My grandmother, if the kid was all night out getting drunk or doing drugs or fuckin' around and you were workin' for grandma and grandpa was already at work and your uncles and you were livin' in her house and the breakfast was getting cold on the table and you were still in bed...1,2, fuckin' bucket of cold water...right on you in bed...g'day, you up now? Good, there's the fuckin' door...you're not getting any breakfast...get the fuck out...

Lucky my uncle let me sleep in the truck and shit, (laughs) but anyways, if you didn't ask permission to...granny ...respect...and thankful...and part of a team, then, you're, you know, and all that's good, like the sports thing you see...

Otherwise, they tried to create a criminal in me but I'm not really a good drunk or a good criminal, cuz I got better things going on...I know better. This is the trouble nowadays, they don't...(mentions several friends) their kids are all fuck ups and it was a laissez faire thing and some of the hippies were the same...

That's why it wouldn't work for (ex-girlfriend) and I cuz I wanted to participate in their family rearing and there's no discipline there, look at the fuckin' mess now...he's an oxycontin alcoholic who hates his mother...they got restraining orders on each other...her daughter's a heroin addict and probably a whore, living in (city) now and she did everything, and laid down and they walked all over her and in the end...what do you get? No boundaries, and no direction."

They also blame the education system and note that it is failing boys in particular.

"I think school is a horrid place now for kids to go. What's the first thing you make a kid do? Sitdown! That's the wrong thing to do to a friggin' five-year-old boy, make him sit down, all he is, is, I mean he's restrained, and now what they do if he doesn't sit there is he's chemically restrained.

Oh, he needs Ritalin, you know (son)was in grade five when they told us he needed Ritalin, we said, no he doesn't we will just keep him really busy so we put him in sports and kept him busy, all the time, all the time. That was our way of dealing with it, you know" 
"I could go on about schools. I disagree with the way kids are taught right now. You know, they should be taught reading and writing. If you can't read and you can't write you can't succeed in life, period. ... that's where I feel the educational society is failing right now, is, you can pass grade 12 and not be able to read or write, like is there something wrong here? There's something, am I not getting something? “

"We need to emphasize basic skills, reading, writing, arithmetic. It's not rocket science, it's very simple and do we need to emphasize arts and phys ed, of course we do but at the top of the pile is reading and writing, and who do I blame for that? I don't blame the teachers, I don't blame the unions, I don't blame the government, I blame the parents.

They don't seem to care. I mean I went to school and raised hell for 12 years and I got things done. Can you imagine if every parent walked in the door and said I'm not happy with the situation that's going on here.

I remember one particular time...(son) got $50 \%$, do you know what $50 \%$ means? You passed! It means you failed but not quite, but we're going to move you on so I went in and I said, he got $50 \%$ in math, can I get him some help? Well he didn't ask for help. 10-year-old boys don't ask for help, 12-year-old boys don't ask for help...can he get some help? So I said 'when?'...well he'll have to come in at recess. So, I said, well fine.

When I was in school that was after school but I went to see the teacher and I did my extra work and I said are there any other kids that got $50 \%$ and they said, 'yes there's a lot of them'. And are you getting them help? They didn't ask for it (laughs), but I went in there and I got it and I also paid for help... we eventually hired a tutor... I had to do it and that's who I fault is the parents.

If the parents went to the union and said, this is wrong, the union would have to listen if all of them went there, but you go, and a week later I go, they just brush you off. Did you ever have any trouble with the school system?... boys.... yeah... 'Could Do Better.' Did he ever have 'Could Do Better 'on his report card?"

"Grade five. Sit down! You know, how 'bout grade five let's run around for an hour and then we'll do our math class or our reading class or what ever class after you're not so stimulated. I mean, what do they do now? Kids get up in the morning, walk down the hill, sit on a bus. That was the social life. So I mean, we can fault the teachers, we can fault the education system, what ever, it's the parents. They are the ones paying the bills."

"Women are the ones that are better in the school. My daughter was the first class in law that had one more woman than man in the graduating class. Now it's way more women. Medicine's the same.

So women are thriving in this new environment and men aren't...because women hadn't had it and are so glad to have the opportunities with the conveniences, all the electronic appliances and the birth control and the choices to go to school and not to be stigmatized like in Afghanistan, you know women don't go 
to school...they don't leave the compound. They only marry to who we say, and you know, controlled like chattel.

So women are thriving because it's... their time and men aren't because they're not keeping up with this new urbanization and globalization thing which is all happening at the speed of light, electronically and it's all in the head, not in the body."

"I think it's our education system...oh definitely...well, the first thing is they get up in the morning ...they don't even walk to school... They stand out the side of the road in their runnin shoes...

You take a young lad that's just born and you start to school 3-4 years old...what did he ever know but get on the side of that bus...get in and siddown and he's gotta sit a certain way on the bus,..get there and get off and that teacher writes on the blackboard whatever the hell he's gonna learn, and unless it's playin hockey or rugby or something...that's the full extent he gets...

Now when he's out of grade eight, he's into high school, when he's out of that, he's gotta go to college. He never got to build a fence, drive a horse, milk a cow, feed his dog or anything."

The notion of "papering up" emerged in several interviews.

"You have to get papered up"

"So I had a lot going for me you know but then if you're going to work you better get papered up"..." that says you know how to do it...yup...even if you know how to do it, you still need a piece of paper...if you don't know how to do it, you can just get a piece of paper and still not know how to do it...so, yah...that's been hard to swallow".

The consequence of not being "papered up" is loss of work,

"Hasn't got his papers yet so he can't sign the work off if you know what I mean...someone's got to sign the forms so they closed the truck end but they've got one awful pile of machinery", and "(my son) says you've got to have grade 12 to sweep the floor now".

One man described his struggle with the process of 'papering up',

"With the dyslexia, it's always been a sort of daunting task and it's been sort of something that...I know I can do, but...the framework for me to do it...it's not in line with the way that I do things...but without this piece of paper you weren't recognized for what you're capable of, but if the system changed, they would have seen that years ago...that you were perfectly capable of doing what you do...it's a total problem...it's allowing a lot of people like myself...or if you didn't have the 
gumption to say 'fuck it...fine l'll just get that piece of paper'...they would have lost you."

\section{VII-Life course - Social time-the individual's experience of broad societal change in their life:}

Within the Life Model, 'Social Time' refers to the expected and unexpected transitions, traumatic events, and other time issues in a family, group, or community, and the consequent positive transformations of the collectivity or grave disorganization that may occur.

"The big changes are...when I was ...in my formative years as a teenager and young professional, there didn't seem to be any constraints, at least in my limited knowledge and triangulation on reality, that everything was possible ...

I mean, the world was full of opportunities...with regard to resources and ...energy and...climatic things...those weren't even on the radar whereas now, I find myself with really an overwhelmingly pessimistic and grim prognosis for the planet...I really think that we are fucked...so I guess, my brief answer is ...before ...I didn't think we were fucked and now I think we're fucked ... in most ways...socially...

I mean, if we were to look at America as the model the world emulates, I see that society as fragmented and ...and losing it's values and...in many ways I think that we're behaving badly generally...that mankind is being very predictably...bad.

I think that the default...drive....is kind of mean spirited ...take care of yourself...capitalism...survivalism in it's extreme in the right wing of the republican party in particular...I would say that the predominant feeling in rural areas is...'well, we've worked for our money and...these leeches in the city...the civil servants ...haven't and so there's this kind of tough...libertarian inclination that I think is totally misdirected...misinformed and...minimal taxes...you know, cut taxes..."

The oldest participant identified the same restricted opportunities, at least in an economic sense but did not endorse the neo-liberal solution of tax cuts for the wealthy, although he did speculate that all the people who used to work in "little shops", making, "furniture and this and that", might be "lookin' for a government job and I don't know how the government keeps hirin' people."

It is certainly true that the participant selection was skewed by my own 
experience and convictions. It is interesting to note that in the interviews with participants with more conservative political convictions, there are considerable portions of the interview in which the participants turn the tables on me and ask questions of me on such topics as why welfare guys don't work, and what my experience is of having children in the school system, and what the definition of child abuse is. This research aims to elicit their life views so those portions of the interviews don't appear in the analysis but the fact that they are prepared to hear, and interested in, my opinion on matters that they have staunchly conservative views on is worth mentioning. They also want to be heard and have their point of view respected.

Several participants voiced strong support for neo-liberal capitalism and the opinion that social supports were over-utilized, too generous and fostered laziness and multi-generational dependency.

"They create jobs because you need people to service the welfare people and then they get money and then they go spend it on whatever...and they also spend it on lottery tickets and booze and cigarettes so there's lots of taxes...the problem is, where do they get the money from?

The hard worker, you know, wealth redistribution. Work like hell and then pay an enormous amount of taxes and give it to the people who aren't being productive. It's just wrong and I have no problem with helping people but help them with, here is your bag of groceries.

Don't give them money. Give them food, and by the way, we're going to show you how to cook this egg and potatoes, and meat rather than taking the money and going to McDonald's and buying whatever.

You know, that's how I envision helping these people, and it's a generational thing, you're not going to help this generation right away, although supposing you took a hundred people and two of them learned how to cook a nice meal for the kids that would be a good thing. The thing is that their kids are going to learn how, so, then we start with a little and it starts to grow, rather than just giving to people."

Other participants criticized the neo-liberal economic agenda, 
"Not the old way where it used to be...your barn burnt, we're going to rebuild your barn, Oh, your crop failed, you're not starving, we got food, you know what I mean, it was a more communal sharing thing, you know what I mean, now it's everybody for himself, we've been divided and conquered by the government, the banks and the insurance companies and the lawyers and accountants keep us in our places, so the bigger and deeper your pockets, then you get your way. It's like I just heard that thing on the radio...Exxon Valdez and Bush said, "Well. You can't tell these guys what to do...they're bigger than everything". It's just like they're finding out in Washington that they don't run the country, Wall street does, and Wall street ain't main street and main street is the rural, it's the common wealth, the common good, the common man...the mean. The other is the extreme and then in the extreme you've got winners and losers and then you've got our culture"

Some participants criticized both the welfare state and neo-liberal capitalism, demonstrating a considerable depth of critical structural analysis based on personal experience and an outsider's observation of modern economies.

“It's not necessarily immigrant classes...there's some really seamy white people too, eh. Like hereditary welfare people and we've got that here and we've got an inbreeding class system, especially (local village) and south of it, man and then you look around and see like the body language and the stupidity and the fuckin' kids that shouldn't have kids havin' kids and they're not even out of school.

The system is supporting this...the system is fucked! They've got to change and start punishing and taking away...fuck off with this endless fucking support of lameness. It's fuckin' too much. They don't take it on themselves to fuckin' withhold and educate and change the dynamic...

It looks hopeless to me. I think we need a major fuckin' teardown and it's maybe coming with Greece. Once it goes and the banking trembles we'll start ...

You see it's all based on trust too, eh? ... like I said about your word being good...so then when you've got piles of litigation but there's nothing to fight over cuz main street's pulled out of wall street then wall street's on it's own...

Like I used to say, up at the river, you can take water from the river all the time and nobody would ever know cuz it's flowing by but you do that to a reservoir or a lake and right away you'll see it. Well that's why they were so freaked out when the towers went down, that the stock market would go down cuz they'd see the dipping that's going on. They need it to continue to flow so nobody can see the dipping.

So the whole thing is held together with fuckin' duct tape and binder twine as far as I'm concerned... look at that head of goldman-sachs...do you think any of them trust the other? Look at them. It's reptiles dome. They know they could be somebody else's dinner if they snooze at the wrong time at the wrong place. It isn't sheep...it's komodo dragons... It's like the roman gladiator trip...it's all or nothing, eh? They're cash warriors." 
The participants commented on historic changes they had witnessed,

“Huge... the social changes are...I'm a product of the prosperity curve after the second world war...the suburban mall and the retirement and the middle class growth...then l've lived long enough to see the middle class hollowed out and that it's become an upper and a lower class thing.

I've seen the old measurement of standard to metric, I've seen the unilingual English to bilingual English and French...America hasn't seen any of that, but I've seen it and l've seen the wars and the resistors, like the conscientious objectors and stuff...

I've seen ... the electronic world merge, which I haven't merged with... but I'm going to now, but not fully, I'll never fully, I like writing, and talking, and not twitting me about fuckall you know but I hear the twittering going on all the time you know, they are twitterers and they're building nests and having little ones, eh? So I'm watching that".

The analysis of economic change was particularly cutting and demonstrative of poor environmental fit, disparaging the modern tendency to value economic over human or environmental values, noting and predicting negative outcomes from this modern fixation on capital and hype over actual production.

"I've seen globalization in terms of...the drive to the bottom, the lowest common denominator wins in wages, environment...everything and the greedy are rapacious like the old $8 \%, 6 \%$ manufacturing class were happy to make that as a profit yearly but now your banking class, administrative class want to make, like $30 \%$ in some Bernie Madoff environment, you know we got ta make 20 or 30 ...Goldmann Sachs so that's like unsustainable...somebody's gotta pay or give or somethings gotta give...

And then the whole breach of trust and the dissolving of nationalism and pride and identity to a mismatch of commonality with no commonality like we're all equal but we're not and we still have our particular foods and music and habits and all that, but that's good in some ways and not in other ways but it's being manipulated by the ...ruling classes to profit from our ignorance to... keep us on the edge and desperate so you can do these things like buy a company, which has had subsidies by the government, don't pay the subsidies back, don't give a flying fuck about the town it was in for a hundred years, don't care about the workers that are skilled and all that, just knowing cynically we're expatriating this proprietary information that's been gained over a hundred years of learning and that's all we want...we don't want the building, we don't want the town, we don't want the people, we don't want to pay the government loan back, we don't want anything to do with fuckin' Canada, we're taking your knowledge and we're leaving...just what 
they wanted to do with that Detweiler thing...they should never have allowed that to happen, but then caterpillar's not doing anything different than John Deere...

This is posturing and creating illusion ...so you don't sell steaks anymore, you sell sizzle...sizzles worth more than steak ... why would you dirty your fuckin hands with that? You know what I mean? So the ones that are making the money off of the sizzle need the steak guy but they don't want to give him anything, they want it all.

So at some point there's gonna be a social...when things get tight, racism's gonna raise it's ugly head cuz we've got the multi cultural thing....as long as things are good ...you know we're all happy but as soon as things get mean, you know what human nature's like, they'll be looking for to point a finger....they already are in certain countries...

So in other words, it's not about...what's real, it's about how it appears so this is...the illusion industry and then you got all these people going to school to PR and to management...all this creating the illusion you know and then you've got this blocking communication...oh we can't come today...we're too important or something... and the conversation's not happening...but then they'll put out op-ed pages about excuses, so you don't ask permission anymore."

Participants noted the negative effect that this has on working people who define themselves in terms of the code requirements of instrumental purpose.

"I somehow see the technology as being negative as far as putting men out of work because the free trade system comes into this now where we have turned around and have sent all of our manufacturing offshore...somewhere else and we can no longer get a decent piece of machinery made...a bearing...whatever it is...to put in that automobile...we can no longer get it in this country...hardly...at all...it's almost non-existent...we have to get it now from China...Korea...Mexico...or whatever and that has changed..."

If we're speaking about what it's done to men...men were once proud that we could manufacture this here ...we could manufacture that bearing...whether it be Timken bearings that used to be in St.Thomas Ontario, whether it was Massey Ferguson ...whether it was...you can just go on and on and on...You've knocked...our government...these large corporations ...due to free trade...have knocked all of these men and women down by just taking all of these companies out of here...these men and women that were once proud ...manufacturing these parts here and ...it's all kinds of things...it's your workwear... clothes...whatever...boots...everything... they've reduced them to...I'm not sure what...just think of what that's done to them."

“I realize they've been able to go out and get another job somewhere .... lesser job or whatever, because the unemployment figures show that still the number of people that were unemployed before...it's still at the same rate, so they must have gone out and found work somewhere else but do you think they're as proud anymore? I don't think so...I absolutely don't think so...it's criminal what's happened to our manufacturing sector here...it's totally criminal. 
I'm not saying you shouldn't have trade with other countries...sure...trade is good everywhere, but for them to have done what's happened to this country... no.....and you know our government's responsible for all that...they are. ...they've made it so, hey, we can move our plant to Mexico and get stuff done a lot cheaper...clothing...they've made it so we can get it made in China or whatever and they pay them a dollar a day...wages...and it almost involves child labour, in these other countries, cuz...these countries don't care who they hire...and we know that a lot of the children are being used in these third world countries"

The invisibility of the damage is particularly galling. The negative effects don't seem to be noticed by government or society. The net effect is reinforcement of the belief that your values and efforts are worthless.

"I'm thinking of the government.the department of agriculture...when they instituted using chemical fertilizers and pesticides and selling off all the little farms...making everything bigger and providing more food and literally destroying your land with pesticides and herbicides and everything...

Look at the negative effect all of that has had...not only on the small farmers ...losing all their small farms...we no longer have small farms ...we don't have mixed farming anymore...small farms are gone...you're either big or you're out...one or the other ...the pesticides and stuff...we have so much of that in the soil...it's literally destroying the topsoil...it is...to the point where we'll eventually have no topsoil left...when they did this back in the 40 's...starting to bring these policies in...

They should have thought it out a little more... all of these things that the institutions and our government does, has effected our lives today ...back in the 40 's...I mean, you go back and back and back and whatever you want to do...so we're into our age and we see what has happened and...the small farmers, you know, they were once proud...as well...

I can go back to the 40's myself and think how proud the farmers were in the milk that they sent off to the factory or whatever and the cheese they were able to make and the cream they produced and the different stuff...the individual farmers did all this and all of a sudden all that's disappeared ...they were once proud people as well as our manufacturing industry was...those people....and where has that gone?...it's gone too, eh...

So how can we have trust in a government ...in a ... system, that's destroying our way of life...you know...it was our way of life ....and what was wrong with it?...Do you see a lot of problems with the way the system worked before?...and everybody cared about...farmers helped each other...now everybody's got his own piece of machinery that costs a coupla hundred thousand dollars each, and to heck with your neighbour...if your neighbour can't afford it...too bad...he'll just go out of business and meanwhile...this guy who's got everything...the bank owns it, you know...I don't get it (laughs)... we've lost everything..yah, we have." 
"We've lost our interest in our country...betrayal...these people sold us down the river so go fuck you...so that leads to...people don't vote anymore, there's a great mistrust...and total betrayal".

A social worker noted, "We're seeing an increasing gap between the rich and the poor in Canada which is a very negative social change right now and it's not getting better. It's causing an increasing need for social services, increasing demand and less money available for it."

One participant mused on the effect of peace on his generation,

"I suppose that we're one of the first generations of several generations that have not had to fight in wars and that's a very, very profound and serious boon... I was thinking back to our earlier experience as environmental activists cum, slash terrorists ...but there was a certain element of kind of ...faux war there really, wasn't there?

I mean, we were of the age that we should have been out...killing...Serbs or something, but there wasn't much going on and in this case we were sort of fiercely anti-nuclear and felt that it was our obligation to go out and put our asses on the line, which was sort of the classic expression of putting yourself in harm's way...I was kind of embarrassed by the sort of macho element of it, cuz there was quite a....although there were women doing it...it still was a rather...it was kind of like, 'up you' to the cops ...

I didn't ever get into the resistance part...I got into the passive part and the...testifying to your resistance but I didn't ever get into the 'fuckin cops' , you know and 'we're going to court ' and fighting, you know it seems that the Ghandian principle was one of passive civil resistance and you willingly broke the law ... but to a certain degree I think in our generation ...there were some people that did that... for whom it was a ...kind of unofficial...environmental peace corps. We were part of this conspiracy that was national...there was...local and regional links and we had meetings and discussed strategy, so maybe that was a surrogate...battlefield for us."

Another social change spoken of by several participants was the increasing awareness of the prevalence of abuse, particularly sexual, but also physical, “Because I never ever spoke about my past...even to my ex...never...so how many men do you think are out there talking about it? So that puts the ...the 1 in 6 to a lot 
different figure... I am sure that's it's closer to 1 in 3 ...knowing what I've gone through..."

A daughter of one of the participants came in on the tail end of the interview and began to speak about growing up in a "Cinderella world" because,

"I never seen that shit...I never seen my dad hit my mom or my mom hit my dad or fightin or carryin on", but, "I grew up with friends that had abusive parents to each other. I recall many times ..'Please come help...mommy stabbed Dad...take him to the hospital, he's got a knife in him', or, 'oh my god, dad just took the gun and slapped mom in the mouth with it and knocked out all her teeth and that...that's how my friends grew up...

I remember my best friend telling... 'at five years old I remember my brother and I sittin there and saying to my mother, oh please mommy, just have sex with daddy so we can go to bed.' Can you imagine...I didn't even know what sex was ...as a child...I didn't have a clue...you know, I was brought up...my dad didn't go golfin on Saturday , he took us kids to fairs...my mom worked, like ...you know what I mean".

Mom and I were just talking, we have 4 little girls ..my granddaughter, my sisters 2 granddaughters, my brothers wee granddaughter and 2 of those wee girls will be raped or beat ...or sexually assaulted..."

The participants noted that there had been considerable social change in terms of the roles of men and women, and the increasing acceptance of homosexuality. Interestingly, that was not seen as particularly stressful. For the men with traditional, socially conservative role values, they had been able to preserve that in their relationships and all the participants expressed support for women's equality.

"It's kind of changed now, it used to be the guy gets a job and brings home the bacon but now it's sort of...you know, you and your partner, or your wife, or whomever... you know both have to work to make ends meet" 
"I think it's in the works, cuz, sort of what it means to be a man is...I think, changing a bit, but there's still this strong traditional belief that to be a "MAN" is to be a little bit more physical and a little less emotional "

"An increased acceptance of homosexuality, at least in Canada has...it's very interesting, but there's come a whole lot more freedom, especially for men because you don't get labeled as 'gay', all the time for doing something that seems somewhat feminine.

It's becoming a little bit more acceptable to show your emotions and show your feelings. There was a time when it was never ok for a man to cry...Ever ...now it's totally acceptable for , you know...the birth of a child...you see a guy crying, you don't think, 'aw, he's a wuss', you think, 'he's a proud and happy father'.....and that's ok and these are changes that I've seen, even talking with guys with very conservative values, you know what, there are these circumstances where I can cry....where I can let it out.

So I think gradually we're beginning to accept that, not only do men have emotions and feelings but it's ok at times to show them. So, it's... being able to better and more clearly define when and how it's ok ...not just how to show your emotions but the way they come out...both happy and sad."

This indicates a way to negotiate the performative code by attaching emotional expression to other performative requirements, in this case 'connection'.

"For me in my personal relationship nothing is different but what I'm seeing outside, it's a different world ... more women working, it's more important women work. In my younger life we worked part-time so we could stay part-time with our child, now it's everyone's working $100 \%$ just trying to stay ahead. It's harder on relationships.

I still think that most people want to have a defined relationship, Who does what now? We don't seem to know that anymore... you know, men don't do man jobs and women don't do women jobs, typically in the younger generation.

In our generation they still do but in the younger generation it seems different, there seems to be more demand on men, now I have to work out plus work in the house. Whereas before the women worked in the house and maybe worked out a little bit, but I know a lot of guys who work really hard all day and do their share at home and it doesn't seem quite right to me... it seems to me to be an imbalance but that's looking at it from my perspective which is an older perspective." 
Participants also spoke about changes in how children are dealt with in society and how the family has changed. One man noted the difference in family structure,

“The world's not set up for kids....you see, so that's not right. There was room for kids in the old days when there was those big huge houses that make no sense today. When there was no other houses like old folks homes or places for...retarded or troubled youth or whatever. It was all there.

Mom and Dad that were actually doing the milking and working and shit and the bosses. There was their parents, that were there before but are too feeble now to do it but still are engaged. This is generational. Then they've got their kids, which are shown their chores once they're five or whatever...able to do stuff. They're quite happy to be little adults, eh? They're all living under one roof and they're all living in close proximity to their work. Then the spinster girl that never got married ...that's old aunt Alice, or whatever and there's simple old George...he's one straw short of a bale but he can stack wood forever or whatever, you know what I mean?

...it was all ...a unit... and there was a place for everybody...it was different in terms of creature comforts, but in terms of personal wellbeing...I'd go for that. Then there's this divided thing where I'm alone here with all this big space...then maybe I'll have to go into care somewhere....or I have to have people come in and serve me and, everything's removed...where you made your living isn't where you live and in the modern world may be where you live for the moment and then...oh no, we're moving you to somewhere else once you're settled. So the kids belong nowhere, you belong nowhere, and you all belong to the feed trough which is a moveable feast until they decide one day...oh well, we don't need you anymore...you can leave now.

You know, no notice or nothing...oh well, we have no money for the pensions...thanks for the use of your money contribution though...it's really good...got me a real nice place in the Cayman islands...you know what I mean?"

Another man commented on the increased role for fathers in child raising,

"The good part is that fathers are more involved with kids which is good, which is something I was always very involved with...you're seeing more of that, which is really good, and something that's not so good, is there seems to be inequalities now that the father still has to work as hard as he had before and still bring in a lot of the income, or, maybe all of the income, but still have to do, come home, do his share, and he should do his share, but there should be a...share both ways."

One man looked at the effect of top down changes that do not have ecological feedback loops, 
"Our system has set up a lot of things that have a negative...they weren't intended as this...their intentions were all good I'm sure , but they certainly weren't carefully viewed and looked into as to what could ...

If we all had a looking glass and could look into the future ...that'd be great...the things that our government has set up and our institutions ...CAS (Children's Aid) and other institutions ....yah, if they could only look a little farther and see...probably what policies they've instituted and brought forth, that there's a possibility of something negative coming out of it, because I do see negative stuff with the CAS, I've seen a lot of negative stuff...

Now I don't know how closely tied our main government is with the CAS...I haven't gone into that part of it...it's funny..it doesn't interest me but I know it can be affected..one by the other ...so the policies they write down and institute should be more carefully scrutinized before anything is ever done...this one idea of you know...hands off relationship with your foster child is a very, very negative thing and it shows up in later years,,,I know it does."

\section{VIII-Life Stressors}

In the Life Model, "Life Stressors" refer to life transitions, traumatic events, and environmental and interpersonal pressures that disturb the level of person environment fit and a prior state of relative adaptedness. None of the participants reported life stressors which permanently exceeded their personal ability to manage them. This is probably due to the fact that this research is "strengths based" and focusing on the ways that men have successfully made sense of the changes that have occurred in the course of their lives. This undoubtedly skewed both the participant selection and the data gathering. For ethical reasons, it was decided that I would not seek participation from any of my current or former clients, which would have provided instances of life stressors which are beyond the coping ability of personal resources. Nonetheless, it is worth noting that in some instances participants related issues with coercive power that permanently altered their attitudes and behaviours and temporarily incapacitated them. 
"I still go back to the fact of being hurt and...the hurtin' has to end somewhere, and that's the only way I would've known at the time, to take care of it.

So, the rule is, 'nobody is going to hurt me... or pay the consequences...it's one or the other... because the first one I wanted to do big damage to would've been my foster brother in that home, that brutalized me...he's the first one I wanted to take care of ...and of course...my mother when she was murdered...there was that one...there were a few numerous smaller...but not to the intensity of that one ...".

Another participant identified that the break up of his marriage put him into an overwhelming depression. Both these individuals eventually sought counseling and found it useful. This is covered under "Adaptations".

Some of the participants talked about financial stress both as something which had severely tested them and also as something that they see testing others in the community.

"There were times when it was tough, y'know, you're working two jobs and going to school full time, it was...it does interesting things to your mentality...you know, sometimes go a little bit crazy and curse and swear a lot, but....it can be stressful... and I think it's stressful for a lot of people who are working multiple jobs and trying to make ends meet and they're not able to...and ...and facing that reality that in spite of my hardest efforts...this is not working...

That's a really tough pill to swallow. ...and it's humbling and if you can get past the...the feelings of guilt... and that humbleness and look at how I got to this place and how I can get so it's less overwhelming... it can make you stronger, but it's...sometimes that which doesn't kill you makes you wish it had. "

"It's devastating. I see increased desperation of people...reduced sense of pride...increased feelings of failure...see increases in depression. “

"The young people today ...particularly young men, are committing suicide because they've seen ...I guess by either listening to their fathers or grandfathers ..or other people around them.... what we had before and no longer have today, and they're thinking and looking a bit into the future and thinking...well, what's going to be left for me? I might as well not live any longer. I'll just do away with my life because there is nothing....

That's what it's come to...mind you, they've got all this other stuff piled upon them...baggage...that children come into the CAS...they've been abused or whatever but that's only part of it...the other part of it...well, what future do I have? “ 


\section{IX-Adaptations}

Within the Life Model, Adaptations refers to actions designed to achieve personal change, environmental change, or both in order to improve the level of person:environment fit. For most of the participants, there is a genuine acceptance of egalitarian relationships in their core beliefs. "I'm not really concerned about being in charge so much as figuring out what can work...so, my wife and I negotiate a lot... a lot of it is communication in terms of how to get stuff done...it doesn't really matter who does it, as long as it's done."

“It's kind of how I was raised too, eh...I was taught that there's no job that's too good for a man or too good for a woman...work is work. Just get it done, do what you have to do and treat people ...regardless of who or what they are, fairly."

The key environmental fit is with domestic partners (wives) and this is achieved by clear communication and shared experience...

"It's always just worked out. Have we ever had disagreements over who's doing what? Probably. I mean, for whatever reason I clean the washroom. I don't know, I mean that probably goes back to my (police) days, we cleaned toilets and what ever and (wife) doesn't particularly like doing it, and I don't care. I don't need rubber gloves to clean the bathroom, I just clean the toilet, you know.

It's a division of labor, you know, who likes or prefers to do what job but the main thing is that the jobs get done and I mean they do get done. If (wife) is doing something and it's not working right she just goes, here, because I can fix things, and she can't. I don't know how to do laundry. (Laughs.) I don't care to know how to do laundry and she can so... it's not a problem.

I know in a lot of houses this division of labor becomes a problem and people... just make problems. ...I know people who fight over the stupidest things. We look at each other and just go, it isn't worth it. It's not worth fighting with your mate over some stupid little thing but then some people have to be right all the time.

I don't have to be right, I'm happy. I just wanna be happy... You can be right all of the time, which means you're also going to be wrong half the time. I'd rather just be happy." 
The strategy of improving environmental fit by avoiding conflict was echoed in identical terms by other participants, "The day I got married I got the best advice of my life. 'You can be happy, or you can be right'...so that's sort of how I negotiate it...l'd rather be happy...you live longer."

In order to adapt to the generally poor environmental fit to modern urban society the same strategy of avoidance of conflict can be employed. The necessary support for the behaviour comes from adherence to the personal code performative of 'connection to self, rather than external approval.

"Everybody has to be right. I have to know I'm right but I don't have to tell everybody. Everybody doesn't have to know that I think I'm right. I'm happy enough knowing I'm right. I know I'm doing the right thing, that's all I need to know. I need to know I'm doing it. I need to know I worked hard. I don't need to tell anyone.

(Wife) gives me a hard time, you know we put on the poor act. We're not poor, we're not wealthy by any means but we've done well for ourselves all things considered but I tell people we're poor and we drive shitty little cars and what ever. I don't care. I don't need to put on the dog. I don't need to think people think that of me...don't care what the hell they think it doesn't do anything for me and that's just... and (wife) is the same way. We're strong enough inside that we don't need to."

Establishing and adhering to a personal code was supported by all participants as a necessary strategy for negotiating poor environmental fit.

"That's the way I choose to live my life, is the standards that I've mentioned before, sometimes it's easy, sometimes it's not, and...the ultimate judge is me, as far as I'm concerned. I'm not really...I'm to the age now where I'm less worried about what people think of me and l...want my actions and my presence to speak for me."

Another way to avoid conflict, as well as obtain information, is to play stupid.

"The other thing I do very well my friend, is hide my intelligence, oh ya, I do it on purpose... but l'm gonna get you." This is a particularly interesting adaptation as it uses the stereotype of the rural male as a camouflage to hide within. It is effective as 
a survival strategy but has cost. When asked how it feels to conceal his intelligence this participant said, "Do what you gotta do. A man's gotta do what he's gotta do (laughs).", then went on to say that it feels, "A little yucky...that's not a good adjective. (both laugh) No...it's the world that's gonna come...can't help it...". Acquiescing to, or at least not openly challenging stereotypical assumptions allows for gathering of information which can be useful in navigating away from negative social connections,

"I don't feel a need to live up to anybody's stereotype. I'm not a clique-y guy ...I don't fall into cliques...a fella...that I was playing with .... told me an off-colour joke that was racially motivated and he kind of, on the sly when he finished the joke, after I you know, politely give him a chuckle because it wasn't particularly a good joke or anything, and then he said that he thought that he'd tell me the joke on the sly because he didn't think that the other fellas would appreciate it, but he just ...assumed that I would".

A creative solution to meet code performative is to substitute one type of code performance for deviation from standard of performance in another area,

"I try and counterbalance...I spend a lot of time kicking my own butt so on my off time I try and do more physical things... more exercise, work-out, y'know, play video games that blow things up...go around and shoot paint at each other with friends,... that kind of stuff, it's kind of...counteract and throw some testosterone in there...almost compensating in some ways, it's interesting."

Attitude was identified as useful in adapting to environment, "a twisted sense of humour helps", and one participant spoke of the need to stay open to learning, "if anything you didn't know, it'd be damn few days that you did know", noting that he had felt a negative attitude made it impossible to learn or adapt, "nothing'll register, and everything's turrible, I mean ...like there's no bright side to anything, or happy ...you're beat before you start." Experience of success reinforces adaptation, “I think just experience and kind of maturing. What's been helpful and what hasn't 
been...learning through experience. That's the way everybody learns." One example of adapting by attitude adjustment was how a participant rationalized some of the physical abuse he suffered by seeing it in a historical context as the method of discipline common in that time,

"Lookin for me and she found me in the bush...way, way out...well anyway, she had broken off a switch and I got that across my ass and ..'don't you ever run away again, mother was worried sick about you, and don't you know the children's aid were here, and'...yah, that's why I run away, you know, so...but I always, uh...I always...I was never mad at her for doing that...I knew she cared about me."

Solid social connection was seen as critical to being able to maintain positive self regard in the face of adapting to environment.

"A very understanding family and...my wife [emphatically]...I think I have a pretty supportive partner now... I certainly have a very supportive boss. She's...wonderful and she's been a really good support in some difficult things that I'm struggling with at present, both professionally and personally, and...even though those things are difficult and she's kind of helping me letting me vent to her about these things, it kind of validates my position in a way".

The sense of community connection is also helpful, "One of the flattering and nicest things about, um...living in (small town), is that the effort you put in, comes back a thousand fold, in a thousand different ways, that you never thought possible."

Another participant said, "I also see...community...people taking different ways of trying to help each other out and people trying to come up with...different solutions, trying to think their way outside of the box and recognize that...alright, you know what...'plan a, is not going to work ...we need to come together and figure out something else"'. 
In terms of adaptation to changing economic times, the theme that emerges is constant "re-inventing" of the economic self according to personal core values rather than extrinsic regulation or law.

"I just kept re-inventing myself...I did the art thing, I did the (trade certificate), I did the bushwork, I did the construction work...then I did the marijuana, and I usually blended it with doing other things, because I wasn't just that...I'm not just a fuckin' money grubber...

In 1988, 1990's when I was recovering so I decided that I was gonna go for money but then it fucked up royally because it's bad and I got busted and robbed and everything and I didn't do it for awhile and then my mother died and I gave her that year ...and then I went really hog at it and I guess I must've had 15 or 16 years of pounding that pavement and I'm glad I'm over with it...the timing was just too much because getting in and getting out were just by luck because I got in at the right time and out at the right time and it's sort of like...I look at marijuana like estrogen with horses. At one point there was thousands of horses in barns all over the country for estrogen and now there's synthetic estrogen and there's no horses in barns around the country so agriculture...it's niche markets.

What're you in? When? I could never make a living at (food processing) like I did then. I turned over probably between the (farmer's markets) and all the deliveries 5 thousand a week or some fuckin' thing but I had a bunch of people to pay and travel, and what do you keep...it's like a band on the road...good times, eh, but the thing is, you couldn't do that now...you'd be lucky to fuckin' pay your gas and your packaging.

So, people that're doing it now are doing it as a lifestyle choice and if they're not...they're...they're dinosaur shit and that's coming from the city, so I don't have an answer cuz I don't see it as a group. I see each one as an individual...what do you bring to the table and how could you sharpen that tool to actually get an exchange going within the society that you're included again so it's individual...mine is an individual solution."

"Sharpening the tool" sums up how men adapted to the changing economy, but once again there is a cost to this, and many of the participants felt it was a social cost, as well as a source of disappointment in their lives,

"I suppose the realization that I couldn't make a living doing what I wanted to do ...my goal was to come out and farm ... Fortunately, I went to (local community) college, while I was doing it, I went to College and became a carpenter...

There was no really big life changing things that happened, it was an evolution, I mean we just started slowly getting fewer cattle. The last thing we did was we used to get 100 or 200 meat birds and we had a market for that, but when 
that market started drying up because we were charging like two bucks a pound when you could get it for $\$ .89$ a pound. That was probably the last thing so we ramped up and then slowly it just wasn't working, it just wasn't working, it just wasn't working. We were selling lots of firewood at one time and that just slowly petered out and it just didn't work, it just wasn't working, so we slowly evolved."

The oldest participant adapted to changing economic times with the same tactic of "sharpening the tool", and his narrative of wheeling and dealing would fill an entire library, let alone this thesis (Appendix-Transcripts). He advocated for understanding what market niches were available, a broad network of available resources and a readiness to change direction and do anything necessary to survive, "all honest, though". Although he advocated pro-social, legal activity and criticized those who worked in the underground economy he also noted that the increase in "rules" was a problem for him and admitted that he had worked for years with a dual system of "declared" and "underground" income, and still has access to economic resources which are undeclared income. He felt that large debt load to support inflexible infrastructure hampers economic flexibility. One example he gave was a detailed explanation of how a man starting out right now could establish a profitable firewood business by refusing to buy into the current trend towards highly capitalized specialty equipment. At the same time he noted that none of the younger generation in his family were following this advice.

There is something very British in the notion that things will be alright if you just keep trying,

"If you're going to do your own thing it's 7-24 and all the time and there's lean times and you gotta...there's lots of questions about whether you're doing the right thing or not and if you're gonna make it with your attitude and all that but in the end over time, it's all worked out, but, you have to work at it all the time, even if it looks like you're doing nothing." 
The governing factor for adaptation was not societal moral or legal strictures but adherence to personally determined code performatives. One participant explained his decision to grow marijuana like this,

"I know what I did...I worked until I said, I'm never getting anywhere like this and I didn't care about money until I had these injuries and had to be operated on and recover and that and then I realized, geez, I'm in my fourties and I got nothing together for my retirement and I never trusted in the system like my father did where it looked after him and his wife. I didn't believe there'd be anything for me and hey, it's turning out to be like that, eh?

So I decided to make a big left turn and I just took the law unto myself and I grew marijuana, and I said fuck you, and I believe it's hypocrisy because I know judges and lawyers and police and all this that're doing it so it's just a two-faced game here. It's a prohibition just like alcohol. People made fortunes at it and their families are high and...judging , and all the opera companies and blah blah...They became wealthy at that.

Because it's human nature it's not like you're forcing anything on them, you're actually providing a service, so I decided I'd provide a service and I'd do agriculture, cuz I did all the other agriculture and I was managing...just, but I was never gonna retire on it or own anything or fuck all...it was like a ...like a hobby in a way but it was actual serious, like the (food processing business) and the... I tried to make a living...I did make a living, I don't even know how I survived ."

While this particular path worked for this man, he said,

"Each one can find their adaption. I wouldn't recommend it to anybody. I didn't want my son to do it. He did it on his own and then friends of mine tried to seduce him and he did for a bit and then in the end we did it a couple of...twice, and I told him when it was over and he still was going to be seduced and I told him forget it... cuz it's like, why would he ruin his life?...for what...it's history!

It was good at the time.... Let them experience it. Like don't be... the bad parent. Like that's why our kids are our friends so if they got shit to talk about, they can talk about it because we haven't closed down the conversation into a narrow channel."

The use of antisocial tools to adapt to poor environmental fit was understood to have it's own costs, 
“I had an offer ...in the family ...good ...blood...you need somebody beat up...I'll beat him up...get somewhere else...I haven't beat anyone up in a while...this is my cousin and I have to owe him a favour where he would be somewhere else and something would be made right...completely...no connection...why would I be there?

You understand?... lot would happen...little blind connections..get an alibi...make sure you're somewhere where folks can fuckin see you...then you owe them one, and so be it...so be it...make things right...so be it...just to make things right."

Another participant said, "I've learned to launder (money) too, eh. I learned all the criminal shit they forced on me. Survival, eh?"

The participant who had survived the foster care system described his survival adaptation as,

"I'm already putting up the battle armour ...just to protect myself...do I have to run or do I have to fight? I don't know what I would've done without it ...had I have been some wimpy child or something...but I learned to be very strong at an early age and tough...tough as nails...they used to say...

I went to school ...down at the one room school I went to...they also remembered me the most for sticking up for them...if there was some other big bully there that wanted to do something...trying to harm them, yah, I intervened right away...yah ...you don't touch this kid, you know ...and here I was no bigger than them."

He identified that this left him outside of most social situations, alienated him from 'authority figures' and,

"I just internalized it all in myself and couldn't learn...it was like I was sitting there in a daze all day long...whatever they were telling me and whatever they were saying...it wasn't that I wasn't listening... I just couldn't hear it...

There's still times today I'm like that...especially when people tell me their names. I hear them telling me their names and 2 minutes later, I don't even remember their name. I don't know if it's... a defect in my brain...I haven't got a clue...most of it's names... maybe places as well...but names, places ...nouns, eh...don't know...it's almost like they're talking to me in a fog, yah, it's almost like a fog." 
One participant supported this notion of fight or flight or freeze reaction for

men who are unable to make the necessary adaptations for environmental fit.

"If they don't adapt, they're dinosaurs, and if they sense that they're becoming marginalized and trivialized and neutered, then they're gonna react viscerally. They're gonna be angry, not sad, like they're not gonna cry and woe is me and what did I do wrong.

They're gonna point a finger and say, "those fuckers" and whether it's family, job, government, whatever...police, authority, that's taking their ability to make choices for themselves, and taking the zeroes out of their paycheque and rendering them decapitated, like, or...handicapped, right, so now they're operating like that...

Or, if they come from the right stock or they're ambitious enough ...you know what I mean, that will take a gamble and work overtime and everything, towards it, then they'll get somewhere, but they're still in the squeeze of the bigger picture which is litigation and the authority of "we're right"...the moral authority and that you're our next victim or we're gonna punish you, even if you're a winner. Like they can make losers out of winners easily. They'll just make up a rule."

This visceral type of reaction is detailed here,

"That control affected me a lot I think. It wasn't the same as being abused by these other people but it was still abusive and it became so abusive that she'd literally use her fists on me and I still remember the last time she did that...I was at home and I sat down at the dinner table, the table...well, there was no dinner or anything...

I just sat at the kitchen table and I was reading the newspaper and she said something to me ....and I have no idea to this day what it was, and I didn"t answer cuz I was reading an article and you know and of course, we were speaking there just previously about sometimes when somebody would say something to me, it would be like a fog, cuz I always had my wall up with her, as well,...the wall was getting bigger actually, the longer I was with her ...

Well I sat there and I was reading the newspaper and she come up...I didn't even see her coming up, over to the table...she just hauled off and drifted me in the side of the head with her fist...almost knocked me out...all I saw was stars, eh ...and when I sorta came to my ...my, I wouldn't say my senses, I certainly wasn't coming to my senses ...

When I come out of that...all I could see was red...just total red and I thought 'nobody is ever going to hurt me again', and 1 just lashed out at her...man, my god it was the worst thing I could've ever done, but...she took the brunt of that and that ended the marriage and...

I still remember the thing ...that came to me first is...'no-one is ever going to hurt me again'...and...it didn't matter if it was my wife or what. It was terrible....absolutely horrible and I felt so awful about it afterwards ...I'd never ever laid a hand on her...l'd never laid a hand on her before, but that just brought it to a...I 
guess a head and it still took a couple of years before I was able to, I guess, get out of that...shell and out of that prison I was in."

This man recognized,

"From that incident on the marriage was breaking up...I went and got counseling...but I wanted to bring her along with me ....counselling for both of us because I knew that this had to stop somewhere...you know, especially what I was doing and the way that I felt .

I had to get this out of me somehow, so I convinced her to come... to the counselor and I still remember ...in the very first session...she says, 'I will only come to counseling here...if this counseling...ends our marriage'...and I thought, wow, that's great... I'm trying to fix this...somehow, for both of us...especially for me....and she will only partake...if it ends the marriage, you know?

So that was the end of her counseling...the counselor just said...well, we'll take you and we'll see what we can do, so I went there for a year and a half ...over different periods...it helped quite a bit, but still...lovely, lovely lady...just can't remember her last name right at the moment but beautiful lady ...

It's like she reached out to me in love, more than anything...you know...we can go to a psychiatrist and you sit there and you feel no connection at all, other than you're just talking to them, but this lady I actually felt, was reaching out in love, just by her expressions, the things she was asking me and that and that's the first time in my life that that ever happened...and so that in itself...she had a big breakthrough in me"

This experience of positive social connection, "Wasn't exactly the major breakthrough because...l'd gotten into drinking after that, ok, just to kill the pain". The healing for this man occurred with a religious epiphany (see appendixTranscripts) which occurred at a point where he, "Decided I didn't want to live any longer...hey, it's over...I haven't got my children, my marriage is broke up...I literally have nothing". He experienced,

"This immense power...and love, and it was a hundred thousand ...a hundred billion times stronger than the sun...our own sun...in the universe here...it was. Well I thought it was going to blow me away ...I thought I was going to blow up (laugh) ...you should ask people who got to know me, or did know me after ...they, they couldn't believe the change." 
This experience of connection to something much larger than himself, and full of unconditional love led him to quit drinking, engage in discussion of his issues with "Good Christian people" and eventually led him to conduct a street ministry, where he gave an example of how he,

"Showed that guy...love...this kind of love that l'd had now...you know...I was able to show him that and calm him down, you know, and hope to have changed his life...now, that would only be... a seed being planted ...

You know, I'm not the one that would have changed his life..it would only be a seed cuz ...going back to (counselor)...she planted that seed, which, you know... evolved... and then you know I would hope that this seed towards that person, would take the same effect and that's the way you do it...

You don't go in there you know pounding over their head and this and that...you just love them, that's all. You show them that you care for them...this one individual, I found out that his father almost killed him when he was 12 years old and he's been living out on the street basically after that...course, can you imagine what he would have thought of authority figures? The same thing I felt before as well."

One of the interesting aspects of this man's narrative is that he identifies that because of the abuse he suffered,

"I would be able to ...and of course you could decipher immediately...oh you have this ..you have this, oh, I'm trying to think of the word for it now, uh...ability ...to immediately...tell what that person was like...

Now...this is not a judgement factor, ok...I know... I had to be careful cuz I would think...'Am I judging that person?'...or do I really know what that person is like without judging them and of course this is where I would go with it and you would know immediately, almost immediately, what that person's vibes were towards you...oh yah, you felt it, and so I could distance myself from that person if I thought it wasn't right."

This can be seen as a highly developed ability to read social situations originally developed for threat assessment but also useful for empathic understanding of other's thoughts and feelings. 
Another participant described his sense of connection to a larger reality in terms that parallel the First nations concept of the Medicine Wheel,

"I'm not about winners and losers. I'm about understanding and harmony and the big kaleidoscope of life you know, and what makes sense at one moment doesn't at another cuz it's all about perspective...where are you looking at it from, what are you bringing to your observation, you know, and it and you know that 360 degrees you can have 360 different interpretations of the same event from different angles, right?"

This development of empathy and understanding and acceptance that other viewpoints have validity was seen as a useful adaptation in intimate relationships as well.

"Women see things totally different than men do... for an example, every partner that l've been with, this is the third......they are more demanding of my time than I am of theirs....That's important for women....not that you're going off and buggering off on your partner or anything but you know, (sport) for example...

If (current partner) wasn't (involved in the sport), there'd probably be a lot more friction at home because I spend a lot of time doing that. Luckily so does she, but I mean she just got back from two weeks (holiday) and I mean I missed her being around the house and all that kind of stuff, but...off you go, have fun. Actually, (current partner) is more like that. My last two relationships... were very clingy and demanding and needed all of my time all the time."

It was also identified that the element in empathy that removes you as the target of other's actions is critical. "The part that really hit home for me was when he talked about if you take behaviour and point it at you personally it's really hard to find compassion. I was thinking about that a lot since I heard that." This is identified as critical to adapting towards environmental fit, both for the individual and the social system. One man noted that this is paid lip service to in modern society, and advocates that it would be an effective means of achieving environmental fit if it was actually adhered to, 
"So this is what these kids have to understand is that you don't create antagonism like when you know that you got a plan and you want something, say from the Arabs or from the underclass, you want them to straighten out and pay their fines and be good boys and pay taxes, right? That's what you basically want...

So the confrontational approach of us and them and you're right and they're wrong and all that isn't really the future. The future is...engage them...ah...tell me what's bothering you. It's them that's bothering them...well, express it...like, get it out... where are your allies?"

\section{$\mathrm{X}$-Adaptations- meeting the rural male performative}

One of the most interesting data gathering exercises occurred by chance after a dinner party. Two men (early 30's and early 60's) agreed to participate in an interview and a partner of one of the men galvanized an interesting discussion when she contributed her observation of her husband's interaction with his local friends and neighbours. The men began by commenting on the difference between rural and urban men.

"In the city you've got to be more effeminate in a sense...you got to lose the masculinity"

"I would say that the predominant feeling in rural areas is...'well, we've worked for our money and...these leeches in the city...the civil servants ...haven' $t$ ' and so there's this kind of tough...uh..libertarian inclination that I think is totally misdirected...misinformed..."

“Usually a rural situation, it's a collective situation, whether it's you and your wife or you and your family or you and your extended family, which would be the more traditional situation...

You may not have the tractor with the snowblower on it but your fathers brother does down the road and of course he's going to run up your driveway as well...it's sort of all these interlinking...things...so part of the thing is that you're a provider, you can heat the house...put food on the table..."

'Yeah..I believe there's like a 'back to basics mentality'... there's some sort of....basic ...kind of like bush knowledge...I think those skills are more valued in the country...like, who gives a shit if you can start a fire in the city?...if you're remote...removed from...immediate amenities it's just stuff that you should know to be self sufficient" 
"If things got tough or I needed someone to help me out with something ...I would be much more inclined to engage ...(younger participant) as opposed to a peer... of equal age who was brought up in Mississauga and maybe a computer whiz or whatever...may not... just be a dolt in the shopping mall...

But nonetheless there's an assumption that someone who is brought up or has rural experience has some primary skills..you've seen things happen, you know, to a greater or lesser degree and those things are generally ...perceived to be valuable, you know whether they're ever useful or not in the future, it's just kind of like a manly thing to be able to, you know, fire up a chainsaw and not...cut off your...limb."

At this point the female partner of one of the men said,

"Well I just noticed, whenever we go up and talk to other men in the country... it's the guys sitting around shooting the shit and its sort of like they are sitting around talking about nothing and talking all slow and... they just like have this banter with each other and its almost like a different language and I notice it more because I'm sitting there waiting ..."

"Ya I think it's...the banter, its just familiarizing yourself and like...becoming...like speaking a dialect in a sense...kind of like reassuring your... place in a sense. I don't know if that's a bad terminology"

"Its sort of like, you're not heidy-feidy you're not city folk"

"Yeah, you're kind of identifying yourself as belonging. And then there's the sense that, I almost think the rural thing is like, as if you've been through an ice storm and come out the other end....you can be counted on like...if shit goes shit..the power goes down and you need to light a fire and you need to find a candle and you need to crack a hole in the ice and pull out water...you're the guy to go to"

"That's why you like this guy...he can do all those things...you can go get your phd and you still can't do all that shit "(laughs)

"Being able to cope without all the comforts that we've become accustomed to...like take me back $60-70$ years and throw me in there and ya, I can still cope"

"But I think it's like a camaraderie too, because like, he fits with them more than I do...ya...this was really strange...they're not really talking about anything...I was just an observer at that time, and I thought it was really interesting..." 
"I think it's a lame attempt ...most things in our Calvinistic, puritan culture are withheld and restrained and so on...and I think what we see in our culture is a reluctance...we see it come out in like Tim Hortons... why the fuck is tim hortons so popular?...it's shitty coffee but it's where everybody else is, right ...it's...they crave social interaction..."

The participants then looked at the difference between urban and rural in the social intercourse of "belonging". "It's like one is... let's talk about the weather and then the other one is like, let's talk about the next election...kind of like that...two worlds"

I asked what is the difference between a weather pattern and an election.

"One you can be of any denomination ...any political association...you can still talk about the weather but if you're talking about something... like your political sort of views and your personal aspirations...that more defines you...

But in the country you almost want to be undefineable..you want to just kind of associate with everyone and the weather's like ...uniform like sort of association...you can be hard core conservative or ultra liberal but you can agree that, yah, fall's coming and fish are bitin...the blue jays are losin...and the hockey strike is imminent... it's stuff that no matter what your convictions are, your political associations are...you keep them at rest...you keep them close to your heart."

"So that when you need to do the instrumental things like pull someone out of the ditch or whatever that doesn't get in the way...you keep your personal convictions to yourself...

Cuz I think in the country it's like...your neighbours are your neighbours...you can't change the belief of your neighbours...so you have to find a thread that ties you to them so whether you or them share the same political beliefs or aspirations...you need to find a commonality so that if shit hits the fan you have an underlying connection."

"In the city, the community in the city, within a block you're going to have every denomination, within a block you're going to have a hard core conservative, you're going to have a liberal, you're going to have a ...hardcore this or that, so you can pick your associations...you can...navigate your connections more towards someone who shares the same beliefs as you." 
"We were talking about how fucked up the world was and how...the shit was going to hit the fan...(your father) summed it all up by saying, 'you better get to know your neighbour'. You better like your neighbour, you better get along ..."

"Yah, that's totally it."

This dialogue nicely explicates the functionality of the rural male social communication rules. It contrasts with the assertion of emotionally restrictive pathology and "conversational cock-fighting" noted in the literature review.

A rural social worker commented on the same social performative, linking to the concept within deep ecology of "tolerance levels " for change in ecological systems.

"I find living in a rural community there's a very strong sense of...people have a strong sense of privacy and individuality so you know some matters are to be shared but family stuff is family stuff.

That's why as a social worker that's a big barrier of, 'well how can we trust you, and why are we going to tell you about our personal stuff and why are you here in the first place? What do you want? There's nothing you can do to help us. Go away, this is none of your business.'

I think it comes from pride in being self reliant and having an appreciation for being able to deal with life...on your own. You know, being able to forge your own path and...that...unit that you've created, that family...and not needing other people's help...that focus on the individual, in addition to just recognizing that someone else coming in and offering advice and help may have a completely different value set...

One of the things I run into a whole lot is people saying, 'Well, you don't know me, you don't know what we go through' ... basically asking 'How can you help me when I don't know your values and...you don't know mine', so... 'I don't trust that'"

Other men explored contrasting aspects of the urban and rural male culture in terms of the analysis of body function as a performative suggested by Little in the literature review,

"The metrosexual I'm familiar with cuz my daughter lives in Toronto and her friends are all the six figure creative class, and the men...don't do the sweat'n grunt'n and physicality thing...metrosexuals can make a living with a keyboard....

But my mother's father made it by having tools and by shaping things, building the world, you know. The urban one is more reflective and more 
esoteric/philosophical and more soft/gentler, like not macho male physical. The rural one is the ability to shoot a deer or cut a tree up or open the ground and have something come, or, with animals, see it from the whole cycle, you know.

You give and you take and all that so it's ...the rural one, the horizon's way smaller and the patterns are way deeper, they're not exploratory like the urban. “

"I think the urban one is a work in progress but it's a lighter touch and the rural one is a deep old pattern that has echoes... The urban ones don't fight so much, they negotiate or use litigation...but the rural one is, "If you're going to say that, then say it to my face, come outside"...If we're going to have a difference, it's visceral and the other's...philosophical...one's in the body more and one's in the mind more."

One man who has lived his life as a constant battle assessed the difference in terms of levels of threat and how country people deal with that in a different way than city people.

"I think the city's probably more dangerous...those kids come home from school or they go to the mall and they form gangs...they have their little pack...that stuff involves shoplifting...drugs...it's sitting right there for them...

Whereas in the country you could have two parents still working but they've got to come home on the schoolbus, and they know they have chores to do...like pile the wood, feed the chickens... whatever, where in the city, I suppose there's some household chores to do...but what?...I just think that the city is a far more dangerous place...

Thank god I didn't grow up in the city...I'd a been a full blown criminal had I grown up in the city...believe me...I would've ...there's just too much there.."

"I think in the city people are so paranoid that if someone comes to their door... they won't answer the door or they call 911 right away...please send the police...

So they've set themselves up for not ever knowing if that person really needs the help or not...the police carry him away and possibly he might go to the sally ann or he might go to jail...let the system deal with it...that's what happens in the city today...

The chances of me...if someone came to our place to do us harm...the chances of ...calling 911 would be virtually nil...I can tell you that right now". 
When asked what he would do if the person at the door was not a threat, but simply hungry, he said that he would provide a meal and not think about sending them to organized charities such as the Salvation Army. He noted that he and his wife had taken a roast beef and garden vegetables over to a local children's camp the weekend before and provided a meal to the campers and staff. When asked why they did it, he said,

"I care about the person...why rely on the system? Why shouldn't we do that ourselves...it's not only pleasure...it's our given duty". By comparison, he thought that, "I know in (the city) they're very generous... I think there's a lot of good people and they're very warm and generous cuz they give a lot, but it's money that they have to give because I guess that they can't...do these meals."

Another man who returned to his small town after living in the city for several years, said, “The city's more impersonal and your circle of friends is not as large...if you're driving enough times up and down the street [in small town]...you'll see somebody..." The interview with this man was conducted in a town park and was interrupted three times by acquaintances passing by and stopping to chat. When this man was asked about differences between small town and city, he said, "I don't know that the stereotype would be any more rigid...this is kind of a progressive area...you know, things happen here that you don't hear about happening in lots of other places....both good and bad." As an example of the good things he spoke about the community involvement in a yearly free music festival, and in terms of negatives, he said, "I find (small town) very homogenous...there's not a lot of diversity...certainly culturally...there is diversity as far as the arts and I think the stereotypes are kind of bent...you hear of quite a few in-home dads as opposed to just being the hunter and gatherer, so kind of straying away from that 
traditional role." Another man spoke of living in a "split world" where he felt like his political convictions and participation in such things as a writer's festival meant that," to a certain extent you jeopardize your credibility". He said that he sees that changing to a certain extent and feels that he is working towards that, but, “Obviously we're not very successful...I mean, if you look at the political map of Ontario, the conservative party is totally in control of all of the rural areas..."

\section{XI-Coping Measures: refers to behavioural and cognitive measures to change some aspect of oneself, the environment, the exchanges between them, or all three in order to manage the negative feelings aroused.}

Coping measures are generally seen as negative behavioural attempts to improve environmental fit. The "armour" and anger described above certainly can be seen as negative coping behaviour, but were included in adaptations because they originally develop as a justifiable self defence and become dysfunctional as the need for self-preservation in the face of overwhelming threat declines.

Drugs and alcohol are typically seen as coping measures for poor environmental fit and this emerged in the research,

"When I was a boy and then a teenager I very much wanted to.... fit the role of being a strong and masculine man and as I got older I sort of gained greater comfort in, $y^{\prime}$ know... I'm in touch with my emotions and feelings and with those of others...that's who I am so let's use this to be useful somehow...

But it's taken, years and years of learning...and drinking and other things to come to terms with that...to grow comfortable... in my own skin...still learning, but, ah, but it's easier now. I think something comes with some maturity ... life experience and seeing how other people navigate that too. Role modeling is a big one as well...

It's hard to explain how you learn to deal with problems by drinking but it's a taught behaviour...and it's socially acceptable if you know I'm having a bad day...guys go and drink when they're upset or they drink when they're happy and it's seen as socially okay as a means of dealing with stuff...if you can't ..pour out your emotions, then you'll drown them." 
Another participant nuanced the use of drugs, making a distinction between the social belonging aspect and the analgesic aspect. I asked him why he drank and why people use drugs.

"Well...killing the pain...I think a lot of drug users...from my perspective and my...being amongst them...it was a social event...they got together...it'd be basically the same as with you and I if we went and basically had a visit with a neighbour or if somebody wanted to do some jamming, you know and your guitar and stuff like that... we'd bring cases of beer and have some beer...

So the drug...idea , is...the younger people, because drugs are so accessible ..... lot more of it is a social event more than anything. Now the ones that are into it for killing the pain ... basically hard core drug users are doing it for a different reason... they're doing it because they have to kill something... themselves or the pain....whichever comes first."

One man describes differential use of alcohol and drugs to manage different

environments,

"But I'm doing pretty good cuz I'm not really in pain cuz l'm learning to manage it, but...l've learned how to become a drinker now though, over this, but 1 was pretty good at a bottle of wine a night but now I can only do half a bottle. Like, I'm not really a good drinker...you know what I mean, to manage the pain and the space and everything...smoke a few joints but then I went out of that...when I travelled I never had tobacco or joints or booze or nothing...well ... like one at dinnertime or something and it wasn't really about that."

XII-Environmental Fit: favourable or unfavourable fit between the needs, capacities, behavioral styles, and goals of people, and the characteristics of the environment.

In terms of environmental fit, many of the participants spoke about how they feel betrayed and angry at the loss of societal value for instrumental purpose. One man railed about the poor quality of modern firebrick for his woodstove, "Them old bricks...they're pretty hard to burn out...it's the old hard glazed bricks...they don't suck." When asked how his code fit the modern world, another participant laughed 
and said, "It doesn't. Everybody wants it easy. They want fast and easy, they want good fat cheap stuff and buy it from China who cares where it's made. Go to WalMart...it's just, to my way of thinking it's wrong but that's the way it is.

An eighty three year old man who has spent his entire life farming and working with horses in the bush, was highly critical of the instrumental effectiveness of urban and modern youth he had come into contact with, saying,

"Well a young lad, going to be a man, first thing he's got to learn to do is tie his boots in the morning. I worked with the government on these projects, trying to teach chainsaw, and you have no idea...no idea...there's about $90 \%$ of them don't know how to tie their boots, or tie it that they stay tied and you and I both know that's one thing cause an awful accident to trip over your laces."

He also said,

"You myswell be teachin' a stone wall....you know, that's what I run into, you don't do yoyo stunts...you clean your chain, you keep your chain tight...you just steady, steady, steady, and they ship a whole busload in and you...you can't keep track of them....and half them (indicates unsteady)...are weavin' ....and you can smell it from here to the road....and you're tryna,...and they haven't a clue what a horse is ...or skid a log, or anything."

Another man commented on the instrumental ineffectiveness of a "townie" who was a member of his hunt camp,

"But he doesn't get it...he'll show up with junk at the hunt camp but he has no idea what good junk is ... what is actually feasible to be re-used...give you an idea...he pulls a plastic lantern thing off beside his door...we' don't have hydro (laughs)... he screws it on the wall (laughs) ...sorry you missed a beat there boyo...he's...'well we could put a candle in it' ...I'm going...it's plastic...I kind of like huntin here, I hope you don't burn it to the ground"

By comparison, one man commented on the instrumental effectiveness of his children. 
"Our kids ...they were learned how to work about the age of 7 on, you know what I mean, and agin they were 12 or 14 they knew how to clean a box stall, knew how to drive a horse, knew how to run a chainsaw, they could take the truck and go and do anything with it, or backing in wherever you wanted and no tailgate to the door and they wouldn't smash the lights and all that...they could do anything you know."

Unfortunately, they too were infected by the disease of civilization,

"But then when they got a little older than that and they got that trip west ...everybody went west...then it was impossible to do anything with them. I'm not saying they're dopers but they're on the p-pot....and h-ash and ...whatever it is, I never seen it in my life, and....

They went through a session of....stupidness....if you wouldn't imagine, (son) was makin' 40 some hundred every 2 weeks and then he's come out for so many days, cuz they worked you from the time you go in till you come out and they fly you in and out and when he come out ...he'd be broke to go back in...wouldn't have a cent, and if he ever come home, you might have to give him a load of money to get home, or he'd get home and you'd have to definitely give him money to go back...only thing I can tell you about him...once he'd done his shift there, he'd send it to ya...he'd pay it...

But one time he's gonna drive out...he'd no car no money so... I bought the car for him...so he went to head west but you couldn't give him money today if he was going tomorra cuz it'd be all drank tonight and he wouldn't get outa town, so I said, no...you're leaving early in the morning...I want a ride down to the bush...cuz I stayed in my camper there, with the horses, so, alright so let me out, I hand him his money, I knew he was on the way...and (laugh)...

He had to go to Calgary to pick something up ...and then he was going to Edmonton cuz that's where he was going to work ... So he went up to a stop sign and he had to turn right and of course he couldn't leave a stop without trampin 'er...doin a burner...but she went Cu-lunk, the transmission out of 'er and it wouldn't move, so he shoved it into park and...run out and get on the bus and away they went. I said, 'well what become of the car?'...'well maybe dad it's still there if it hasn't run out of gas.'... out of it"

You know that was the carry on.... just left the car...never even took the keys

He told another story about being sent to work in the bush and then being ordered out by a young supervisor, "Now that job ...she was all through forestry college to get that job...she didn't know what skiddin' was and she didn't know what a horse was...yuh...now what are you going to do with the likes of that...and her sent 
to run the job..you know how much she knew before you started...you know what I'm coming at?"

This same participant spoke of having to give up his team of horses and his farming because, "I wore out and I couldn't do it no longer"."I wasn't safe with them any longer because my arms ...are done...I can't get em any higher than that...hell of a time scratchin my nose unless I put my elbow on the table to do it".

The loss was intolerable.

"I come home here and I couldn't stand it you know ...with nothing, so I got...(Grandson) found that pair of ponies for me, then (son) had the donkey and it was comin' on fall and he was scared it was gonna get shot, they'd think it was a deer so he sent it out here"

Now what the hell's a man going to do with nothing to do but get up in the morning...you know what I mean...I don't drink...I don't smoke...what are you going to do?...you can't just sit here...I like to get up in the morning and have to feed them ponies and the wee things glad to see you....I wanted something to get up for...course I had the hens but anyway, that's what I wound up with and I never was sorry a day.

I say l'm a great farmer now...2 ponies ...like this high...2 kittens ...you know what I mean...now what are you going to do?"

This narrative speaks to the critical importance of instrumental purpose in maintaining self worth for the rural male and the adaptation that can be made to maintain the performative as physical capability changes.

A participant who defined himself as "the outsider" said, "I'm a physicality guy... All my learning came after school, I'm self-taught. I had a hunger for knowledge but I didn't like the packaging."

This theme was supported by many of the other participants. This man had moved to the country as a young man, where he continued to "invent himself" by immersing himself in activity, travelling the world and reading voraciously to contextualize his experience. He summed up the mis-fit between his core value of 
instrumental production and the modern urban world, by saying, "it's all about the sizzle, not the steak" in today's world. He spoke of other belief systems that he assessed as comparable in that they were not based on empirical data,

"I don't value that...slickness, just like...they could have booths in fairs you know and the poor old peasants would come there and seek advice from the tea leaves or the ball or whatever ...you'd milk them for a chunk of cheese or a loaf of bread or some fuckin thing.

You produce nothing but they gave you something and I thought that's using your smarts...not to uplift but to maintain the status quo which is exactly what the church did with it's imaging and sound and everything. They couldn't read or anything so they created visual storylines and sculpture and paintings and the sound, and the smell and the hoogly boogly of it all.

They took them out of their drudgery and their pain like.... a panacea...but it wasn't...enlightening. This religion is just a creation...we got it together after we killed that guy. We decided we could make money off of it. You know and this is how...we're gonna say sorry forever and everyone is gonna pay for sorry. We killed him, but no really he died for our sins, we'll change the language, ok. "

"That whole thing about the kids and stuck on a screen and the twitter world and the facebook world and... a bit more dinosaur about the hands on world... and is it for the better or is it for the worse...

The whole up-ending of the language and the behaviour and everything into something that they see as weakening our..gene pool in a way...weakening our value system...breaking the chain from our generations of what we've built and the struggle for democracy and freedom with responsibility and all that .

So anyway, plus how to make a living in this dog eat dead dog world...it's not going to work forever. You know how they say that in the songs and everything... you can fool some people some of the time but you can't fool all of the people all of the time.

Just give it time, it's incubating. They're not going to get away with this...people aren't stupid... common sense is at a premium...whenever I'm at (neighbour) we get onto this and at (local contractor) too...'If you know of anybody selling common sense, I'm buying', and they can totally relate to that ...the mountain of paper shit that they have...that poor (neighbour) has to go through now.

They just love seeing cash from this old boy l'll tell ya. So you see how come there is an underclass and all...you're serving...all you're doing is providing a service and you know who they're working for...pharmaceuticals...or tobacco ...or alcohol...they want a piece of everything, like goldman-sachs...pha...wild eh?" 
"I like to work and I need to work and I need to be... busy, and when I was working I worked hard, I mean I always did hard work, I didn't have an easy job, a city job, I worked hard and I liked doing it...

I see these guys walking the streets, a cell phone in one hand, cup of coffee in the other hand, and they are doing nothing, and I just can't, imagine, looking like that. I just can't put myself in that position, you know, I'm out side until it's dark still, right now I'm fixing bikes up and giving them away, I need to be busy, that's me"

"What would you ever know but to play with that machine (indicates computer)...but if it didn't give you the answer, whatever you could do with it, I don't know ...but if that isn't the answer, you're screwed."

"They keep changing the laws..you gotta do this and you can't do that... more and more rules... all the time"

These men fit in their physical environment but many of them do not feel they fit in the modern world at all. They travel through it as if it were a foreign country with laughable and distasteful customs that make little or no sense.

"The Code" emerged as a dominant theme that is useful in examining the Life Model domain of Person:Environment Fit. The idea of core values, or "The Code", was resisted by some of the participants most enmeshed in the culture, but they were able to readily identify aspects of the performative and name them as part of a personal code that their pride insists they live by. "I guess that's my code is it? Hard work. Hard work ethic... Work hard and prosper. One of my favorite sayings is the harder I work the luckier I get."

The central aspect of the code requirement for rural masculinity identified was that a man must have personal integrity. This can be understood as meeting the performative standard of your personal code. Participants identified that the two key code requirements are Connection and Purpose. Connection involves 
understanding ones place in the natural, social and sometimes spiritual world in terms of actions in the present linking the past and future. Connection requires keeping your word, making up your own mind about things (self -determination), and being responsible for your own actions. Purpose involves making a positive contribution to society by being a provider, protector, nurturer and role model and serves and informs Connection. Stoicism, Respect for Individuality and Control over one's environment were recognized as traditional code requirements but most participants expressed some willingness to negotiate these performative demands when they come into conflict with the mandatory aspects of the code. 


\section{Chapter Five- The Code-Imperative/Negotiable}

\section{I-Code Imperative: Connection-to yourself}

The connection to yourself is imperative. A rural man must be self

determining and his word must be good.

“Don't let somebody else decide it. Decide it for yourself. Don't be cowed......because I don't believe in that law, I believe in law, I totally do, because we'd have fucking wild anarchy otherwise and anarchy's great if you've got responsible participants that take it on themselves ...

'No freedom without responsibility', but if it's just a fuckin yahoo trip, like drink Jim Beam and pop fuckin' acid and thinkin' this is the way you do it, you're missing the point."

There is a strong value on making your own decisions and respecting others right to make theirs. One man said of his code, "It has served me well and It could serve everyone else well but I'm not going to tell them that". This leads to conflict in the social sphere, where it is accepted that there are increasing areas where society has a right to intervene. A social worker spoke about the male performative conflicting with social priorities,

"I think we're (men) taught more though, you jump in and intervene if there's a physical threat, but when it comes in terms to people actually managing their own lives...it's more common for men to want to step back and say, 'you know what, that's really none of my business, let them do it on their own', so that attitude of wanting to help and intervene goes against that. Often what I run into is people saying, 'well why are you sticking your nose in this? Why are you butting in where you don't belong?"

"I think it's a combination of what people have heard... some people's lived experience and...but I think one of the biggest ones is simply the mentality of...'You know what? Leave me alone, I can do this on my own.' or, 'thank-you, but l've got this'... and recognizing that there's been times as well where I've been struggling with something and someone's offered a hand, and it's been more pride than anything else ...it's hard to ask for and accept help. That's a hard thing for guys." 
"I'm not going to do what anyone else tells me, I'm going to do it my way', and that gets.....you know, reinforced in all kinds of popular culture but primarily in peer groups as well. You don't tell your friend how to run his life. He's going to do it his way, and you respect that.

If he's really going off the rails, you might say something but you don't try and intervene too much and...it's difficult navigating those waters, especially...if some of your peers or the people in your community...you disagree with how they do stuff...or they disagree with you.

The sword cuts both ways so if someone has an issue with the way that I do something , I want them to take it up with me....yelling as little as possible [both laugh]...but be direct. Tell me, what's the issue? What's your issue, how do we work on this, then?...if we can't agree, how can we either co-exist so we're not going to drive each other nuts or kill each other, or how can we agree to disagree... that's a challenge, agreeing to disagree...it's possible, but it's hard."

"Being a man is to take the condition you're given and to make it ...like a pillar that you lean or stand...a support pillar so that's what I think about that."

"I think the young men of the neighbourhood should find their passion, cuz it might be buried, eh? What is that you really come back to, when strife, and what gets you jollies and how do you feel belonging and good and ...up....

...and then do it, whatever it is, just knuckle down and do it, that means work ethic, that means discipline, that means you're doing it for yourself...you're not doing it for Mom or Dad, the man or nobody, and...you might do it for the wife and kids though.

So, that's it, it's pretty simple... I was passionate about maple syrup, passionate about apple cider, passionate about marijuana, passionate about painting, passionate about whenever I worked, tried to do my best, if it's worth doing, it's worth doing well, and if you don't feel like doing it, don't do it. The choice is yours and you gotta stick handle through life and hope that you might score one, and if not, you played the game."

It was seen as important to take responsibility for your children.

"You should have a parenting agreement in place before you even think of conceiving a child... a license would be even better, but that's not going to happen...but you should have a parenting agreement, which means... that if you're in a committed relationship and there's a possibility of you both becoming parents...what's your parenting belief? You know...work that shit out."

"What's being a man? It's having a dick and then having kids and then having the responsibility of kids and then it's not all about you anymore. Cuz just havin' a 
dick it's like two heads are struggling with each other which one's gonna prevail at what time...

Having children's permanent cuz whether you're with the woman or not, the male thing kicks in and nurture and protection...like passing the torch sort of thing. So there's responsibility there. That's why I didn't want to have kids with other people so I have a long list of abortions and shit but then vasectomy saved that one."

Several of the men said that it is very important to them to have their "word" be seen as believable and none of them felt that this fit outside of their community of friends.

"When you're doing business with others and everybody's survival is at stake, the handshake and eye contact is better than fuckin' paper and authority and all this crap ...make your relations with others above the table, not deceptive but straight up, be real and true and straightforward and it's sooo much easier to tell the truth than start to lie again cuz it's too hard to remember who you told what to."

\section{II-Code Imperative-Connection to Social Environment: Ecological thinking focuses on the reciprocity of person-environment exchanges in which each shapes and influences the other over time.}

It is perhaps surprising how important and nuanced this code imperative is

for these men. It emerged in every interview and in some cases it was the "trump"

performative that allowed negotiation of other aspects of the code.

"I wouldn't want to live at any other time ...it's very, very interesting to be bridging both worlds, where you can see the automaton and appreciate that as genius and then you can see this robotic, nomadic, pneumatic, and hydraulic and electronic advancements on the mechanical. Trouble is, we're too smart...we brought that fire off the fuckin hill and we weren't ready for it and that was god giving us...he gave us two heads...we can fuck up...he gave us two approaches...all selfish and ME, or maybe what's best for all is good for me too."

All the other aspects of the code have to be available within a social context,

"To be kind, to be available...to be compassionate....to be strong...to be somebody that people can count on....just try and be a good guy. 
One participant described a social ecology of function, "Everybody here has a place or a part to play, everybody belongs, and if they don't, if they're broken like ...that. It's like a broken piece that has to be fixed...the purpose, you see so that the machine can't work properly with broken parts, so they have to be addressed so that everything works." This can be seen to contrast with the general sense of poor environmental fit with modern urban society and seems key to understanding how to engage men.

There was recognition that the benefit of social connection involved learning from perspectives outside of their own,

"Family.friends, and a bit of a good solid swift kick in the butt...saying, 'alright, do a budget, where are you spending? What are you blowing your cash on? I was pretty lucky...it was a good swift, proverbial kick ...

I've got an uncle who's also a Presbyterian minister and he was a very...good, role model man, very close with people, very understanding, very patient, and...teaching that you know, you listen to people and no matter who somebody is, at least give them the time of day and treat them with respect and courtesy... he'd always, no matter where we lived he'd always come out and visit, you know that sense of...for people you care about and love, you make time for them...you spend time with them, you show them why they're important to you ...and it's that, sort of, active engagement he really helped to engrain and teach...

I was also influenced by school bullies and stuff like that but the stuff that really sticks out is, is that value of 'this is what it is to be an adult'...Now the terrifying thing is when you wake up on your $31^{\text {st }}$ birthday and go, 'holy shit, I am an adult, how did this happen?' [laugh]

When I think of the happiest moments in my life, none of them were ever when I was completely by myself, so you know, we need other people around us to validate both what we're doing and to reinforce and complement our own values."

Several of the men stressed how important it was to them that they have a sense of connection that extends throughout their life course.

"I was blessed in high school with a lot of really close friends that I hold right now (refers to person that just walked by us in park) and I still hold those friendships very dear. The other thing that I was very proud of in high school was that all of my really close friends ...their parents were almost like parents to me and 
my parents were like parents to my friends and I'm really proud of that. I'm proud of my friends, I'm proud of my family, I'm proud of my friend's families for taking us in...

[passers by stop to chat...ask what we're doing. We tell them. Participant asks what son of woman is doing now, hears he's off to university in the fall, asks her to tell him he was asking after him]

Here I am spewing off about never seeing anyone I know, but I think that's one of the flattering and nicest things about...living in (small town), is that the effort you put in, comes back a thousand fold, in a thousand different ways, that you never thought possible."

Some men saw the connection as being multi-generational. One man spoke of how pleased he was when someone told him that he "has his uncle's neck".

One participant spoke of the importance of this connection in assisting him with medical issues,

"The ...community of like mindeds that you can share with, you know...and so, I was never alone, even when I'm alone here ...(neighbour) comes every morning and sticks this on me...(old friend) comes every other day and takes me to (nearby city hospital) and back...people phone or stop in...or want to do stuff for me."

This code of connection is seen as a poor environmental fit with modern society,

"Yes, it's changing for sure. Yes, when I go up and... volunteer at the (community run free store), I volunteer with people who are older than me. There's nobody in their thirties and forties coming up and spending the day up there working at the (free store). Nobody.

Now, I understand they're busy with their families, but I always had time to go out and do things in the community when I was a young guy. I mean, it's not only is it the right thing to do, it's good for business, it's good for you to get out into the community, I mean I was a (tradesman), how do you get to know people? You go out into, and 1 didn't do it for that reason, but it sure generated a lot of work for me.

That's just, community, and people are not seeming to do that, how many people know everybody in (village)? I don't anymore and I used to, I go by when I name houses, oh that's (elderly neighbour) house."

Several participants complained about the "disrespect" they see in social relationships nowadays , particularly among young people (and sometimes 
immigrants), who wear their hats indoors, speak disrespectfully, use social media rather than face to face communication and "have their pants down around their ass".

“Other immense change that I can speak of and I was going to say it doesn't affect compassion and really in a way it think it does and that's technology. When somebody's sitting there, running their blackberry or whatever it is and you're sitting there having a conversation with them ...boy, I'm dead against that.

That person's come into your home or wherever it may be and they just sit there and do that... I should have enough compassion towards you and enough sense that I come into your home here and I'm like...oh yah, (researcher) wants to talk to me...lets see who else wants to talk to me ...that is so ridiculous...to me that has got to be...disrespect...

So...that form of technology is one of the most hurtful things that I can think of...l'd sooner come over here and talk to you than to talk to you on the phone...I would drive 20 miles just to talk to you in person rather than talk to you on the phone....when you're lookin at me eye to eye and I'm lookin at you eye to eye...that's what counts."

Most were careful to devalue their criticism with statements such as "that's just me and I'm old fashioned" but they were clear that they value the performance of "gentleman" for themselves, don't find it in the modern world, and at points will take action to demand the same respect (particularly for seniors) that they feel they approach others with.

There is an expectation, often unstated that the respect for connection must be reciprocated. It is an understood and obvious part of the code for these men and should not need to be explicitly said.

"So I bought him this snowplow...I said...here's this snowplow...If you do the work for me ...it was a gift of love really but it had an attachment..

I thought, well.. this man's so talented, maybe he can help me out...and I actually made the deal with him face to face ...you help me out in rebuilding this truck, I said, and you can have this snowplow...well he's never, ever bothered to help me out and I'm totally fed up with it...

I just told (wife)...that burns me so bad...especially after I made this deal with him and he hasn't lifted a hand to... (sigh) ...I'm beside myself really about it, 
because he's my nephew and godson and I don't know how to handle that because... I put this wall up now...this wall's up between him and me ...and I trusted him to do this...to help me."

The prime imperative for connection is family and when connection is not made or is lost, it is a problem,

"My regret is my father...him dying too young and not having a communion, you know, where ...acceptance...he was way too young and I was way too young so that bridge never got built and my mother I got to totally heal with her and now my grandson is a reenactment of my father except he's alive and I...do what I can there, and there is a bond there, but it's...who knows what it might be...later, you know...who knows? ...I'm hopeful, but...

There's a big regret there is that I didn't get to participate fully in my grandkids... and I didn't get to participate fully with my kids... and I didn't get to live with the same woman, which we made all this together... and all the other women were...less than (mother of children)."

Other men also noted regret over lost or missing family connection.There was a recognition of the pressures of modern life that limit the amount of time available to maintain social connection,

"Well, you kind of wonder where everybody is... and it just seems like it's really difficult to...keep connected ...particularly when you have your own life and your own family....and your own bills and that kind of stuff.

I always remember when I was a kid, wondering, like my parents knew...thousands of people...and my dad especially, but it didn't seem like they ever hung out with them and now that I'm an adult I find that I'm experiencing the same thing...

Everybody's busy and you talk to anybody, you know, as long as they're, you know, from, like, the end of high school and beyond, you talk to anybody ...oh, busy, busy, all the time, even retired people...'what are you doing these days?'...'oh I'm so busy I can hardly even move."' 


\section{III-Code Imperative: Connection-to 'Something larger than myself'-natural environment/spirituality}

All of the participants expressed a code requirement for connection to the natural world and some of them additionally expressed deep spiritual convictions. One man in particular said that a connection to the vast love of God had saved his life. This is covered in detail under 'Adaptations'. Even in retirement, participants described a need to connect with the natural world through activities such as keeping pets or small stock, gardening, cutting firewood, maple syrup operations, hunting and fishing.

One man expressed his connection and how he sees it as being contrary to modern urban society, in this way,

"It's ecology...social ecology ...because we are a natural...form. When I was sitting there, all fucked up one night, and the little chipmunk's out on the deck and I see him as a mammal...you know he's got the same spine and little appendages as I have and I look at how they're all working on him and then he sits there on his haunches and turns over and starts scratchin' ...(indicates spot on his back and scratches it...laughs)

He's just a little wee fuckin guy but he has all the behaviour. Yah, I've seen bears do that...we do that. It's like we're all the same... the fuckin integration of everything together is respectful...in nature, but humans are bad, eh? They really are off and they can actually become extinct. They're most vulnerable but they're so arrogant that they don't see their vulnerability."

Another man spoke about what he sees as the modern ignorance of the carrying limits of our ecosystem,

"What I'm afraid of is how desperate we have to get ...we have a limited amount of resources inasfar as energy ...call it whatever you will...whether it's water, energy, we have a limited amount and when we get to that desperate point do we stop being people or do we look at it and go "hey, we can support so many people on the face of this earth or we gotta get the fuck off"...

So we gotta stop making babies, man...start thinking like a fuckin' farmer you have so many fuckin' acres of land, you can only raise so many fuckin' 
cows....and then this moral hierarchy...so do we just contain people and we keep producing people cuz people are power or do we actually take a look at the benefit of humanity and go...this is a comfortable level so we don' $t$ shit in our own nest, we don't lose the biodiversity that surrounds us and do we actually slow it down a little.

China did it ...serious uproar and they were whackin' little girls on the head and there's more men in fuckin' china than there is in all of Canada, all lookin to get laid ...Fuck!...do we wait till it gets to that desperate level before we figure out ...hey ...mind your own fuckin' business and you have enough space and your neighbour can have his space and I can have my space and we gotta stop makin babies."

\section{IV-Code Imperative: Connection-to the past and to the future}

The participants saw themselves as a link between past and future,

"Teach 'em the code...it's the nucleus of old, walking through the new... my grandpa gave me something...and my kid ...you plant a seed of integrity and what makes a man and send him off into this new world and my kid shakes his head at some of the shit that's going around him and you give him the strength to think for himself."

The code requirements to provide, protect, nurture and maintain connection

are situated within this temporal understanding,

"Taking on the responsibility and the...the certitude of getting married and trying to plan a family together and, it gives...not just a sense of purpose but ........ sense of community/wholeness, you feel ...almost like more of a man, if that makes sense, you know, I'm a somebody because I'm now part of a family...I'm building a family.

I'm making something that's going to last beyond me...something that's larger than just me. Being a part of that...it's terrifying and invigorating at the same time."

This is not seen to be a good environmental fit for society at large,

"Yah, that's your role is that you produce this progeny and that these kids depend on you to build the bridge to their better life which every generation should try and improve for the next, but it's like that culture carrier thing ain't happening." 
There was also an awareness of having to allow the next generation to assume power and control over society, but there is a concern that social homogenization will lead to the loss of possibly valuable learnings,

"Us old fucks, we gotta get outa the way so the kids can rule the world and hope they don't fuck it up any worse than we did...I hope they don't fuck up much more than we did...

The only thing I'm afraid of, and again change is change, I'm really afraid of ... is the bureaucracy... and characters aren't allowed or become this homogenized bunch of automatons, where an individual thought is crushed...where somebody who picks his ass in a public place and doesn't have a problem with it and everyone else frowns at him...

I don't know how to articulate this properly...I just hope we don't lose our characters and our individuals and our free thinkers, or if we do have them, they have to subvert themselves and hide it and fuckin' nurture it in the dark."

\section{V-Code Imperative: The purpose: Provide}

A younger man who grew up in the area but has had to find work in urban centres and northern communities identified the code for rural male as, "In the country you should be able to change a tire, light a fire...run a chainsaw". An older, university educated, rural man who participated in the same interview, responding to the question of why a man should be able to do these things, said,

"A lot of them are primary sort of survival things, right? You're the provider, you're a hunter maybe...you go out with a gun and you...run the equipment and the snow plow and get out in the winter to get the family out and that kind of thing.

I suppose that would be a differentiating element of a guys life in the country as opposed to a guys life in the city where your....survival responsibilities or whatever you want to call them are less pronounced".

"They took me on, eh, as the hippy but, so... different than them but so... the same language, so the trust was built cuz of they knew I knew how to cut a tree, how to dig shit into the ground, how to grow stuff , how to build stuff...they knew that I was the real mccoy, not just some fuckin blahblahblah booklearner guy."

"So what I'm saying about myself is I like the hands on guys...they got a foot, they got a brain, but they can translate their ideas into physicality and the 
physicality can serve the community or their survival. But, that's too much to ask of these guys but there might be guys like that in there that given the right horticultural conditions could just blossom like an orchid or something. They just need the right environment."

"I have multiple gurus you'll be happy to know...another is a right wing, antiunion... contractor in (village in rural area) that I (winter sport) with from time to time and he's kind of a country redneck and he kind of summed things up ...

There's a few things we agree upon and one of them is the expression that he uses quite frequently that we're not that many steps out of the long grass and it seems to me that we...mankind, kind of demonstrates that almost every morning when you turn on the news that people don't behave well...particularly men, don't behave...behave very badly given the opportunity (laughs)...

I think because, I suppose on a very primitive and crude level, we're hunter foragers and competitive and ...I think there's an inherent...lack of generosity and co-operation. I think we survive by engaging in sort of ...tribal or community sort of ...savagery in the crudest form and in the earliest days when we were carrying clubs and chasing down animals we would steal the other guys...prey, rather than find some for ourself...I dunno... just take whatever you can get (laughs)

I'm saying that's where we came from and when ...you know...pose that question again in the context of me being broke and the crops having failed and my family is in distress and I desperately need sustenance....well it certainly tests ...the...the...ties that bind ...

If you were the only one, no doubt there would be retribution in the community either officially or unofficially...but...there would be vigilantes or whatever that would try to...change my behaviour. If things were going south simultaneously for everybody and we were facing an anarchistic sort of free for all...I think that people would behave badly...everybody would behave badly...not everybody...most people would behave badly."

"Well, certainly, if you're going to be a man properly, get out, get a girlfriend and get married. You're going to have to have a home...and furniture and all the rest that goes with it, so you better learn something and do something to afford it."

Even the social workers recognize the performative requirement to provide.

"I'm a social worker. Every now and then I'm worried about either being overwhelmed by not being able to address the issues that I'm dealing with in my job...not having the tools to actually be able to get to the root issues... and sometimes facing the possibility of being laid off myself. How do I provide? How do I...be a man?" 


\section{V (i)-Instrumental Purpose:}

One of the key aspects for many of the participants was that the positive contribution that fits most comfortably with the male performative for them is the creation of something concrete and physical. I am calling this key concept "instrumental purpose" and cover it in detail. One man who runs a sawmill and prides himself on being the third generation in his family to do so, said;

"It's easier to express when you have a physical result of your efforts...much easier to express...I'm talking about volume of labour producing a piece of product and it will be a piece of people's homes, and they chose me...I figure that is a little honour...anytime somebody chooses me to supply the product for their home ..it's a compliment you can drive by, you can see the result."

Another participant expressed his admiration for a man who persisted in achieving instrumental purpose despite adversity and compared this to what he sees as a problematic attitude.

"This one guy out there is a one armed guy driving this biggest tractor they make...a John Deere with this fuckin plant behind that goes from here to the log house of all the equipment behind...the air drills and the fertilizer bins and the oh fuck...it's unbelievable. But anyway...one armed bandit...lost his arm to cancer, he does it all, one guy...can you imagine here? One arm, I want fuckin disability for life, you know what I mean? How you play your card"

Another described his challenge with an education system that didn't recognize that his learning style focused on concrete, instrumental learning,

"That's what the whole education system is about...how do you measure someone's understanding and knowledge of something and that's what I have a problem with...it's directed towards a certain type of learning...not everybody fits into that criteria...

Ultimately I think it's more of a ...hands-on...learning through doing thing, and evaluated...through doing as well...not evaluated through an essay or a paper...concrete, not abstract ...

If I was teaching a class and you were way in the background and I didn't even know you were there and you just evaluated me without me knowing you were 
there...that's, I think, a true evaluation of someone's...ability to do something...not whether they can write an essay on it...like I need to practically...kind of, exhibit what I have learned and show it physically".

\section{VI-Code Negotiable-Instrumental Purpose}

The code requirement of 'Instrumental Purpose' can be negotiated and this is valuable to examine because aging, physical injury and economic change often remove the ability to do instrumental tasks and this can be psychologically debilitating to men who define themselves by what they do and what they produce, their 'instrumental purpose'. This was illustrated previously in the case of the retired farmer who found it necessary to keep a couple of ponies and some chickens. It is also important to consider because many of the jobs available in society today are what Richard Sennett terms 'relational' (Sennett 2006) and have no concrete object that they produce.

One man commented on how he sees this performative as problematic.

"Every circumstance is different, so... you know people are treated differently. I don't know how you can have a code that everyone is supposed to measure up to when there's so much diversity and...pain. I think that there's ...societal standards...but a lot of people.... lot of men, don't live up to those standards for whatever reason...to be tough...and firm and fix everything right.

I was...where was I the other day? ...Something needed fixing and somebody said, 'well why don't you go ahead and fix it?' and, oh it was at the office, and it was like, 'Oh, l've just been stereotyped'. I don't fix anything. I'm not a good fixer. I'm a supporter of the trades. Get somebody to come in and fix this thing cuz I don't know how to do it and I don't really want to know how to do it, so, you know when you're talking about a standard code of being a man, I don't think I fit that mold.

What the societal standard is, I don't...see myself fitting that mold too well. I see that in my work too... with kids it's like trying to shove square pegs into a round holes and you know, having expectations that some kids, or men, just can't, or won't, or don't live up to ...and then the frustration that comes of that because this is the way you're supposed to be...you're not that way, so what's wrong with you? It seems like that's the way it always works." 


\section{VII-Code Imperative: The purpose: Protect}

"You can't stand by and watch someone drown... it's part of the code of being a man, if you see someone in danger...you do something about it ."

This aspect of the performative was voiced most assertively by the man who had learned to fight for his very life within the foster care system.

"Well, for myself...stand up and be a man..stand up and protect yourself especially... if you have to....I guess until I had this experience..... with the lord .......my theory would've been on it...don't walk away from anything...didn't matter if you get hurt...like to me I couldn't be...

I said to one guy...we went to a strip joint you know one day and this guy wanted to do me some harm or something because I said, you got to leave those girls alone...well, 'Mind your own business'...I am mindin' my business and you don't... be botherin' her ...oh so, lets step outside and I said, yah, we'll step outside ...it wouldn't bother me if I got two black eyes out of this cuz I said, I'll lay a beatin on you .....so that's the kind of person I was ...I'd stand up for what I thought was right...not only protectin' myself but for someone else...

After I met the lord ...had that experience...I wouldn't challenge a guy ...again...not so sure whether I'd walk away but I wouldn't say, yah, let's go, you know ...I wouldn't be a chicken and just back down but l'd want to talk to the person, talk it out, you know...

People need to be protected and ... so, a man protects... and now of course, protect your family...to me that's the most important cuz I look at it now...livin on the (country backroad, known to be a rough neighbourhood), or it could be anywhere I live... if somebody came to do my family...there's only my wife and I there, but if someone came to do us harm and I knew they had guns on them, well, sorry to say this, but l'd have my gun loaded first, because you're not coming in here to do my family harm...period...

This idea of someone coming to the door to do us harm is so small on the list that ...I know the chances of it ever happening are almost nil but it's in the back of my mind. I'd see what was going on and l'd step in...they never asked for my help...and I'd still do that today...if I seen a robbery going on or something, I'd step right in there no doubt, even if I got shot...if it was to protect somebody else, you know ...it's my duty."

A university educated social activist exercises the performative of "protect"

in a different way. 
"I think this was during the (antiwar) demonstrations but it was ...quite a contrast in a way cuz here we are in the ultimate macho, warlike environs of the infamous Don jail and they parade in, I don't know, maybe there were 25 of us or something...on a Saturday night, late.

We were all soaking wet, miserable...these guards... didn't really want to be admitting 25 prisoners at 11 oclock on a Saturday night...the place was full...they didn't have the resources and besides there were some weird looking folks in that group of twenty peaceniks...there were some cross-dressers and obvious faggots and this and that and so there was a very threatening environment...

and so, the first time I ever heard the term, 'slipped'...be careful you don't slip...careful you don't slip...could be dangerous if you slip....and they were making grim menacing remarks about these gay guys in our group and I felt personally relatively secure because I'm a white heterosexual guy that looks fairly straight and that they were ...sort of unlikely to....abuse, but I was terrified of being put in a position of sort of having to heroically defend these others...you know, discharge my responsibility, so what happens if they start beating on these guys...what do I do? So that was a ...manifestation of...pasty white boy up against the hard realities..."

\section{VII-Code Imperative: The Purpose- Nurture}

The participants identified that they need to nurture, but , "I don't...coddle...I nurture...but not with a velvet glove"

"You should be a loving person to begin with, cuz if somebody does come to your door you need to know if they're going to do you harm or not and if they're not, you should be compassionate....let's say somebody comes to your door and they're down and out and um..what are you going to do...just kick them and be on your way...I'm not like that...the large majority of it is to give and give and give and give...give everything you have."

"I just want to try and make some kind of meaningful difference in the world...make life stink less for some people...I have fairly basic goals...

"Yah, because the motivation is the filthy lucre only and nothing else counts, just like the poor women in the house, they're not valued in the monetary sense for the job that they do but if they didn't do it, where would we be.

We don't value children...they're just a fuckin' irritant, you know, what I mean, they're nice to trophy, here's my trophy kid but the thing is, they don't...the world's not set up for kids....you see, so that's not right. There was room for kids in the old days" 


\section{VIII-Code Imperative: The purpose: Role Model}

All of the participants expressed appreciation for role models thay had

learned from and an understanding that they need to perform the same function,

“He wouldn't let any of the boys go into his business until they went to high school. After high school they had to go to university or a trade school or a college or have some piece of paper for something else so that he could show them the door, ok. You're not going to suck onto me and suck me dry, like so you're gonna have something so you'll be proud of yourself and that's something you have yourself.

There's this whole gang of boys...not on the street, not doing drugs or fuckin beatin on women or getting them pregnant, they're learnin skills on their own and he just venture them and sees that they're on vices or whatever but there's a pecking order and the older leads the younger and some are more natural at it than the other"

"That's your role is that you produce this progeny and that these kids depend on you to build the bridge to their better life which every generation should try and improve for the next, but it's like that culture carrier thing ain't happening."

"I'm gonna tell you an old story bud..ya I think you'll get a kick out of this, and if I've told this story, just stop me, ok? But I was about 12-13 years old, I think I was coming on 13...my grandfather owned the house we lived in and he never stepped foot inside the fuckin door...you wouldn't see him...or we would just like, or he would call for you and you would go the eighth of a mile down to his place. Even though he owned the house, he wouldn't step inside the fuckin door...

Except outside the fuckin door.."grandpa's here and he's lookin for you" ..."What?" he was a definitely a patriarch...serious hardcore serious fuckin miserable human being and I never realized that he had taken me under his wing and we had some golden boy cousins and he would fawn over them and me...he'd be back to attitude and this is how it fuckin is.

I realize he was makin an effort for fuckin me...them he wasn't making an effort for, ok? Do you understand...? Ok, so he's in the house and my siblings came and they went, "grandpa's in the house and he's lookin for you, what the fuck did you do?"..." I don't know, I don't know" ...I go out and grandpa's there.."Er!" and that was about as conversational as he was "got something to show ya" and we go out the back and there was an old single cylinder john deere engine.

Now this man, you have to realize, that I heard something through the grapevine, that this man was one hard workin motherfucker and I've seen me workin in the rain and thinking, "Grandpa you'd be proud of me" and they're goin, 'That man would work in the weather that wasn't fit for a fuckin dog' ...

Anyway... 'sum'thinta show yu' (gruff voice)..turn around and crawl up...and it was a step side old chev, eh? And there's a big old fuckin single cylinder motor and 
this man used to make his living with these old darlin's...he was a very progressive human being in his time...

I'm lookin it over and go 'Yah?'..he sez, 'Ain't workin...think y'can fix it?'...uh....'wu...I dunno'...'I think y'can ...be up the house tomorrow..8 o'clock'. That was the end of the conversation...

Now it gets better bud, the next day I show up, eight o'clock, ride my little bicycle up, there's my uncle and my fuckin old man tryin to lift this fuckin 250 pound fuckin motor out of the back... there's brand new bedsheets laid out on the fuckin lawn and a toolbox and a rockin chair at the top of the sheets and my grandpa turns to my old man and my uncle and says, "you two can fuck off..we're busy" (laughs)...

I stripped that motor down, laid it out on the sheet in a row...every part was organized and laid in a row...his big claim to fame was it was the first fuckin motor with a fuckin actual fuel pump on it and it was just a cam that came around and slapped on the fuckin rubber and it actually had a fuel pump. I remember I took it all apart and to this day I still remember a cigarette pack is 17 thousands of an inch and that's what you set your points at no matter what the manual says...

We put it all fuckin back together...one revolution and it ran...thirteen years old...with my grandpa, fuckin chewin at me in a corner ...ahh..it's the kernel that I'll give to my kid, that I'm hopin ...bit smaller...bit diminished...that he'll hand to his kid, and it's something that's left from back there...a lo-ong time ago...eh..that's the size of it."

"If you can get (local mill owner) for an interview, you'll have one of the most intelligent old school individuals I have ever met in my life...his mind is a fuckin walking computer...

He balances cash to receipts to a fuckin T and he gave me, when I started, as a parachuter, as a transplant, the highest compliment of my whole life, and it is through (neighbour), do you know (neighbour)?...he's an old alcoholic ...now the old alcoholics have a really cool gift ...they have a very hard, firm grasp on common sense and (neighbour) was not an unintelligent man he just hid it as well as I do, ok...

Well, (neighbour) came into my yard one time and he said ..well, I want to pull some squares for (mill owner)...ok...now this is (neighbour) (so I say) 'Do you want me to squeeze them? Or do you want me to make it so (mill owner) is happy?' He sez..'well let's make (mill owner) happy' and I said, 'in that case, l'll do you a fuckin tally sheet and it'll save us a lot of time because I won't open up your squares that are dubious...I will scale them back and make it so that he gets a fair shake' and when we were done the day, (neighbour) turns to me...'do you mind if I pay you when I get paid?' ...I said,'(neighbour), that's not a problem at all...but could you do me a favour?'...'what's that?'...'would you mind sliding by (beer store) after you get paid and pick me up a dozen beer cuz I'm a little dry'...'w-w-w-wul I don't think that's a problem'...that was his first fuckin destination whether I asked or not...

Well, he comes back...he's got my dozen beer and he sez,'We got a problem', and I said 'Whaddaya mean we got a problem?'. I said, 'You get paid?'...'Yah, I got 
paid'...'Well, what's the problem then?' He says, 'He wouldn't look at it'. I said, 'Whadaya mean he wouldn't look at it?'...'Well as soon as he saw your tally sheet and he heard you milled it, he sez...he wouldn't look at it. (laugh) He sez, the tally sheet's good enough if you milled it and that's his tally sheet and that's whats on that wagon.

That was one of the highest compliments of my whole life...in this game, and (mill owner) is an icon in this neighbourhood. He's a brilliant man...he nudged me toward doing paperwork because he sez, 'You're too busy...do some fuckin paperwork', and he put it in such a way that I was half a mile down the road before I knew the advice he'd given me and he'd given me this advice all the time but in an old boy way, not cuddly, not sweet...

I remember I used to sleep in the fuckin lunch room at work and there was an old boy, old school way, it's not warm, cuddly and fuzzy ...it's the old way and he turns around and he comes in and he fuckin counts the cigarette butts in my ashtray and he's right in my fuckin face and he's like, 'Dump the fuckin ashtray, you know how many hours you've been here by how many cigarette butts are in there' ...yah..but he made a big fuckin show out of it...got right in my face."

\section{XI-Code Negotiable-Control over social environment}

The participants all endorsed the idea that there was a set of identifiable core values that constitute a "code" for performance of male in a rural context. They demonstrated variable depths of perception of the latitude for interpreting and negotiating that code in direct correlation to the amount of practice they had in adapting to other cultural norms. One participant was a social worker who had grown up in a small town, moved to the city for his education and worked there for a

few years and then moved back to his hometown. His only criticism of his small town was a certain amount of cultural homogeneity.

"I mean you certainly see it in the lack of tolerance in a lot of people. My belief is that when you have those kind of influences around you, you tend to be more patient and tolerant with it because you have some experience but if you're working from a place of ignorance, then that's not always a helpful thing for a lot of people."

He did note, however, that, 
"I don't know that the stereotype would be any more rigid...this is kind of a progressive area...you know, things happen here that you don't hear about happening in lots of other places....both good and bad."

Another man acknowledged that it is increasingly difficult to maintain the traditional code, although the expectation still exists,

"It's kind of changed now, it used to be the guy gets a job and brings home the bacon but now it's sort of...you know, you and your partner, or your wife, or whomever... you know both have to work to make ends meet...but...you know there's still that stigma that ...a man's gotta be...if not in charge, at least appear to be... if not in charge in the home, at least, you know, respected... part of the code of being a man is to show respect to other people but to not suffer fools gladly."

Another said,

"I think it's in the works, cuz, sort of what it means to be a man is...I think, changing a bit, but there's still this strong traditional belief that to be a "MAN" is to be a little bit more physical and a little less emotional."

One of the social workers interviewed, said,

"I get challenged on the code all the time, and not taking, you know, a traditional masculine job. I don't work with my hands, I'm not building things, I'm not doing something physical and so it's sort of like I ...I'm working against the code in some ways...

I don't want to try and...wreck it or say, this is all junk, cuz some of it has merit, but on the other hand, things like you know, 'a man's supposed to appear big and strong' and you're supposed to like tough masculine music and watch masculine entertaining tv shows and you know...project that image of strong, in control, and basically not being too feminine."

\section{X-Code negotiable-Stoicism-don't show emotion}

The code requirement for stoicism was obvious to the participants, "You're working...you fuck up...you stand up...you get reamed (the code)...you stand up, you get reamed and tomorrow's another day and get the fuck over it." Most participants 
felt that this is changing and that men are beginning to be able to express emotion if they fulfill other code requirements to maintain an acceptable performative standard.

"We're taught there's like 3 or 4 acceptable emotions ...happy, angry and horny....sometimes when men need someone there for support, they don't have the tools to ask for it because we're taught not to be too in touch with our emotions ...

I mean, it's ok to laugh and stuff, but the deep stuff...y'know the strain, frustration, and...crying's out...it's getting better actually, I'd say, with crying, I think guys are allowed to cry now at like... when a child is born or something like that, but if you hit your thumb with a hammer...you just kind of suck it up and keep going."

Participants noted the benefits of greater emotional intelligence and expression,

"I think women find nurturance...and gentle, easier than men do...I almost think there's almost like a ...I think being gentle and nurturing and stuff, it goes against the stereotypical man, and...

I think there've been points in my life where I've struggled with that, but when you are gentle and nurturing and forgiving to people, and patient...there's a lot of great personal satisfaction to that as well. I've learned through experience that I would rather have that than follow a stereotype."

The participant who had suffered the most severe childhood abuse had the most trouble allowing the vulnerability of emotional expression, "Step outside (laugh) we'll deal with it...that's way easier...you know...I'd rather die than say I was afraid, or sad, or something."

One man reflected on how he was able to negotiate allowing more emotional intelligence and expression into his performative.

"You do it carefully ...cautiously... you do it by finding people who back your own values...people who recognize, at least on some level, the importance of having that value of showing affection and care to other people... and of talking with those who care...those who get it, or with people who've gone through similar struggles, you know ... 
Talking with clergy kind of helps because it's just similar you know, you do that sort of supportive role and ok, how as a man do you navigate this and how do you deal with the emotional thing of say, like dealing with vicarious trauma or something like that, because again, the...the minister isn't supposed to look weak or sad, but we all get sad and I don't know any man who hasn't cried. We won't talk about it and we won't admit it but we all do it."

\section{XI-Code Negotiable-Sexuality-'Not Gay'}

Most of the participants expressed tolerance for gay lifestyles and showed no sense of being threatened in their own sexuality by contact with gays or lesbians or by use of identity labeling as a pejorative to enforce code compliance. One participant told a story of an evening he spent in a gay bar and concludes with,

'It was the fuckin' best night of my fuckin' life...I remember it vividly because there was no testosterone involved...the first time in my whole life I wasn't driven by testosterone for an evening and it was just all a big fucking giggle."

Another participant described,

"Something that happened to me, twice, as a teenager. I guess I must've been a good-looking teenager. Hitch hiking, get picked up, guy puts his hand on your leg, you know, sexual advance, and you jump out of the car and go tell your friends and you laugh like hell... didn't affect me in any way.

I mean, as a bunch of young guys, we almost looked for this kind of thing to happen. It was like excitement to have the sort of things happening as long as we could control the situation."

It is interesting to note that in both these cases the factor which seems to allow negotiation of the code requirement of "not feminine/gay" is a sense of personal safety and ability to make choices and maintain personal control.

\section{XII-Social Value of the Code}

Participants identified that they felt there was social value to meeting many aspects of the code. The code values of Provide and Connection were seen as socially 
devalued but necessary. One man identified that even the problematic aspect of Stoicism has Social Value in some instances where it serves the Code requirement to protect.

"Having the ability to sometimes fight and need to separate some of your feelings and emotions and have that ability to act and react and think rather than feeling...I think there is a role ...in order to protect society you need people who are strong and are able, if necessary to defend it, and part of being a man...

It's funny because we're taught you know...violence is wrong, unless you or your family is threatened, at which case...it's ok to be violent and it's ok to be aggressive and it's ok to respond to force with force. I think same in our society, because you know, who do we turn to...we look at police who typically are men...we look at firefighters when there's a danger, an emergency...it's often the expected role, is when there's an emergency or some kind of immediate scary physical threat, there's going to be a man who comes and helps or saves the day, and having that ability to not get overwhelmed by a situation is necessary in order to meet that need....

Maybe not in the way that it is now and I think if we had a better understanding of how to process emotions we'd have fewer issues with all the troubles that our forces members experience when coming back, or in dealing with long separations from their families and that emergency services workers deal with, with the crazy stuff that they have to face."

\section{XIII-Consequence of not meeting the code-Enforcement}

Despite a clear understanding that they are able to negotiate aspects of the code for themselves, there is also a clear understanding that the code is enforced by inclusion/exclusion, verbal and physical harassment, particularly the code requirements for gender identification and stoicism.

"Men and women, and boys and girls, although they're different in some biological ways...you know, really very similar and shouldn't be treated that differently growing up, you know, if girls want to play with trucks and cars and things like that, then that's ok.

The problem is when boys want to get into things like dance or more creative expression, there's this social pressure that that's not ok...easing up on that a little bit would be nice...it's funny, I say this but I don't think l'd ever buy my own nephew a pink shirt...at least not till he's older ...

It's interesting...because the social consequences of it are just not ok...you don't want to encourage your son to be too feminine because he might get teased or 
beaten up by either the boys or the girls ... you don't want to see your kids get hurt and so you teach them the code so that they can navigate through life and learn to be accepted, because the code exists as something...

You see it happen to other people or we hear people talk and say, 'Well, if they did this, this is how we react 'It's reinforced quite firmly. It's not always talked about openly but there's always this implication that if you break the code, it might...you'll either be shunned... teased, or harmed and sometimes being shunned is worse than the other two, because that feeling of being alone is hard. I mean, men pride themselves on being individuals and being able to stand on their own two feet but we all know we don't do it alone.....we always have to have a few friends."

"I see it all the time...it's...very difficult...to engage...on certain topics with other men... because they don't feel comfortable talking about feelings...or, or when they do, they'll ask that no one else be told about it...there's a lot of... walls and there's a public image that they don't want distorted.

The other thing is, I get challenged all the time, because of my work, on my orientation. They figure because I'm a little bit emotional, or because I do what's traditionally considered women's work...'So, what... are you gay?' and I'll laugh and go, 'Does it matter?"'

"Aside from the ability to pee standing up... the second greatest thing is having that sense of camaraderie and you know when you're with other men and you sometimes get that sense of...almost like brotherhood, you know, and it can work, it's a double edged sword though, it can work for and against you."

The code performative of Provider is enforced by negative labeling and exclusion/shunning of those who don't meet the code.

"The welfare people, they just don't want to do anything... We collect bottles, returnable bottles for the food bank, and I'm opposed to food banks because they cause a dependence, however, if one kid this year gets fed because of the food bank, then it's all worth it, because if one kid goes to school with a warm belly then it's all worth it because I know there's a huge amount of abuse of the food banks, but they're out there for the people that really, the working poor, the person who usually makes it but they just didn't get enough hours in this week or what ever, they just don't have enough money, there's a safety thing there...

I know so many people go, 'Oh, we will just go to the foodbank, we can waste our money and it doesn't matter, we'll just go to the food bank', and its just wrong but that's why we put $\$ 2000$ into the community last year so far and we're not even a year yet so that's a good chunk of change for the food bank." 
"They need to have a sense of self-worth so they can go work for eight hours a day and come home and they're tired and it could be the woman who's doing it too, I'm not just, what do these guys, these guys you are dealing with, what do they do all day? Nothing." 


\section{CHAPTER SIX-CONCLUSIONS}

\section{Implications for Social Work}

In the small group interview I asked, 'If you had to say one thing to a social worker, what would it be?' The immediate answer was, "No experience...do parole officers count?" The female participant noted, "That's probably a problem right there...there's a stigma for men who want to get help...most of them won't go to a social worker." The two men both agreed. One said, "Yah, talking about my problems is a weakness." That immediately puts the onus on men to overcome this weakness.

Another participant compared social workers to black flies, "There's a purpose for black flies, they apparently... pollinate blueberries. Well, I do like blueberries, so, as painful as they are, there's a purpose. There's something that eats them somewhere down the chain becomes a benefit I'm sure, as horrible as they are." Another said,

"The people in the system that've actually got a job working with the victims they've created.... Social workers and psychologists and prison guards and lawyers and judges and police....and health people and mental issues and stuff, and on and on it goes...there's so many little jobs to be done and so much university time and community college time spent on creating a class to deal with the class and if they hadn't done that in the first place it would be a completely different picture."

One man said he would like to tell social workers,

"Be human. Forget your education, pretend you're having a beer...and try...and feel something, instead of pitching a homer, and yes, you have an advantage over me cuz all I have is life experiences...

You have a general way ...your education will nudge you into a direction where you can help this person but be a human being first and professional second and you will actually be able to help people...

I ran into that in the CAS system...I had a social worker break down in front of me ...in tears in front of me, going, 'I'm the professional here'...yah, but you're fuckin up and you're fuckin somebody's life up and you're messin with the wrong people...be human first." 
Experience teaches men that the cost of accessing social work services will outweigh the benefits. Their personal code will be disrespected and,

"They're not going to listen to it at all except to have you go through the rote, like do the mantra and get it out, don't you feel better now, you know what I mean and don't respond to change anything...

We're not going to tell you what we're doing but ...engage in the conversation, and isn't that what all this fuckin' PR shit and everything is all about is making the kettle black or the pot black or just fuckin' around with the optics and the language without any intention of making a change or taking it seriously or being committed to.... growth."

The interesting thing that emerges in this research is that the performative requirements for men are rooted in some degree of positive function and there is a cost, both to the man, and to society, involved in negotiating this performative.

“It's definitely harder for me to... accept help than it is to offer help...cuz you got to be the provider, you got to offer help, you've got a role, it's like a super hero complex."

If we accept that for these men, their personal code is utilized as a guide for living, then understanding the code allows us to assist them to change behaviour that they see as dysfunctional, by negotiating alternate ways of meeting their own masculine performative standard. In particular, it emerges that Instrumental Purpose and Connection are key code elements that have positive social and personal impact, great potential as motivational and engagement domains and are implicated in many of the social problems that these men identified.

The small group discussion that led to the thought that talking about the weather and maintaining private boundaries around convictions in the country 
serves the function of allowing connection even with those who have fundamentally different world views than ourselves can inform social work practice as well. There are many things we do not need to share opinions on in order to work on projects in common. In fact, this exchange points out to us that sometimes it is best to not know some things if we need to work together.

It is particularly important for men who have been sexually, physically or emotionally traumatized to meet the performative requirement for control over social environments. Interaction with 'authority' triggers defensive reaction and a simple awareness of this dynamic would be useful for social workers. One of the social workers who participated in the study noted this,

“The guys that ...you know, they've had bad experiences in their life, in lots of different things...lack of trust and...very suspicious, and everybody's out to back stab you and all this kind of stuff.

Those guys are going to struggle no matter what, but...trying to be patient and tolerant enough to deal with their bullshit so you can get to the other side, you know, once you've heard their story and they feel satisfied in that they've told their story, then how do you turn that around and start making a difference?...and that's a really tricky dance sometimes... and I think it comes from...

I think it comes from a fundamental lack of trust, lack of attachment, people have been treated poorly in the past...I really try not to be heavy handed and judgemental and all those really negative things that people balk at, understandeably."

"I think it's...trying to help... the front line workers, look at their approach and how they engage with men and how they talk with them, because there's a whole lot of body language that comes across and verbal and unspoken things at the very outset, at a first meeting where someone may perceive that, you know, the man is emotionally shut off or that he's not engaged or that he's not trying, because he's got his walls up and he's not going to tell that worker or that social service worker what his needs are or what he's actually doing to make things work...

Every day l'm trying to figure out how to make social services more approachable and it's difficult when you've got men who have this strong sense of 'I don't need somebody else's help' and it's hard to encourage them to come out and talk about it if they don't see themselves as getting something out of it." 
There was also a recognition that social workers need to put aside their preconceptions and be willing to learn from their clients what is going on in their lives, respecting their experience as well as the reality that there is a functional reason to mistrust authority. One social worker stated it from a client's perspective,

"How can you help me when I don't know your values and...you don't know mine', so... 'I don't trust that'...Absolutely... It's very true....my values are different so what I find is successful is to state that at the outset, 'yes, I'm not walking in your shoes, I don't live in your home, I don't know what it's like, so help me to understand... recognize, while I might disagree with some of what you do, I'm not going to disagree with who you are.' "

'Who you are' for many men is 'What you do'. This is a central finding of this research. Men define themselves largely by what I am calling "Instrumental Purpose'. "I think sometime a lot of men define themselves by what they do...what you do is seen as who you are and so to challenge or to question what a person does becomes a challenge of that person...the behaviour is the person."

In addition to the fact that social work often seems intent on challenging men because it challenges their behaviour, it is also difficult to see instrumental purpose and thereby measure any worth to social work,

"We're a bunch of whiners ...accomplishment is difficult to measure...I think that's one of the reasons that a lot of guys don't go into social services, because it's less tangible...success and accomplishment isn't really something you can do...it's more helping people through a process...and it's more... abstract.

You know you don't get that instant gratification of say, being a chef, preparing a beautiful meal, you know that you can watch people enjoy and go, ' $\mathrm{Ha}$, I did that', versus, you know, I help people along a process but I only did some of the work, they're the ones who got through there...accomplishments are difficult to measure. You almost live life vicariously through others. It's an interesting [implication 'strange'] way to work."

The same thing is noted by another participant, 
"When you have a physical result of your efforts...much easier to express...like you, you poor fuck...what you're about to tackle...how can you ....where's your measuring stick as to how you did good, you know what I mean?

Not to diminish it cuz what you're doing is fucking kick ass cuz you're helping folks, cuz ...before my ex...I wasn't a therapy kind of guy...all of a sudden I got a new respect for that and how you can get people off that negative emotional merry-go round and it's a really black place to live and for you to be able to go...here's the exit sign off the merry go round..."

When asked what had made the therapy accessible and useful to him, this man said,

"When (counselor)...ah-ha...going back to the code, man...said, " Did you fail as a provider?", and I did not, and once I realized that I did not fail as a provider, I was able to start healing myself....

And you're talking to a guy that lost, what ...20-30 lbs off his frame...that would sit, pinned in a chair for $2-3$ hours at a time and not be able to move...that emotional devastation meant that you have something pretty fuckin valuable to offer to people and unfortunately, you can't measure it by a weight, a volume, a number, or drive down the road and see the house...but what you're doing, if you can do this right and you can help some people pull their heads out of their arse ...it is golden..it's just fuckin golden...

And if you'd talked to me five years ago..said, 'you need professional help' ...ha, 'your arse is suckin wind, boy'...I went to such a black place that if I hadn't had professional help, I'd still be in that black place...and here's the truth, because there's a lot of...really nas...folks telling other folks what to do ...back to the code again, eh...

Well, there's lots of folks that'll dominate your world and take you to a really bad place and they can do it in such a way that nobody else will ever know...and sometimes you just need somebody else to recognize that this person is not the giggly blushy persona that walks around in public ...they actually have a pretty black mean side to them...and I need help...that was it...

I wasn't completely fried...it was a balancing act...if l'm going to give this much of myself up to a therapist...there's gonna be something balance back out of it....as much of a black mood as I was in, as much as I was comatose by my own emotions...I was... I'd never been like that in my life, that's why I have new respect for therapists and I'm go...you guys are a bunch of fuckin wankers suckin off of the system...

Well, no, bottom line is bud, if you go to a third world country and all you have to worry about is putting food on that fucking table you don't have the leisure or time for mental fucking fuck-ups, right...you understand what I'm saying? If your world is so basic then you do not have the luxury of having mental illness...get the fuckin rice on the table...now you have a purpose....back to the code...it's only societies that have enough that we have the luxury of having mental illnesses and 
the time to treat them...otherwise, you're just a character and get your fuckin' ass back to work."

The other participant who had accessed counseling and found it helpful identified that it was the therapeutic relationship that was most important to him, "This lady I actually felt, was reaching out in love, just by her expressions, the things she was asking me and that and that's the first time in my life that that ever happened."

In terms of accessing other types of social services, such as family support, one of the social worker participants noted the importance of recognizing the strengths that men demonstrate.

"The fellow I was telling you about earlier... at the end of the interview said that he learned a lot of things in that interview and he was going to try and he didn't feel he needed the in-home support to do that, which is very gratifying you know, when you're talking about offering people good service.

You empower people to do the things that they need to do, you know, you don't have to go into their home and so... that was a profound meeting. I'm going to make sure that I tell him that. "

One man summed up the essence of the performative code, posed the question of relevance to social work, and went on to provide the beginnings of an answer,

"The whole of society, of human life and interchange... is that... everybody here has a place or a part to play, everybody belongs, and if they don't, if they're broken like ...that. It's like a broken piece that has to be fixed...

The purpose, you see so that the machine can't work properly with broken parts, so they have to be addressed so that everything works, just what l'm learning with my body.

Well, why aren't we learning that with with our behaviour and attitudes in our fuckin institutions? And in our history?...learning from our history? How come the little guys like us, like the fools on the hill, can see it, or digest the learning in the changing of our lives and toning down the aggression and being more tolerant and compassionate?" 
"The assumption is that they're better than we are and that we need to be straightened out and they're the ones to do it."

“It's like me not seeing pain when I didn't have it. They're not scrambling ...they're in the demographic...like they've got the clothes and the car and the job and the house and they're doing fine...or, the guy who's comfortable feels that the main threat to his comfort is the...underclasses...so, don't you like that?...Parts.....and everybody belongs and every part has a function and the thing doesn't work until we're all working."

Psychology calls this the 'Fundamental Attribution Error' (Myers 2009 p 5658). This is the natural human tendency to understand our own actions to be the result of situational factors and the actions of others to be the result of their personal traits and attitudes. It is a useful and necessary cognitive shortcut that helps us through the bewildering overload of sensory stimulus we encounter every day, allowing us to reinforce our self concept and make decisions about social inclusion and exclusion. It becomes dysfunctional when it screens out information that prevents social functioning. This dysfunction can be seen operating in two major ways in the narratives explored in this research. On the one hand, it can be seen to be at the root of some of the participants' social and personal alienation. On the other hand, social workers and society in general are practicing the fundamental attribution error on these rural men.

The solution is simple,

"They gotta take the game out of it, they gotta take the formula out of it...clear the slate...tabula rasa. This is a new person. I am a new person, I have a new attitude, I've got to see if I can have a communication here you know, and try and build bridges cuz you can dictate all you want but it just goes in one ear and out the other...

You gotta get a conversation going. That's about confidence, trust, so your whole thing is about building trust, eh?" 
This research clearly shows that, "The biggest issue... for the men in this area right now is to try and keep their head above water and keep... their sense of self intact. Like...this is a depressed area.", and when I asked what is needed, "For men? In the country? What's needed? ...0h boy... they need to belong and they need to be in a place... where it's accepted that the change has taken place so fast that it's left so many behind and mostly men."

\section{II-Conclusion/Future Directions for Research}

I believe this research holds considerable promise for informing social work practice with men in general as rural males follow jobs to urban centres and carry their core values and culture. None of the core values that emerged in these narratives is novel in terms of the existing literature on masculinity. Indeed, this research finds many of the same issues but by using the lens of Ecological Theory the same issues that are pathologized in the bulk of the literature review are understood as behaviours which can be negotiated towards positive growth. One theme that emerges which may prove useful in terms of understanding the problematic nature of men's relationship with social work is that aspects of the male performative have social value, payback and punishments for non-compliance.

This is often not taken into account as we work with men to change dysfunctional behaviour. It is also interesting to see that some of the code requirements that may be most dysfunctional, such as control over social 
environment and emotional restriction, are also identified as more negotiable than other aspects of the code.

It would seem useful to examine whether incorporating specific work with examination of the performative would increase 'buy in' for men in counseling and other social work services, and possibly improve outcomes as well. In particular, the emphasis that these men place on Instrumental Purpose and Connection would seem to point to direction for further inquiry. The "Men's Sheds" model referenced in the literature review supports this hypothesis and provides a template that has already proved useful. The literature on Men's Sheds points to the need to communicate with men "shoulder to shoulder" rather than "face to face" and the small group examination in this research provides an interesting glimpse into the functionality of this communication style as a way to maintain working relationships and common instrumental purpose when core beliefs may be different.

I believe there are also lessons here in how to break down barriers to developing deeper relationships of trust with men. This is commonly viewed as "resistance" and even hostility by practitioners but this research reveals that it can be a function of the fundamental attribution error on the part of both the practitioner and the male client. An initial stance of non-judgemental inquiry into the context of a male client's life would be useful in breaking down this barrier but it is also obvious that without a recognition that learning and change is a two way street, any gains in trust would be short lived. 
In other words, there must be a sincere willingness to accept that we will be changed in the process as well and not merely a token pretence of consultation. If we expect men to listen to us we have to listen to them, respect their knowledge and code and engage their opinions honestly. Similarly, if we expect men to intelligently engage their feelings, we must respect that there are genuine social performatives that mitigate against that and it must be a process negotiated by the individual himself, whereby emotion serves a functional purpose and produces a positive result.

Engaging men in discussion of their personal code could prove useful in helping them negotiate changes in behaviour that they can identify as dysfunctional or too costly to continue. One of the key findings is that men aspire to 'Integrity' and this requires 'Connection' and 'Purpose'. In order to maintain or build Integrity they were willing to make behavioural change. It is also worth noting that building opportunities for experiential learning and recognizing the valuing of instrumental purpose could also increase our ability to communicate with men and might also open up opportunities for informal skill exchange in the community and community development. Purpose and Connection are pro-social values that deserve support and recognition. This approach moves personal code from pathology to strength. The two men who had positive benefits from counseling identified 'connection' and 'purpose (provider)' as the code imperatives the counselor helped them identify personal strengths in, which allowed them to face their issues and negotiate change in their performative. 
The findings on negotiating the code for 'not gay' indicate that a sense of safety and control are necessary for men to be able to engage in breaking down the fundamental attribution error here. The findings that link aggressive reaction to experience of coercive power are similarly suggestive of ways to engage men by understanding motivation for their own aggressive actions that destroy trust and connection.

I also speculate that examination of the performative would be useful for working class women who I believe define their performative in some similar ways to men, especially as women assume more of the provider role in families. My experience supports the conclusion that working class women share many of the same objections to social work as these men. This current work is perhaps useful in beginning this examination because the high level of social alienation felt by these men brings this theme into sharp focus.

A minor theme that emerged is the conundrum pointed out by several of the participants that non-sexual physical comforting is essential to a person's wellbeing, particularly to a child, but the understandable determination to protect against sexual abuse and/or the personal consequence of allegations of sexual abuse, makes even allegations of physical contact unacceptable. It would be worthwhile to begin to enquire as to ways that persons in need of physical comfort could receive it in a safe way. 


\section{References}

Barlett, P. \& Jewsbury Conger, K. (2004). Three Visions of Success on American farms, Men and Maculinities, Vol. 7, No. 2: 205-277.

Brandth, B. (1995). Rural Masculinity in transition: gender images in tractor advertisements. Journal of Rural Studies, 11 (2): 123-133.

Brandth, B. \& Haugen, M. (2005). Text, Body and Tools: Changing Mediations of Rural Masculinity. Men and Masculinities, Vol. 8, No. 2: 148-163.

Butler, J. (1993). Bodies that Matter: On the Discursive Limits of Sex, London: Routledge.

Bye, L. M. (2009). "How to be a rural man": Young men's performance and negotiations of rural masculinities. Journal of Rural Studies, 25: 278-288.

Campbell, H. (2000). The glass phallus: pub(lic) masculinity and drinking in rural New-Zealand. Rural Sociology, 65(4): 562-581.

Capra, F (1996). The Web of Life. New York: Anchor Books

De Montigny, G. (2007). Ethnomethodology for Social Work. Qualitative Social Work, Vol. 6 (1): 95-120.

Evans, J. \& al. (2009). Health, Illness, Men and Masculinities (HIMM): a theorethical framework for understanding men and their health. Journal of Men's Health, Vol. 6, Issue 1: 20-27.

Evans, R. (2000). You questioning my manhood, boy? Masculine Identity, work performance and performativity in a rural staples economy. Arkleton Research Papers \# 4, University of Aberdeen, Scotland.

Germain, C. B. \& Gitterman, A. (1980). The Life Model of Social Work Practice, New York: Columbia University Press

Germain, C. B. \& Gitterman, A. (1996). The Life Model of Social Work Practice, (2 $2^{\text {nd }}$ ed.), New York: Columbia University Press.

Gitterman, A., \& Germain, C. B. (2008). The Life Model of Social Work Practice, ( $3^{\text {rd }}$ ed.), New York: Columbia University Press.

Glicken, M. D. (2005). Working with Troubled Men: A Contemporary Practitioner's Guide. Mahwah, New Jersey: Laurence Erlbaum Associates. 
Hoffman, J. (2011). Father Factors: What Social Science Research Tells Us About Fathers And How To Work With Them. Peterborough, ON: FIRA. http://www.fira.ca

Hogan. M. \& Pursell, T. (2008). The "Real Alaskan": Nostalgia and Rural Masculinity in the "Last Frontier", Men and Masculinities, Vol. 11, No. 1: 63-85.

Lero, D. \& al. (2006). Inventories of Policies and Policy Areas Influencing Father Involvement. Father Involvement Research Alliance, Guelph, ON. http://www.fira.uoguelph.ca

Lichter, D. \& Brown, D. (2011). Rural America in an Urban Society: Changing Spatial and Social Boundaries. Annual Review of Sociology, 37: 565-670.

Little, J. (2002). Rural Geography: rural gender identity and the performance of masculinity and femininity in the countryside. Progress in Human Geography, 26,5: 665-670.

Little, J. \& Leyshon, M. (2003). Embodied rural geographies: developing research agendas. Progress in Human Geography, 27,3: 257-272.

Littlefield, J. (2010). Men on the Hunt: Eco-feminist insights into masculinity. Marketing Theory, Vol. 10(1): 97-117.

Mackie, D. (2012). Mensheds Manitoba Inc., Personal email Corrrespondence. mailto:dmackies@mymts.net

Marx, K. \& Engels, F. (1976). "The German Ideology"in K. Marx/F.Engels: Collected Works, Volume 5, 1845-1847, New-York: International Publishers.

Morgan, N. (2010). A room of their own: Men's sheds build communities of support and purpose, CAMH Crosscurrents, Summer 2010, Vol. 13, No. 4: accessed at: http://camhcrosscurrents.net/achives.

Morris, E. (2008). "Rednecks", "Rutters",and "Rithmetic": Social Class, Maculinity, and Schooling in Rural Context. Gender and Society, Vol. 22, No. 6:728-751.

Myers, D. \& Smith, S. (2009) Exploring Social Psychology , $2^{\text {nd }}$ ed., p 56-60. Toronto: McGraw -Hill Ryerson

O'Connor, (2005). Local embeddedness in a global world: Young people's accounts.Young: Nordic Lournal of Youth Research, Vol. 13 (1):9-26. 
0'Shaughnessy, S. \& Krogman, N. (2011). Gender as contradiction: From dichotomies to diversity in natural resource extraction. Journal of Rural Studies, 27:134-143.

Panelli, R. et al. (2009). De-centring White ruralities: Ethnic diversity, radicalization and Indigenous countrysides. Journal of Rural Studies, 25: 355-364.

Smith, B. A. \& Peak, T. (1997). Support Groups for Older Men: Building on Strengths and Facilitating Relationships. In J. I. Kosberg \& L. W. Kaye (Eds.), Elderly Men. Special Problems and Professional Challenges. New-York: Springer Publishing Company, Inc. 262-

Stenbecka, S. (2011). Othering the rural: About the construction of rural masculinities and the unspoken urban hegemonic ideal in Swedish media. Journal of Rural Studies, 27: 235-244.

Ungar, M. (2002). A deeper, more social ecological social work practice. Social Service Review, 76 (3),480-497.

Walmsley, C. et al. (2009). More than a Playmate, less than a Co-parent:Fathers in the Canadian BSW Curriculum. Canadian Social Work Review, Vol. 26, No. 1. 


\section{Appendices}

\section{I- Local Demographics}

From: Lads o' Lanark: An Examination of Social Support Programs for Men in Lanark A paper for Dr.Colleen Lundy, SOWK 3201A, Carleton University, Oct.27/09, p. $9-17$

Slightly over fifty percent of Lanark County residents aged 15-24 have not completed High School, which is $10 \%$ above the provincial average (Labour Market group of Lanark and Renfrew, 2009, p.32). Among Males age 15-64, $24 \%$ have not completed High School and an additional $28 \%$ have a High School Certificate or equivalent as their highest level of education (Truemnar, 2009, quoting 2006 Census). Numbers of Apprenticeships, Trades Certificates and College Diplomas are well above provincial average and University Certificates, Diplomas and degrees are well below provincial average, particularly in the 25-44 age cohort (Labour Market Group, 2006, p.32). There is net out-migration of the 18-24 age cohort, despite moderate in-migration in all other age groups (Labour Market Group, 2009, p.30).

The figures from the 2006 census indicate employment levels near provincial average but the closing of the Rideau Regional Hospital, Stanley Tools and Hershey Chocolate represent 1475 jobs lost (Labour Market Group, 2009, p.43). These were good jobs with above average wages, union representation, pensions and benefits. The jobs that have primarily replaced them are in the retail and service sector (Labour Market Group 2009, p 22). In addition to the precipitous drop in 
manufacturing jobs, there has been steady job loss in the agriculture and forestry sectors (Labour Market Group, 2009, p.33). These three sectors have traditionally provided reasonably well paid jobs for males with lower levels of education.

Another interesting statistic is that approximately one third of the workforce of Lanark county commutes to Ottawa for work (Truemnar 2009).

The transition to a service economy has been characterized as the "Feminization of the Labour Force" (Armstrong, P. 1996). Service sector jobs have traditionally been held by women and typically pay less, are more often part-time or part year, and have no job security, union representation or chance of advancement. In addition the corporate culture emphasizes the horizontal, team work approach developed in the women's movement and uses this culture to extract more work from fewer workers by giving them more responsibility and less power. Armstrong argues that the marginal narrowing of the gap between men's and women's average earnings is the result of men being forced into the service sector jobs previously held by women (Armstrong, P. 1996).

Richard Sennett has examined the changing nature of work and notes this movement from hierarchy to concentric circles of workers that can be rapidly shed or acquired to suit the business needs of the times (Sennett 2006, p.49). The skills required of the modern worker are more relational than technical or knowledge based (Sennett, 2006, p.51), and this conflicts with traditional male socialization that emphasized skill competence, action and production and discouraged understanding and building relationships (Levant, 1995, p.73,75).

This seems to be playing out in the latest economic downturn as we see that 
$71 \%$ of those who became unemployed in the first eight months of this recession are men and the unemployment rate for men hit $9.2 \%$ in June 09 , compared to $6.8 \%$ for women. In fact, this recession has seen a $5 \%$ increase in full time employment for women over 55 (Hennessy, 2009).

Ontario has been particularly hard hit, shedding $66.4 \%$ of the jobs lost across Canada by June/09. These latest figures are not reflected in the demographic stats for Lanark County listed above, although they do note, "we have experienced unpredictable and unprecedented volatility in the global, national and provincial economies which have impacted these local sectors significantly. Readers should interpret the report in the context of these turbulent economic times." (Labour Market Group, 2009, p.1).

Looking at statistics for the only Court located in Lanark county, we see that between 2005 and 2009 there has been a 68\% increase in Criminal events heard at the Superior Court of Justice, $133 \%$ increase in Superior Court of Justice Criminal Indictments and Appeals Pending, a 59\% increase in superior Court Criminal Indictments and Appeals Disposed, a 191\% increase in Superior Court criminal indictments and Appeals Received, and a 77\% increase in criminal events heard at the Ontario Court of Justice. These percent increases are among the highest in the province, well above increases in the numbers seen in Toronto and only surpassed in some instances by a few areas such as; Cochrane, Kirkland Lake, Goderich and Sarnia (Ont. Min. Attorney General, 2009, B27).

I haven't been able to break down these "criminal events" by sex or offence. Anecdotally, the two jails serving the male population in the area are severely 
overcrowded, with some of the offenders estimating that most of the guys are in for "domestics and drugs", and the Partner Assault response program runs four, fifteen man programs a year and has added three extra programs in the last two years.

Lanark has been identified as containing $13 \%$ more heavy drinkers than the provincial average, 15 of 22 children placed for adoption in 08-09 came from families where substance abuse was a problem, up from 5 children in 06-07, and Lanark OPP lay an average of 43 charges per year for drug offences, and they have already laid 21 drug charges in the first quarter of 09 (Gesner, 2009).

In terms of family structure, we see that $20 \%$ of the lone parent families are headed by men. This is consistent with the national average, which increased by 15\% between 2001 and 2006 (Stats Can, 2008-11-21, document 11-008-XWE). As Lynn Segal notes, along with the financial punishment of lone parenting that female lone parents experience, the male lone parent is often socially isolated as well, with little in the way of social support, and loss of traditional male support.(Segal, 2009 p.45)

For the purposes of this thumbnail demographic sketch, if we take the Low Income Measure (LIM) of $\$ 15,179$ suggested by Stats Can for a single person in a rural area (Zhang, 2009) and compare it to income levels in Lanark county, we see that just below $30 \%$ of men are below this measure (and just below $40 \%$ of women). If we take into account the number of men who make below $\$ 20,000$, or the rough equivalent of a full time, $\$ 10 \mathrm{hr}$ job, then we find close to $35 \%$ of men in Lanark fit into this category (Truemnar, 2009, quoting 2006 Census). I was unable to find data on family income, but even a rudimentary snapshot such as this gives a picture of a 
sizeable proportion of the community that is experiencing poverty. It's perhaps worth noting that there are 840 men and 1430 women noted as having "no income"(4\% of population)(Truemnar, 2009, quoting 2006 Census).

What does all this tell us? I feel like the proverbial blind man in the room with an elephant, trying to describe it. I haven't even touched on an analysis of this from the perspective of the death of a proud culture of rural Canada, but that is certainly there as well. There are any number of active and largely invisible social, economic and cultural networks that see themselves as largely alienated from mainstream society.

I think from a structural perspective we are looking at something like the perfect storm for men in Lanark. Some men have symbolized it as living in the wrong time, some as being dinosaurs. The essence of it in social work jargon is marginalization and reduced sense of social inclusion for a significant portion of men.

\section{References}

Armstrong, P. (1996) The Feminization of the Labour Force: Harmonizing Down in a Global Economy., in Isabella Bakker (ed.) Re-thinking Restructuring:Gender and Change in Canada. Toronto: University of Toronto Press.

Evans, R. (2000). You questioning my manhood, boy? Masculine Identity, work performance and performativity in a rural staples economy. Arkleton Research Papers \# 4, University of Aberdeen, Scotland.

Gesner, T. (2009) Building a Case for a Drug Strategy Network. The Record News EMC, Thursday Sept.17, 2009, Smiths Falls, Ontario

Hennessy, T. \& (2009) Canada's "He-cession": Men bearing the brunt of rising 
Unemployment. Canadian Centre for Policy Alternatives, "Behind the Numbers", 10(4).

Labour Market Group of Lanark and Renfrew. (2009) TOP Report (Trends, Opportunities, Priorities), Pembroke, Ontario.

Levant, Ronald. F(1995). A New Psychology of Men. New York: BasicBooks, HarperCollins.

Ontario Ministry of the Attorney General (2009) Court Services Division Annual Report. ISSN 1708-198X. Toronto: Queen's Printer for Ontario

Sennett, R. (2006). The Culture of the New Capitalism. New Haven \& London: Yale University Press.

Segal, L. (1990). Slow Motion: changing masculinities, changing men. New Brunswick, New Jersey: Rutgers University Press

Stats Can, (2009-09-22) 2006 Census:Family portrait: Continuity and change in Canadian families and households in 2006: National portrait: Census families. document 97-553-XWE2006001

Truemnar, L. (2009) Re:Changing Face of Work in Lanark, emailed Spreadsheet and analysis of 2006 Census Data by the Labour Market Information Analyst, Service Canada, Perth, Ontario.

Zhang, X (2009) Low income measurements at Statistics Canada, Statistics Canada Website. www.statcan.gc.ca 


\section{Appendix II-Interview Guide}

\section{Working with Mandatory and Negotiable Aspects of Personal Codes: Implications of the Narratives of Rural Men for Social Work Practice.}

Review letter of consent, discuss, provide opportunity to sign.

If consent signed:Introduction to study. Any questions before beginning? Answer questions.

Proceed with interview.

The interview guide is shaped by an ecological approach. The interview guide addresses a number of core ecological concepts. "Person:Environmental Fit" addresses participants perceptions of whether their physical and social environment is seen as favourable or unfavourable to meeting their needs and goals. "Adaptations" examines strategies for improving environmental fit. "Life Stressors" are life issues that are perceived to exceed personal resources to manage. A subset of Life Stressors examines challenges that are perceived as an opportunity for growth and as within the ability of the individual to master. "Stress" is an assessment of emotional and physiological responses to stress and challenge. "Coping Measures" are behavioural attempts to improve environmental fit.

The next four concepts explore the adaptive relationship between the person and their environment. "Relatedness" is defined as perceived connection between the person, other people, and the natural world. "Competence" assesses perceived self-efficacy, "Self Esteem" looks at the level of respect for self, and "Self-Direction" probes for perception of personal power to make choices and ability to take 
responsibility for those choices. The places that these men feel comfortable, their "Habitat", will also be examined, as will their "Niche", defined as the status they feel they occupy in social life.

More recent concepts in ecological theory will add to the depth of material and analysis. "Coercive power" looks at perception of social exclusion from power and experience of injustice, while "Exploitive power" looks at perception of the effects of technological pollution on the person. The last key concept is an examination of the "Life course" of the individual, without trying to mold it into any pre-determined set of stages. This is done by inquiry into "Individual time", defined as the person's own narrative of their life, framed within "Historical time", or the experience of the individuals birth and social cohort, and "Social time", the individual's experience of broad societal change within their life.

The questions articulate a strengths based perspective and are ordered from general to specific to obtain the greatest detail and to follow a natural conversational flow. The interview guide is not intended to hamper the develoment of a more conversational structure in which participants will be able to examine their own significant themes. In addition to questions designed to elicit information on the life model categories listed above, I have added a question at the end relating to core values as it seemed to flow naturally from the line of questioning.

\section{Semi structured interview guide}

What does it mean to you to be a man?

Is there a "code"-rules, moral structure, ways of being? What are these?

Where do you think you learned this? Where did that come from? 
How have you tried to live up to that code? What does living up to the code look like? What is it like for you 'living up to the code'?

Has the way that you understand and lived up to the code changed over time?

What has changed?

What are the major events that have changed the course of your life?

Individual life events?

Family Events?

Community/economic events?

National/global events?

What helped you at those times?

What obstacles have you faced?

Do you feel that you have been successful dealing with these changes?

Who are the important people in your life? (draw a genogram)

What are the communication patterns between these people (draw in the patterns)

What communities do you belong to? (If you had to attach a label to yourself, what would it be?...How do others perceive you- niche and habitat)

What do you think the biggest social problems are that you, and other men in your community face?

How would you deal with it? (like to see it dealt with)

What do you think the major social changes are that you've seen in your life?

How has that affected you?

What are the major changes that you've seen in your own personal life?

How has that affected you?

What do you believe is true? (core beliefs) 


\section{Appendix III-Individual Time-excerpts from transcripts}

\section{Participant 1-early 60's, spent childhood in foster care.}

Well...as our marriage was breaking up...that was about $19 . . .81$...from that incident on the marriage was breaking up over the course of the next year, I went and got counseling at st.paul's university in Ottawa but I wanted to bring her along with me ....counselling for both of us because I knew that this had to stop somewhere...you know, especially what I was doing and the way that I felt . I had to get this out of me somehow, so I convinced her to come down to the university, to the counselor and I still remember ...the first time we had an interview and the next time... it was a week later in the very first session, she directly told the counselor, she sez, 'I will only come to counseling here', she sez,'if this counseling...ahhh...ends our marriage and that'll be the only reason why I will come ', she said....and I thought, wow, that's great...her, I'm trying to fix this...somehow, for both of us...especially for me...and she will only partake...if it ends the marriage, you know? So that was the end of her counseling...the counselor just said...well, we'll take you and we'll see what we can do, so I went there for a year and a half ...over different periods,,,it helped quite a bit, but still...the lady was diane, uh...lovely, lovely lady...just can't remember her last name right at the moment but beautiful lady and she real...it's like she reached out to me in love, more than anything...you know...we can go to a psychiatrist and you sit there and you feel no connection at all, other than you're just talking to them, but yah, yah ...and so that in itself...she had a big breakthrough in me (laughs)...but it wasn't exactly the major breakthrough because $1984 \ldots$ this was starting in $1980 \ldots \mathrm{I}$ 
guess the beginning of $80 \ldots 82$ the counseling at st.pauls university ...around 82, ,the beginning of $82 \ldots$ my ex and I separated midway through 82 , so I was off alone then and living by myself and in $1984 \ldots$ it was on a good Friday...the day before I had gone out...I'd gotten into drinking after that, ok, just to kill the pain,

You mean the experience I had...because it was filled with love and this is ...going back to the counselor from st.pauls university, it was love coming from her, and I accepted that...she truly cared what happened to me yah, yah, and of course gods love is greater than anything... yah, every day it's ...when I think of how beautiful the world is,...we hear of all the horrible things happening and everything, and we see it, all you have to do is turn the news on and yet there are so many beautiful things happening..people helping each other, you know... and people loving each other..truly ...and you think, you know...here is all that hatred and here is all this love and hatred will never overcome that love...love will...it's bigger

I can only relate this to you and I'll relate it to you as an incident for the children's aid applying...that theory...or whatever you want to ....

...my first wife and i...I don't know how she allowed this to happen, especially the kind of person she was, but we got a young lady from the children's aid...she was about 13 years old, she was on the street in Ottawa...um...I'd only found out years later that her stepfather had raped her...anyway she came into our home off the streets of Ottawa and ...it's strange...when I had all of these defences before and 
didn't have this love connection with god, I was still able to reach out to her in that simple plain love. Now I was her care worker, through the children's aid...so I had to be responsible, I had to be really careful...I had to...numerous things...and try and help this child develop and try and help her get through...now the children's aid never told us what had happened, other than that she came from a very dysfunctional family...terrible,terrible, terrible,terrible but no big explanation or nothing, but I still remember and this is the incident I'm going to bring forward to you and I think the children's aid should listen to, because apparently you can't do it today, from what I understand...that young girl, even though she was $13 \ldots$ she turned 14 in our care...was a young, healthy, vibrant girl...quite muscular...she was very athletic...umm...she would come over to me...I would be sitting on the couch and she would come over and she would curl up on my lap and I would hold her and hug her ...that was it...just to show her that I cared...and I would hold her ...and that's all she wanted...she wanted someone to care for her ....somone to...uh (sigh)...I don't know if you call that compassion or what...to me it goes a way beyond compassion...when you hold a child...to me, I'll call her a child because she really was a child and you pick a child up and you hold that child...they have such comfort...they feel so secure ....and that's what that girl was looking for...and I would do that and she'd be as happy as anything...and...today...I don't even think you're allowed to do that...you know...that is a...to me that is a crime...I know you gotta be careful...I know because there's so many incidents of things actually happening and on the other hand, there's accusations made that're false, so that's why you have to be so careful, but if I had not done that with that young lady, she probably would have turned our 
household upside down as well...you know...and been even worse, I don't know ...what I got out of it was...she was teaching me something ...that you have to have care and compassion and still be able to hug the child ...you know...to make them feel, at least wanted. There's discipline and all kinds of stuff involved, yeah, of course , but that was one of the things I took out of that more than anything, and of course, growing up myself, and maybe that's why I felt that...I don't ever remember being hugged...ever...maybe comforted or something if I fell or hurt myself...I remember one time ...I was about four years old, I was wandering about the hen house, chicken house, old shed or whatever...seen this...what I thought was a ball on the ground...don't ask me why a hornet's nest would have been above ground, on the ground, but I went and reached down to pick it up and boy, let me tell you, did they ever come after me...they literally stung me...they were in my mouth...you...and that's the last thing I remember cuz I was runnin from there up to the house screamin, but I guess I passed out...like, there were...a thousand bees onme, and ,uh...unfortunately, I can't remember what happened after that..i'm sure I was well taken care of ...back then, they used to put the mud on you and everything else to try and get these bee stings out of you and so on ...but..you know, other than being taken care of..um...in a ...in a comforting way...I don't ever remember ...ever being hugged, the only thing I would've ever felt would've...oh, if you're walking along beside one of them or something, they'd just grab you by the shoulder or like that...kind of squeeze ya...you're ok...or whatever...never this kinda intimate hug that I'm talking about that I gave my foster daughter, It was more intimate...it was like you were holding a child...and that's the way she cuddled up and curled into my 
breast...a number of times...uhh... I cannot assume that she was looking for anything other than just saying...'you're here for me, you care about me, and you do love me'...that's the only thing yah, safety, that's right, and it's such a shame, because we can't allow that to take place anymore, cuz I know I would have loved to be hugged ...when I was little...like that...I would have loved it more than anything...maybe I would never have built those walls around me, you know...as deep as I did...had I been hugged...non-sexual but physical...comfort...it's so gratifying to know that you're there and you love them...you know...it's that physical contact...that's the only thing I would ever want to...well, there'a number of things I would hash out with the children's aid, but that's one of the big things...

kick the dog again...here we go back to the dog again...that's fine too...any dog...I meant to mention that before when we were talking about feeling like a dog growing up...uh...kick the dog...uh...get rid of the dog...any dog that has ever come into my care has never left...even though people have wanted them...you know...what a cute puppy...what a this/that...why do you need so many dogs...all the dogs we've taken them from abusive cases or whatever ...or stranded...well, that dog has never left...and I vowed never, ever to let a dog go out of my home ...he stays until he dies, yah. It's funny how I feel that strong about it... because I internalized that when I was a child and seen the dog being kicked...me being kicked and everything and my, my siblings and the children's aid would come and take one of my brothers away, one of my sister's away...they were gone...you never seen them again...ya, pick of the 
litter...it was just like a humane society...yah, that's how I internalized it...it was the humane society for humans, and it's so much...the similarities are so close together it's incredible between the humane society and the children's aid ...yah, I'm sorry I have to say that, but to me, the similarities are,...hey...they're right up there with each other....same model...well I remember going to Ottawa when I was very young, they had to take me in there for an assessment and uh, I just forget...see the cas used to be right there on bank street, I forget if it was there or not...I remember people being in there and looking at some of these children and saying...'oh, is that ever a nice looking boy' and then walking over to another one and going, 'No..no'...they were picking and choosing just like you'd go into the humane society and pick and choose...that stuck with me all my life. What do you think I am... a dog or something? You know, and that gives you a horrible, horrible feeling.

With being in the children's aid...course all my young years, up to $18 / 19$, when they...drop you out ...yah, I'm just trying to get a grip on that because I think a lot of professional people ...and most people would say, you know...you wouldn't have memories that could recollect back that young, but I have things built into me from an extremely early age...uh, I know well before two years of age...probably not much longer than after a year old...being bounced around in different homes...you all of a sudden start to build up a non-trust right there when you're being bounce around, I mean, you're being treated like a rubber ball, eh? Like, uh, my record shows that I've been in ....during my stay with the children's aid, I think somewhere between $10 \ldots$...'d have to look at my records, but somewhere between 10 and 12 different places... 
and more so in my younger years...the very early years. I went through a lot of different places and this builds up an awful mistrust in a child...it would have to, because you don't bond with anybody and when you don't bond with anybody of course, then you build up your fears and it's almost to me ...I internalized the whole thing as like being in...a war cuz sometimes you're facing the enemy and battling the enemy and sometimes you're running from the enemy to save yourself and in the process of all that..in the mean time you're being wounded...l'm speaking of emotionally, at that time..uh, physically, I don't recall any, I should say I don't recall any physical wounds at that early age, but certainly emotional and boy, it just puts a...it puts a...ohh, a terrible, terrible thing on your whole being that you're building this wall around you...week after week, month after month. I recall at a very early age, even before I was 2 ...this one particular family I was taken away from and I can..it's hard to believe but I can still see myself with my arms stretched out to that woman, being torn away from her, who I thought could be my mother and the children's aid worker pulling me away and me just bawling my eyes out and my arms being stretched like that...I still see that today, that very picture. It's so vivid, it's incredible and I know from that point on, for sure, at age 20 months , I built this huge wall around me cuz after that, when I went to the next place, I vowed they would never hurt me again, speaking of the children's aid of course...at that time I didn't know who they were...they were my enemy. Any time they ever came down..i went to a farm down in (Ottawa valley village) area ...anytime after that when they came around...if I saw a strange car coming up the road and getting ready to turn in our laneway, I would run and hide. I've not only hid in the house somewhere...under 
the couch, under the beds or whatever, I've run away into the bush...and this was on a farm. I used to get in a lot of trouble for running away like that but if I was able to run away into the bush, when I got just a little older, like $4 . .3,4,5$ years of age, when I started figuring the house wasn't safe enough...they would eventually leave because I wasn't coming back, and when I seen that car going away, you know ...way, way out in the far forty, in a field, behind a tree...seen that car pull away then I would come back in the house. Yeah...and my foster mother she just like (sigh)...I don't know what would be going through her mind cuz here's this children's aid worker telling her,'well, you have to have control of this child' and here's the child run away and we're going to call you after we leave and make sure you've found the child. I went through all this growing up and it was like battling the enemy...running from the enemy...facing the enemy, whatever it took...and of course the children's aid weren't the only cuz then there were family members, in that family...my foster mom was great.my foster dad...to me I think they were my angels ...they were literally sent from god to save me, and they did, cuz they had family members, like I'm talking about their siblings and that, that hurt me greatly...emotionally, physically..uh...sexual abuse, you name it. The whole gamut...and so right within the family that was trying to save me, I had enemies in there and it was terrible...absolutely, total disgusting. I had one foster brother there...of course, being old...this family was an older family...my foster mom and dad...he was born in 1875 and she was born in 1888 so when I came there in 1947, their children were all grown up...most of them away but they had one son living there, and boy, let me tell you...he used to terrorize me. He would've been in his 30 's eh....around 30 years of 
age and ....uh...besides the sexual abuse, emotional abuse...one day he took ...I think I mentioned this to you before... he took one of those swede saws...the big swede saw with the big bow...about four feet long...four foot blade on it I think ...he took that right across my face...I don't know how he didn't take my eye out cuz I still have the scar from my eye here...underneath my brow here , and the scar across my nose here where he nearly ripped my nose off...and how he ever got away with that and the children's aid never finding out about it .i've no idea...I was too young to know, but...phh (outward exhalation)

Well, they're trying to protect me but at the same time they want to protect their own son, you know, blood's thicker than stone,eh...I know my foster mom was horrified of course and I don't know what she did to him, whether she told him to go away for a while or what, I don't remember...I was about 10 ...I came there at 22 months and I was there till 16...I think I was 16..yah, I was 16 years of age when I went to Ottawa cuz I wanted to go to a technical high school..I wasn't doing well at the high school in (Ottawa valley town)...it was more academic and I had so much baggage I couldn't learn...I couldn't comprehend stuff or anything..you know, and of course my two years in .... high school were a complete failure. I know the second year I was there and got my report card...it came...was mailed to ya and I know my mother opened it up and the day she opened it up...my foster mom, and she showed it to me ...I was outside...I think I was in the garden or something and she come out with it and she just handed it to me...she didn't have any disgust look on her face, she was a great woman, and I had failed again...second year in grade 9...I'd failed again, like really big time, and I wanted to go and commit suicide that day, yah, she 
stopped me, cuz I just thought I was a complete failure...I was never gonna be any good to anybody, to myself or anything ...I couldn't learn, and so...well the schoolbus had to take you there...I was at school...I couldn't learn nothing...but I couldn't learn anything because I had all this stuff inside me...uh, you know like...you're looking at an authority figure and...guess what...what I think of authority figures...you know...who are they, you know... I used to go back in the summer time to the farm, well he was gone, the son, he was long gone...he left in 60 or $61 . .$. he married a lady and moved to London Ontario, and that was an interesting thing too, cuz just prior to that, l'd say from the age of 13 , maybe $14 \ldots 13 / 14$ I was getting myself ready to do battle with him. I was going to take him out and if I couldn't have taken him completely out I wanted to hurt him very, very badly...I mean, I had so much anger in me, and hate, that this guy was going to suffer...yah, him particularly...there were a few other individuals there as well, but him...and then he left...met this woman... he married and thank god, you know, that happened because that saved me. Seriously, I was doing stuff...like I worked on the farm all my young life there, eh...at a very early age did all kinds of things and ...was in good shape, for a young lad but by the time I was $13 \ldots 14 \mathrm{I}$ was starting to do..i set up these things in the barn, off the beams...where I could do flips and everything else and I was training myself ...yeah... cuz I was gonna do this guy in...that's how bad it was. Nobody had any idea...I kept it all to myself...yah Yah, I still had so much anger and everything in me, you know I never got rid of any of that...well, I got married then, at the age of 25 ...ummm..(sigh) and I guess my exwife and I did battle then, cuz ...ahh...I guess that was the next segment of my life 
that ...uhh...that turned sour, and god, when I think about it...she nearly destroyed me...I came this close...a hair of being destroyed...completely.

She was a very strong woman and had no compassion for any of my antics, you know, if I wanted to have a beer with the boys or anything like that, and if I wanted to belong to a baseball team or anything like that because I played, in my youth I played a lot of sports...I was quite active...hockey, baseball, broomball, I was quite active and she had no time for that with me so she didn't want me to participate and of course that took a lot away from me as well...that I was being controlled then, and that control affected me a lot I think

I could have killed her that night ...very easily and you know, when I had her by the throat on the floor ...I'm not trying to relive this as if I'm proud of it..i'm not proud of it at all...I no sooner backed off and got out of that and I thought, "what have I done?", but when I had her by the throat and that I thought, man, you're going out lady and it was only for that instant...remember when I was saying by the grace of god, there goeth i.... think god had his hand on me,,,he pulled me away, I don't know what else stopped me because all I saw was red..i didn't see her...all I saw was red...it was like blood...not talking...it wasn't her blood...it was like ...l'm sure if someone would have been standing there and looked at me, they would have probably seen my eyes red cause that's all I could see...and ...oooohhh..talk about scary $\ldots$ 
oh, I found a ...a few, you know ...l've gone into my family...researched the history of my ancestors and everything...I've been able to do all that, because you're able to find out this information...here, there and I've never did it on a computer...I've did it all legwork...going to gravesites and town offices ...getting information on the early settlers and that...that's how I did it all...but...my immediate family...I met my mother...when she was...I was 25 ...I met her and, um..uh, of course I was still with my...that was I guess the beginning of my relationship with my first wife and, um, my mother then was murdered only five years later, and, uh...I had tried as much as I could to get to know her and had a lot of compassion for her, even though ...the general concensus was that she gave me up at birth...I sometimes wonder if she didn't struggle with thatbecause I know it wasn't until...I dunno, a month later, after my birth that she signed the papers, so that seems to be a fairly stretch in time when this takes place.

I would have been the third one born...to her...when she was 25 maybe...just unable to...to look after any children...uh...I had, I found out over the course of the years, in trying to find out more about my family, that she had a very difficult life...I ...came to the conclusion that she was...oh what's the word for it...the family shunned her..pushed her away... there's another word for it...ostracized...I feel she was ostracized by the family and, uh..i think she lashed out...whether it was getting pregnant or what...just looking for love in all the wrong places ...now we see that today...all the time, yah...with young girls ...young women ...young men...I'm pretty sure that that's what took place cuz I know, from the point ...probably about when I was born in the mid-forties...early 40 's...she...I think had to try and work her way 
into the family and not allowed so her life just kinda went downhill from there. One of my siblings, a girl...that was born before me ...she was murdered as well...about ten years after my mother was murdered, so I never got to know her, but I did get to know my mother for five years...and had a good relationship with her...the day I met her...I was able to go into the hospital...she was at the civic...I didn't find this out through the children's aid...a friend of mine who knew her...I didn't know at the time that this family knew my family, cuz this was going back into the fourties and, uh...he said to me one day...he was in (city) visiting...he said...your mother's in the ... hospital and he said, I'm not sure what's happened to her but she's there if you want to meet her ...I said...really?, cuz I had been looking for her...nobody would tell me..children's aid wouldn't tell me ...I had an aunt that I had found...she wouldn't tell me...this was one of the family that had ostracized her...didn't want nothing to do with her, so when my friend ...had told me this, the first thing I did was I rushed to the civic, asked for (mother's name)...told me what room it was and I went up...I walked in the room and she was...private room...she was in there and I think.....almost immediately she knew who I was, cuz she started to cry and I went over and put my arms around her...now ...this was a woman that i...mind you, I'm 25 years of age, eh...this was a woman that I had a pretty good idea that gave me up...shoulda been some hostility there...but there wasn't...there wasn't any...I didn't have that wall up to say...are you gonna hurt me again, you know, refuse me, when you did before...none of that...I had no inkling...no...nothing...I just reached out to her and put my arms around her and we starting talking...we had a good relationship for the five years...I wished it would've lasted longer 
She was murdered up on the quebec side...some guy decided he wanted to end her life...and...that was another thing, on my ...uh, on my plate...the guy was arrested, I was gonna break into the ...jail...I had a gun...I knew what I was gonna do...if I had to take out these guards in the jail I was gonna take them out first and I was gonna get this guy, because I had a mother that I had not known for 25 years of my life and this...guy thought that he could take this away from me. I was all set to do that and three days later he hung himself in the jail ...saved me...yah...so, you can imagine if I was going to carry out all these things, and I was, I absolutely was...I'm in the middle of my marriage...I've got ...how many children now?...this was $1975 \ldots$ (daughter) wasn't born yet so I only have two children, but ... it didn't matter to me...it didn't matter cuz I had all this stuff from before and I thought...here's someone that's trying to hurt me and my family again...this ain't gonna happen.

my kids?...rarely...very rarely...that ex has turned them totally against me and uh, supposedly how horrible I was, and we were speaking before you changed that...uh...about some of the incidents that I got myself into or nearly carried out...there was another incident before...I was going to take out the guy that murdered my mother. My ex, very early in our marriage had an affair with one of the bosses at loblaws ...and, um..i found out about it very quickly...I've always had this ability to kind of figure things out very very quickly...figure things...you can have a person that can figure things out that's an inventor or something and you wonder..'my gosh they must be brilliant'...how can they do that?' ...you know, and I'm not like that...I can figure things out real quick about human beings...real quick...and my ex...I figured out about her having this affair with this boss of hers 
...very quickly...so, I phones this guy up ...course I know who her boss is, and I sez...'can we have a meeting...preferably tomorrow morning at 7 at (grocery store) just before you go into work?' he already knew that I knew about my ex and him ...he sez...he reluctantly said yes...had he known what I was about to carry out ...hr would've stayed away from work that day, cuz I loaded my gun up...had a clip in it...full clip...loaded...threw it in the trunk of the car and off I went...drove right to the(grocery store) and waited for him...I haven't a clue what happened after that because I didn't carry it out...I was gonna kill him....and I had this chat with him...can't recollect really what all was said, but it was basically...leave my wife alone ...you know...there probably was a lot said but he had no idea that there was a loaded gun right there in that car...and I didn't tell him

...yes...and no...yes and no, cuz she was carrying on anyways and she said, 'this is my body and', uh, I still remember these words that she said to me..."this is my body and I'll do whatever I want with it'..yep...you know...you don't matter. yah, you can see how horrible our marriage must've been...how it lasted 12 or 13 years I'll never know cuz this incident happened very early in our marriage, matter of fact there was an incident just before that, about six months before that where she got involved with an (police)(laugh) officer...you shoulda seen that scene...you have no idea what it was like, gary, back then...this officer was out of the station where it used to be (west end city)...that police stations no longer there...I went in there, when I found this out...I marched in the door...I didn't even wait for an officer to come to the desk...I just catfooted myself right clean over the counter and I said, 'I 
want to see so-and-so right now, I knew the guys name ...well, two officers they came straight towards me ...the secretaries, I kid you not...they just right off their chairs underneath their office desks...I didn't even have a gun on me...I knew enough not to...but I was gonna have it out with this guy,..and then so, they say..well, officer so-and-so's off duty...what's wrong? I said, well, this is what's happened, and I said, and I'm taking care of it ...cuz I said, I know you won't. Well, they were smart enough to say, 'look, we will call inspector so-and-so from the...wherever...orillia I guess, they have the , uh, the main ...inspector...they did at that time and I think they still do...we'll have an appointment set up and we'll have this taken care of ...I said,'are you sure?', cuz I said,'this guy is gonna get hurt'...they said,'well, you will get hurt', and I said, 'do you think I care?' I said, 'I'm taking care of this unless you bring this guy in like you said you are'...a week later this guy met me ...inspector for the (police)...said he'd have the guy transferred immediately...he said, this isn't the first time this has happened with him, he said, he also has a wife and family, but...I was crazy ...you know

She knew how to hurt me, let me tell you...I have no idea...never,never knew and never found out ...well, I had asked for all this forgiveness of the stuff that went on that I knew had came from me...even though she was the trigger and I would just...lash out and o...you know...whatever...I apologized for all that and the hurt that was in the marriage but she never, ever accepted it and didn't care or anything else and just get out of my life so I left it like that 
I'd always...if I didn't go to the hotel and you know, play pool with the lads and laughin...carry on crazy ...I would have a bottle at least at home...so, the day before good Friday I'd gotten a 40 ouncer of rum so that I'd have it on good Friday cuz I knew I was going to be alone and I thought, well, at least I can drink, but I went out that evening...somewhere..still don't really know where I went...and I know I consumed most of the 40 ouncer myself and yet I drove back home and I had a little bit left in the bottle and I went into my living room ...I had no weapons or anything, ok, so I had no intentions of taking my own life but I knew it was the bottom..that was pretty well it ...if I thought the bottom happened with my ex wife and I...there was an even deeper bottom to come to a year and a half later, or two years later ....1984...anyway, that evening I decided I didn't want to live any longer..hey, it's over, like...I haven't got my children, my marriage is broke up...I literally have nothing...course, then I thought about this (counsellor) and I thought...I could go back there cuz it had been a few months... a number of months...maybe six months. You know, she even sent me a Christmas card that year...yah, and I thought that was unusual...you know,'how are you ...I've been thinking about you, and signed it....and I thought, what a wonderful lady, but...other than that, thinking about her, just ...carin'...I thought, you know nobody else cares...if I disappear, what ...you know, what the heck...so , I remember I flicked the tv on ...remember this is good Friday, ok? It's about 10:30 at night...flick the tv on and I went through a couple of channels...(television evangelist) was on...and he... was lookin at the tv audience when he said this and he said..and I was part of the tv audience, and I was pretty drunk, I mean I had consumed over the course of 3-4 hours, almost a total 40 ouncer 
of rum, so I was pretty well loaded, but he said...to me...you know he sez...'jesus loves you so much, he sez, that if you were the only person on earth, he said, he would come just for you, and of course, when he said that you know, jesus loves you so much ...oh wow, that's awesome, and , uh.....I don't remember whether he was still on the air after or anything else but I remember droppin to my knees in the living room, all by myself...prayin to god that he would take my life then ...well, if jesus loves me that much and he came for me, then god, you must be able to end this...cuz... I just pleaded my case then...I said...and I wasn't religious or nothing, ok?...when you hear people getting up sayin prayers just off the top of their heads or anything...I knew nothing about it...you know...any tv evangelists or nothing,...didn't have a clue, but I pleaded with god and gave him pretty much my...my stuff...uh, what I felt and what I had done and the next thing I know, all of a sudden I felt this incredible love and it just came down on me and it was unbelievable , I'm telling you, it would blow you away, and I never, ever felt anything like it in my life before, and I thought, I don't know what this is, but it's pretty strange, and I...was on my knees for about half an hour cuz I was cryin and everything...I was literally emptying myself and um...I stood up about half an hour after all that and I was dead sober ...I was as sober as if I'd never, ever touched a drink ...ever..I just felt like a feather and I had no idea what had happened to me or anything and I thought, well, I guess I'll go to bed and I was thinking about this prayer I had asked god...don't let me wake up in the morning...just take me...take my life ...do...you know that it's garbage...and what good is it here? (laugh)...I woke up the next morning, I had to go to work, and I remember I woke up before the alarm went off ...I woke up about 5 o'clock and 
when I woke up I was wide awake..I was not dozy, anything, or sleepy ...I woke up instantly wide awake ...thought ...oooh, I'm still alive...hunh, I guess god didn't answer my prayer ...this's what I'm saying to myself, so anyway, I went to slide out of bed and I put my feet down on the floor and I couldn't feel the floor, and I thought, oh god, what've you done to me? I asked you to take my life last night and you paralyzed me instead (laugh)...you'd think l'd been on some kind of an acid trip ...it was the holy spirit, I'll tell you that...anyway, I finally stood up and I thought ...well, I can stand up.i. don't know why l can't feel the floor...so, put my clothes on...went to...had a two storey house, eh?...I was livin in...I had bought it around a couple of years before...I went to walk down the stairs...I was...I literally floated down the stairs...never felt a step all the way down the stairs...big old wooden steps,,,never felt a thing...and I went to work and I was a changed person, I couldn't believe what had happened to me...all the hatred had gone out of me...I felt nothing but love,...uh...I reached out to people ...I, uh, I just felt incredible..it was... the most awesome experience I'd ever had...you know, it was months later, of course I wanted to know about this Jesus then...I mean, I learned about Jesus when I was a little guy, eh? Jesus was born in a manger and his mother was Mary and that's all l'd learned ...ya, you don't learn any of this other stuff, so I wanted to learn about this Jesus ...if he loved me this much and this happened to me then who really was he, or is he? So, I got into the bible and I, oh, you name it...I went to church and I did this...I went to bible studies ..but about 6 months after this...conversion I had, and I read it on my own...someone didn't point it out to me, I read this scripture and I thought., oh man, I really did die that night, because the scripture read, 'when you're born 
again, your old self dies'...and it is gone, and I thought, wow...I really did die...my old self is gone, and it truly was, you know. So, getting back to the present day...I still, and I thought I'd gotten rid of all that and I was absolutely sure of it , but, even today I find, and I'm wonderin' if...when somebody comes up and introduces themselves to me..if it's that little cloud of fog ...that's out in front of me still, with people I don't know , they're introducin' ...because I can't remember their name ...two minutes later, I don't even know their name when they're just told me, so I wonder about that, you know... it must be ...something that we have in us as humans and animals have, that...we're still able to defend ourselves ...uh, what's the word for it?...it's very,very basic anyway, in..in, uh, in just being careful..you know...it sure hard wired me, boy l'll tell ya...that was such an awesome experience... I can't even explain to you the immense..power...it was like...it wasn't a bright light or anything...like you hear people say, oh, I saw jesus, oh I met jesus and I did this and this happened, but..no no it wasn't any of that...it was this immense power...and love, and it was a hundred thousand ...a hundred billion times stronger than the sun..our own sun...in the universe here...it was. Well I thought it was going to blow me away ...I thought I was going to blow up (laugh)...you should ask people who got to know me, or did know me after ...they, they couldn't believe the change...what happened to you? Yah Well, I involved myself with a lot of good Christian people,,,the other people that I used to be with ...I sort of veered away a little bit...didn't...can't say that I forgot about them or anything because I still stayed friends with them but I didn't socialize with them after, you know...maybe a little bit but nowhere's near what I was doing before, you know, just quit drinking and of course I never smoked so,...I 
involved myself immensely with good Christian people, you know, people that I knew were nice and people that normally don't judge...now some Christians do...judge...they're only human too, but ..yuyp...it's unfortunate that they haven't learned that...that Christ never judged while he walked on this earth, he never did, and yet they call themselves Christians but they're judging, you know, they've no right to judge...anybody ...and so...those people, that's exactly where my...whaddayacallit would come up...oh yah, because those people you gotta be careful with...you know, especially when you're associating with them .. and I would be able to ....and of course you could decipher immediately...oh you have this ..you have this, oh, I'm trying to think of the word for it now, uh...ability...to immediately...tell what that person was like...now...this is not a judgement factor, ok...like you got...I know... I had to be careful cuz I would think...'am I judging that person?'...or do I really know what that person is like without judging them and of course this is where I would go with it and you would know immediately, almost immediately, what that person's vibes were towards you...oh yah, you felt it, and so I could distance myself from that person if I thought it wasn't right ...you know, and so on and that's the way that I carried on since 1984.

People used to be afraid of me...funny, eh?...and yet I used to get abused by some of these big thugs too, eh? Boy, let me tell ya, one guy in particular...he was mean with me ...oooh, but you know, after I...after I, uh...had this experience with the lord, I was able to talk about it easily...I guess that's part of the healing...getting it out and for those in the Christian circle...in the church ...or whatever, there were 
certain individuals you could talk to you know, and that was part of the healing process...it's funny, eh, some people...if you watch these evangelical shows and stuff you know, you're healed right now, everything is gone...well you know, I'm a little skeptical about that ...maybe sometimes that could happen, totally ...but I think god intends us...he takes us down the path, and it's the path of living ...it's the path of humanity and it's a path where he wants us to learn and he uses our healing in there as well, where we're going to be healed of certain things, because I think if we all of a sudden say, I've just been totally healed of everything, what have we learned from it?

If we go down the path and walk you know, and walk, I'm not just talking about the path of righteousness, but...I've gotten to know you, I've gotten to know other individuals...this is the path I'm talking about...we learn a lot and we heal a lot...we do that and it's a life long journey and I think that's basically what god does with us...he takes us on a life long journey...I suppose you could say, well I'd like to have had it instantly..and everything would have been fine, but what am I going to do...put myself in a bubble? No...i don't want to be in a bubble

I was able to do astreet ministry after, with major thugs and everything ...guys involved with murder..i could walk into an outlaws camp with no fear...nothing ...absolutely no fear...I mean, you'd assess the situation immediately, when you walked in or whatever and I guess you would know...right off the bat if somebody pointed a gun at your head whether he was actually, you know...just trying to psych you out or what...or you would know immediately...well, this guys not going to hurt 
me ...this...to change from before...like back before I would've just stayed away from people like that...they want to hurt me ...and after, I was right in there...to help them, to talk to them, I wasn't in there preachin to them, ok?...i had guys, one was involved in a murder and the crown released him into my custody so that they could use him as a crown witness and he had murdered one of the outlaws ...you know, so that's pretty dangerous stuff, cuz they're comin after him...yah...I had no fear whatsoever...well, I'll take care of this gu... oh, totally different altogether...and I showed that guy...love...this kind of love that l'd had now...you know...I was able to show him that and calm him down, you know, and hope to have changed his life...now, that would only be... a seed being planted ...you know, I'm not the one that would have changed his life..it would only be a seed cuz ...going back to (counselor)...she planted that seed, which, you know...evolved... and then you know I would hope that this seed towards that person, would take the same effect and that's the way you do it...you don't go in there you know pounding over their head and this and that... you don't do that...you know...you just love them, that's all. You show them that you care for them...this one individual, I found out that his father almost killed him when he was 12 years old and he's been living out on the street basically after that...course, can you imagine what he would have thought of authority figures? The same thing I felt before as well

Rebuild the whole thing...everything...you name it...so I bought him this snowplow...I said,,here's this snowplow.,.,If you do the work for me ...I wasn't giving...it was a gift of love really but it had an attachment..i thought, well this man's 
so talented, maybe he can help me out, so this, and I actually made the deal with him face to face ...you help me out in rebuilding this truck, I said, and you can have this snowplow...well he's never, ever bothered to help me out and I'm fed up with it...I'm totally fed up with it...I just told (wife)...I said ...that burns me so bad...especially after I made this deal with him and he hasn't lifted a hand to (sigh) ...I'm beside myself really about it, because he's my nephew and godson and I don't know how to handle that because I..I put this wall up now...this wall's up between him and me ...yah....and I trusted him to do this ,...to help me...it's not a good thing (laughs) what's...what's ...what's the...uh...once bitten twice shy...that's the stage I'm at..i'll not do it again...ever...or maybe anybody else, I don't know, because I know I won't get results, and I think that's what D, my brother down in (small town), might have been referring to...when (participant) gets loose...he gets loose...you know I usually carry it a bit extreme...I mean, that's probably a bit extreme and I'll admit it, but what am I going to do? Should I have drawn up a contract and had him sign it and now I go to the lawyer? That's not the way I work...I trust people . ...it's just hard for me...here I had a friendship with my nephew and godson and it's being destroyed and it's not right...and it's a two way street...it's part of my decision too if it's going to be destroyed..yah, that's right ...the only way I can make it right now is go and take the plow away from him (laugh) and I'm not about to do that cuz I gave it to him out of love...well I already told him this summer...the past couple of months, you know, I need help, every day and I said, you know that...he's never responded , and I told him face to face ...this wasn't over the phone...my first response would be...I know you've rebuilt a trailer for another guy that's not even 
related to you, that's got no money for...I know this guy is using (nephew)...all the time...(nephew)'s done all kinds of welding on this trailer ...redone the whole thing...he's been doing stuff for him all year and he's done work for his brother P, which that's ok with me ...keep it in the family, but he's never lifted a hand for me ...terrible...well it's like l'm nothing to him...kick the dog again...here we go back to the dog again...that's fine too

I had a terrible argument with one of my blood brothers...I could stay here all day and tell you these horror stories, but anyway .....this had to do with the murder of our sister...about 5 years ago ...we had a brother that lives in (city out west)...south of (city)...down towards the ...not too far off of the (American) border...why he wanted to get closer to the Americans, I'm not too sure, although he's worked for them...um...but anyways, he's been long retired now...he was the first born, but about 5 years ago he was down visiting my brother and his wife and (my wife) and I were invited over, but anyway, to make a long story short, the two of them informed me that our sister had been murdered, one that my blood brother and I had never met...but she grew up with...my oldest brother...(oldest brother) nor her were ever put into the CAS...they grew up together and she went off to...she was smart I guess and according to him...I would have had the chance to meet her if our family had been more forthcoming and that, because at that time (brother) and I had met our aunt, we had met our older brother...we were living in (city).,I had moved to (city)and went to ...tech high school and we met them there...the children's aid...they did respond to a rather embarrassing situation that did involve my 
brother and I ...they did respond fairly well to that...you see my brother and I, when we were going to technical high school, we decided to look in the phone book...write down all the (people with our) last name and we were gonna go knockin on doors, which we did. Well apparently there were some (last name)'s there that were no relation at all, of course, that were fairly high society...one was a brigadier general and I don't know what all...but we would go knockin on doors..."hi, hello, it's (we have the same last name) and we were wondering if you were related to us...we're looking for our mother and father" that's kind of embarrassing ...to them...so the CAS got notified and we had a visit with them where we were living...I never called them my foster parents where we were living, as far as I was concerned I was just boarding with them, but my brother had been living with them for 4 or 5 years so he was a foster child...me, I was already 16 when I went there and to me it was just room and board, while I went to high school. So we got a visit one day...poor Mrs. K. and Mr. K...I guess they kind of shook their heads themselves, but the children's aid said, look, you have to stop, decease and this nonsense and we said, well, this is a free world and we're old enough now that we're gonna find out where our mother and father is now and you can't stop us, cuz we went around to firehalls ...you name it, everything, plus private residences and the only reason why I mention firehalls because we were told that, there was a possibility that one of our fathers or, a father, and a brother, worked as a fireman in the Ottawa fire dept...I still remember one of the fire depts.. we went to...oh my gosh, I wish we...in a way, technology would have been great then because you needed a picture of some of these firemen when we went in and said, " hello we're .... and we're looking for our ...either our brother or 
our father who works in the fire dept. Well there was a couple of them in there, their faces just went white, because my brother's father was an Ottawa fireman...not my father, but his father and, I am telling you boy...there must've been a lot of scramblin going on because we didn't get anywhere with that...so children's aid visited us...I don't know if they wanted to give us the strap or what, but we just said...back off...we're doing this, whether you like it or not...what are you going to do with us? Lock us up, just because we want to find our parents? So, next thing you know a few days later...this aunt appears out of the picture...so we got to know our aunt Q...superficially, and I mean superficially...she was our real aunt, my mother's sister but talk about superficial...she was looking after our grandmother...living in the same place, she was looking after her mom, our grandmother and would never let us visit her...any time she ever had us over to the house it was after 8 oclock, 9 oclock at night when granny was in bed, sleeping .... With $Q$, our aunt $Q$, so l'm talking about superficial, very very deceptive, so then she ...figured oh well, we might as well meet A, the oldest brother..he was down in Dartmouth, in the navy, so when he come home we had a big meeting with him..'oh, you're my brother? That's nice...well, what can you tell us about....?" ...nothing...absolutely nothing...never even told us about this sister that...lived there...grew up there, so...coming back to 5 years ago...A's down to Q's with his wife and informs us about this sister. He'd already informed (brother and brother) had not told me, which turned me right off...that she had been murdered about 10 years after our mother...details were a little sketchy other than that she worked for (federal politician) department in ...oh, what's the...internal revenue...external affairs, that's it...anyway... pretty sure she worked for him...at 
least this is the story he gave us this day 5 years ago...that she was murdered in Washington DC...I have a friend of mine who works for CSIS...retired...still does a bit of work for external affairs and I found out that he knew...my family growing up...in (city)...so I asked him about this sister...you know what he told me...and he couldn't give me any more details other than the fact that she was murdered at the (downtown hotel) and it was all covered up and this was while she was working for external affairs, so I have no idea what ...this story that my brother was trying to give me, didn't jive, and then on top of that, him and $Q$, our aunt, not allowing us to ever meet her, telling us about her till 5 years ago, so I said to (brother), you know, 'why wouldn't Q say something?' and he said, I don't know, why don't you ask her? ...oh. Ok, I'll ask her and she denied that this sister ever existed, so I blew right up, and I should not have, but I said,'you know, you (last name)'s are all liers...I can't believe a thing that any one of you say...that was basically 5 years ago, the end of my relationship between my aunt, my 2 brothers and me ...it ended right there...family feudin...

\section{Participant 2- mid 60's, retired farmer/carpenter}

I mean, how many people can say that? Not very many. I know so many people our age, well, I guess this is the way it's going to be. You know, this is my fate, and we're 
stuck. We can't afford to not, we can't afford to live in two places so, just do it. I can't imagine living like that, having to make that decision, but I know so many people our age that have made the decision and they're poor. Monetarily and emotionally it just ruins their lives. And I don't understand that. There's so many things that I don't understand. I was raised by a Sergeant Major. My dad was a Sergeant Major in the army and his world was black-and-white, period, and my worlds getting black-and-white. You know, his ideas on gays, and transsexuals and whatever, it was black-and-white. I'm $0 \mathrm{~K}$ with that. I mean, I don't agree with gay marriage but gay unions who cares? I mean, for me marriage is for men and women but if two people want to live in a relationship, have at er. Good for you, I mean, if you're happy, good enough. I rode today with a girl who's in a gay relationship and they are happy and good for them. I don't know if they're married, they may very well be, but as far as relationships goes its black-and-white. You get married, you don't fool around. There's no sharing, you just, you get married.

In the states they say they create jobs because you need people to service the welfare people and then they get money and then they go spend it on whatever, and they also spend it on lottery tickets and booze and cigarettes so there's lots of taxes the problem is, where do they get the money from? The hard worker, you know, wealth redistribution. Work like hell and then pay an enormous amount of taxes and give it to the people who aren't being productive. It's just wrong and I have no problem with helping people but help them with, here is your bag of groceries. Don't give them money. Give them food, and by the way, were going to show you 
how to cook this egg and potatoes, and meat rather than taking the money and going to McDonald's and buying, whatever. You know, that's how I envision helping these people, and it's a generational thing, you're not going to help this generation right away, although supposing you took 100 people and two of them learned how to cook a nice meal for the kids that would be a good thing. The thing is that their kids are going to learn how, so, then we start with a little and it starts to grow, rather than just giving to people

That's all I wanted to do too, I didn't wanna get rich...i just wanted to be able to make a living at it. you know I mean we had upwards of 20 cows at onetime and a penful of pigs \& 100 chickens and Strawberries \& raspberries and nobody wants to pay for it and that's the way it is now they'd rather go to Wal-Mart to pay $\$ .29$ a pound or five bucks a pound for fish rather than pay 10 bucks a pound for something caught in Canada, well it's easy to know what to buy because we have china and it just became very frustrating. People go, well I can get it cheaper somewhere else and I'd just go, go for it, you know, and it just doesn't work as a business. You've seen it, I've seen it and it's a ton of work, you know at this time of year you'd be out picking stones and friggin around cleaning fence lines and fencing and what ever and as enjoyable as it is it don't pay, it don't put food on the table. It doesn't create a pension. I watched my neighbors work themselves to death...or (previous owner of our farm), that's all they did they just worked right to the last day they could work. I didn't want to do that. 


\section{Participant 3-mid 50's, social worker, living in same small town he grew up in}

I think back to going to a playgroup that's predominately women and going to that playgroup for three years every Wednesday for three years and still getting the look ...'you're a...what are you doing here?...what the hell are you doing here and get away from my children.'.That kind of thing. I was in a home not too long ago and a little girl just wanted to show me her toys but the toys were in her bedroom..it was like, 'I can't go in your bedroom sweetie, I'm sorry.' The parents were right there and they gave me permission and I say, 'no, I can't go in your kids bedroom'. So, sometimes that's difficult because you have to balance what's reasonable as far as societal norms against the innocence and beauty of a young child who just wants to show you her toys. It's just the perfect innocence of that, but...all you need is the little girl to go to school and say 'XXX was in my bedroom', and then all hell breaks loose. Not only, you know the threat of allegations is...very real, particularly in my role working with young children and not only do...would I suffer, but I have a lot of family around here and they'd go through it too and I have to keep that in mind because it's limiting, because you'd just like to, I mean you know very well yourself, you've got young kids too, I mean young children and young grandchildren and you just want to love 'em up, you just want to unconditionally love them...I mean...give them...what they give you, but you can't. 
I'm sure there's other ways of dealing it but I haven't found them yet, so I just have to have those boundaries because it's safe and you know, the whole world's about 'cover your ass', and...the threat of allegation is a very real threat, I mean, that's one of the first things I talked to my bosses about when I first started doing in home work 13 years ago, and they're only going to back you up as long as it looks good on the agency. You really have to be careful.

Well, I've been married and separated twice. That's always a big change and then the fallout from a family perspective of all that. That's been an unpleasant learning experience in both cases, even with the fact that it was an amicable split with both...parties, it still doesn't sit too well. It's not one of my prouder moments. Step kids have been a large effect in my life. Umm...I didn't have any exposure to step kids in my first marriage. My second marriage there was two kids and they're still very important to me although I only see one of them. The younger...my step daughter is just kind of ....faded me out, which is ...still an open wound, but...I don't know whether I'll ever be able to deal with, certainly won't be able to deal with that on my own I don't think. I need some input from her and I don't know when I'm ever going to get that, so....it's a source of frustration, but my step-son, I went down when (current partner was on holiday) and visit with them and we had a $2 \frac{1}{2}$ hour visit and it was great. There was no tension, no friction, there was no nothing. I was coming out of my (family member's) store on Monday afternoon and I ran into my ex and we had a 5 minute chat on the street and it was fine you know, there was no animosity, there was no nothing, and I'm proud of that. My current partner has two 
kids that I don't get along with at all and that's a great source of frustration in my life because l've never experienced that with people who will go out of their way to really be...difficult. I mean there's got to be a part for me to play in that but I don't really know what I can do about that.

\section{Participant 4-early 80's, retired farmer}

Lightning rods and installation...I was a lightning rod man, I could climb, you know, you know...the only break I ever got in my life...I was always an awful good salesman and we'd run out of work so (the owner) laid us all off, you know...so....and I was getting married that spring and I had a fair car...I had a monarch...maybe 2,3 year old ...and the payments were $\$ 44$ a month on it so I had to work steady and watch my dollars to pay for it and still take my girlfriend out ...but anyways...I was lucky...the board wasn't bad cuz they fed you on the road...but you're workin anywhere...but anyways...when I got laid off, I said, if you're short of work, why don't you let me try sellin?..'do you think you could?...i said'damn right I can sell'...I'm going to have to do something because l'm getting married in a-pryell...and this was in the winter...well, if you want to try it...ok...so they were paying $20 \%$.if you sold a $\$ 500$ order, you got $20 \%$ for sellin it, when the job was done, you know...when everything was...sold right and all that. So, I knew she was getting lean and I had piles of prospects all roped in so out I went, selling like I was crazy and they used to expect you to sell 500 a week ...that was what was...your quota...if you 
weren't averaging 500 a week, you weren't long sellin, so...I went out and oh...I wrote orders like crazy ...so, they were scared of my calculations so they sent people out behind me to see I was right and I was so this went on for 2 or 3 weeks and I was really haulin in the money...it was going to be great for my...for getting married , and....all of a sudden I went in one morning...big new monarch car sittin there ...(Owner) sez, 'we got a car for you...you're on wages...we're gonna put you on wages now...no more commission'. So, I got to drive the new car for one day and I come in and I said, that's enough of that for me, I'm not stayin'...so I was about to get married so I quit and I got married and out comes (the owner), coax me to come back to work, and (wife) and him got into it in the yard...he wanted me to go down to the parliament buildings to put lightning rods on all them sleet roofs and I said no, cuz I'd done enough of them church steeples, them real high ones...I done that catholic one in perth and all them...that's high climbin'...she said,' that's the end of that' so I never went back, and I didn't want to sell either....away all the time, you know...they'll say you need to sell, you know ...way the hell down country...you know, some place...like they sent me to Kingston one week ...just up and down the street knockin doors, and I come out of there damn good order...there was men that was with them a long time and I was doublin their sales ...you know

If I'd a thought it today, there wouldn't be anything l'd own than a chainsaw and a woodsplitter...that would be IT! ...and the skiddin cart that I invented that I can hook onto my splitter...ball haul hitch that I can drop on and I could pull it where I wanted and back it in and park the truck here with your elevator and be out of the 
bush and be onto the truck and could do it all with one man...but a load of wood now is a hundred a cord..it's 12 hundred bucks and agin you pay the taxes and all that, it's close to $15 \ldots$ and if you dry it , you get an extra ten a cord...that's all, so it tisn't worth your dryin'...another thing about your dryin if you've got the money to do it...if you've got the money to pile, then you've got dry wood for sale...but dry wood is a problem cuz the people that wait till fall to get dry wood ...they got no money...and they'll cord you to death...I want a cord,I want a cord, I want a cord ...some want a cord twice a week, you know what I mean....that's the only way they can pay ya...now I was in it a pile of years and I had a pile of clientele...when (son) got the wood business from me, I give him the wood business...he got everything free..it didn't cost him a cent and I was bid 50 thousand dollars just for my clientele...I had 900 customers in the book that were phoning for wood, you know ...and, uh, (son) got in with (his friend) went 50/50 and uh, it went to 200 awful quick, cuz the F-you type of thing don't work. (Son) don't work that way but that was (friends) attitude and he was the oldest and runnin the show ...so, he bought (friend) out and went back at it himself and he got it built up to maybe 5-600 and then (friend) took a notion to want to go back on a real deal and he had to buy (friend) out again and that was the last of it, so he went through them 2 episodes for nothing...but anyways....as far as J now, he's makin a living but he's the same as the guy with all the equipment in the bush...he's just....paying for the equipment...yah...workin hard to pay for and when it's paid for, it's all wore out long before the last payment's ever made...treadin water...farmer's are doing the same thing...you know l've dealt an awful pile with the Mennonites and the way they go about things ...you pull in there 
with a load of cedar posts...they'd order a load of cedar posts which was worth $4500 \ldots$ well, now it would be worth about 8000 dollars...then, when I was at it, it would be worth about 45, 4800 dollars, and you'd pull in with a load of posts and there'd be maybe 20 wagons there and teams and you'd be there in the morning and they'd unload it by hand onto each wagon and away they would all go and have their dinner and make a party out of it. I pulled in one day ...oh, the old lad was happy, oh, they're beautiful posts and he said...I had two trucks with me, and he said, what are you doing with that other truck?...well, I said, I'm going ahead to a...there was a store in town had ordered a load...not compulsory but wanted one soon ...I said, I think I'll go up there with it...oh, he said, my neighbour just across the hill there, he could use that load ...I'm sure he could . Well, do you want me to go over and see him?..oh, no, I don't think that would be necessary...now he had a buggy there with an old chum tobacco can...an orange one, you know...he said to the son, go and bring me that can so I pay this man, so he went over to the can..no, no, not that one, the other one and he brought me it over and he pulled out all hundred dollar bills...paid me...well, he sez, I myswell pay you for that other load right now...well, do you want me to take it over there?...no, no, no, no, just put it there in the ditch he said, that'll be fine ...l'll see him, maybe church on Sunday and he paid me for that..one was 45 hundred and the other was 48 ...the two loads..you know, that type of thing. He'd 9 sons and this was the seventh getting married and bought them all a farm you know and in the barnyard, you were there you know, there was a bunch of young lads getting the buggies shined for the wedding on Saturday ...and fixed up, and the neighbours from 
around would come leadin a cow or leadin a pig or bringin something...when he started the next day ...he was gonna have...stock, so he was...I never seen the like I bought (first) farm you know...I only had 37 dollars in my pocket when I come in over that hill..and I bought it in November but I couldn't get it till May but Dad had it full of cattle, he was livin up at (village) but the barns was full of cattle, so I couldn't get it till May so I had to have 12 thousand cash on the first of may...and of course I was dealin hay, that was the dry...when I was dealin hay like crazy so I had it in $\mathbf{1 2}$ thousand cash on the first of may but it was every cent I had ...and of course I had the mortgage to start, getting stocked, you know what I mean, and that was 24 years before I owned it, you know what I mean?...just about get it paid and take a nother notion to expand or something like that ...you know, so borrow more money, and I was on it 29 (laugh)

The swiftest way I know to make a good wage would be to make a deal on a bush, and you don't have to buy a great big bush...a part of an acre or a start to an acre, and cut stovewood....the big deal is ,...(son's) in the wood business...he's got to pay the tax and that to get it off the government land and tax on the truckin and tax and tax and tax and when he gets to the old ladies place ...to dump his load...he's got to say Ma'am you've got to pay the tax...I can't get out of it and that's so many percent on $1400 \$ . .$. you see what I mean...Me, I just cut off your place up there and sell it all day and nobody would ever know I was up there and if you took a look in my billfold in a months time, you'd fall over cuz you wouldn't believe it, because the old lady would buy off me first and give me more money for my wood cuz I don't have to pay 
that tax...and it's legal...I can go 30 thousand dollars...now which 30 you talking about? There's no strings on me as long as I...now I was seven and a half years cutting up here and the deal was...when Friday come...whatever wood I went out the gate with....I deposited in the bank...in his account...he lived in (city) and I kept that up very faithfully cuz he had two kids in college ....he couldn't afford to keep them there without it and we kept shipping it for...we got a few veneer logs...he got a good price for them...and we did awful awful well...awful well...and then I slowed down...one got out of college and I slowed down and the mines back there...(acquaintance) was runnin it and coaxed me to come back and take the bush out ahead of the mines as they expanded and we worked that...I did that for $4 \frac{1 / 2}{2}$ years ...at tatlock...and that was good...didn't cost me a cent and I got ...it didn't cost me a cent for the wood and I got paid for doin it (laugh) so I was comin out of there with good money ...real money, and I had 2 men with me and I drew all the wood to (city)...I was getting 85 a cord for it...it was $\$ 850$ a load and then every couple of weeks I'd get a cheque from the mine for doin it, and the new roads and that, I cut them all out of the bush for them ...with the horses, you know what I mean, and I'd a stable affair made up for them there to stay in and corrals and the whole bit, and it went good and it made a lot of money...well then...at (local operational headquarters for mine) they fired the foreman or the head super and brought another lad in from another country and I was there a day and a half after he got here ...he thought that..."a horse in the bush and nyah..." he got rid of that ...and (local contractor)....he got the job with a big skidder and he just smashed her for acres, you know what I mean....and then they sent big bulldozers up there and just took the slash and 
pushed...you know....pushed it down over cliffs and into swamps and all that ...that's the way they went about it...and when I was cutting...different approach...so then we come back up here for another $41 / 2$ years ...but it was..it was good goin'....good, good, good goin'

oh, yah, but they died of old age...one (pony) died out here 42 year old yeah...(son's)... I bought him for (son) when he was $2 \ldots$ oh, and broke to death...just have to talk to it ...and my good ...(name of horse) mare, she died of an aneurism about 22 and my grey team, they just died 33 and $34 \ldots$ (name of horse) died of an aneurism about 27 but the grey team they just died of old age that's all...they were 33 and 34 and then we lost one that we call the colt...they're 23-4 now...one is and the other one took an aneurism a year ago ...(name of horse) ...she died at 34 , last spring or a year ago ...oh, died fat too...good shape ...and I had a lot of good years out of them but they just got old too..like people and died....that's all......(name of horse) the only one we got left of them all...and he's...we call him the colt but he's about... he's gotta be 23 .

In my days we'd (post yard)'s ...I well remember, I had a truck and I could cut like hell from the morning till dinnertime and the wife and the kids snipped brush and I loaded the posts on the floor and the brush on top and used to put 2 ropes underneath the brush to pull it off, you know what I mean...and then we'd have to go unload the posts...you know what I mean...but the posts would bring somewhere between 50 and 60 dollars and the brush would be about about 10 dollars behind 
it...40 to 50 dollars...and that comin into the house today and then tomorrow you might get 2 loads and so on...yeah, it was good goin...well no, the damn posts...it's like drivin a schoolbus, you know what they want to give you now is 2 dollars and a half for a 6 inch top ...10 years ago... well it was less money, but not a lot...well, wait'll I tell ya...(grandson) bought a farm ...I don't know how he managed but he bought it...200 acre farm...a hundred acres of good land and a hundred acres of bush with a hell of a bunch of good cedar on it ...so (trucking company) got slack and I said, for god sake man, you've got a team of horses, and you've got my harness, you've got everything you need...whiffletrees, you name it...go to the bush and cut cedar and sell it.....'well, how will I sell it?'...I sez, good god man , the way I always sell it...you advertise or there's people out there want a pile of cedar..i had an awful good clientele on ( Large island)...I drew an awful pile of cedar there...now if (post yard) charges you 4 dollars ...will pay you 4 dollars a post to deliver to his yard..i want you to take the first load there and get his price list ...and home he come...well that's the last cedar I'm cutting, cuz look at all I got...it's no good....i said, now you take that price list and double the price ...get 8 dollars for your cedar post ...and advertise...course, she's a cracker on the computer ...crackerjack, so ..he advertised on the computer, or on the...whatever it is ... I don't know what it's...I don't know anything about the computer...and, the phone took to ringing ....and he sold a pile of posts at 8 dollars a piece...and rails at a good...I made out a price list for him...and we doubled (post yard)'s or more , and he's nothing to draw them with...he had a good half ton truck so I sold him my trailer ...so, he was doing great, but ...his trouble was...now listen to this...he could not cut a cedar post unless he had it sold..he 
couldn't go to the bush and cut piles of cedar all along, you know what I mean..he could stay home if he'd no orders, so he'd get orders..he'd run all thrugh the bush looking for a 6 inch post, or a rail or a footer, or whatever the order was, you know what I mean...or a big post ....so logs were payin a quite a good...like they were 650 a thousand..so he took down a bunch of logs and he come home...well he'd never do that again...all them good logs for that price, like, uh, cedar lumber's a dollar something a foot, well anyways he worked at that...well, the horses weren't fast enough and you had to harness and you had to this and that and he stayed at that for awhile and he said he never made so much good money in his life but it was too much like work so he went back truckin and right tonight, he's in Alaska, you know what I mean...he got a load out of montreal for Alaska and why he got that job is because he...2 winters now he's went up and drove on the ice..you know...them ice roads, drawing fuel..airplane gas in and all that stuff...making big money but he's not gonna be home for 2 months because when he got out there, they loaded him for Edmonton, and they loaded him for Vancouver island and then he doesn't know from then on what he's gonna do

Well, my rules are...I get up in the morning and generally have a coffee ...game of cards or some stupid thing and then I feed my ponies then I come into breakfast...maybe get up at seven you know ...come in to breakfast and then I go out...and farm here that's what I do...I have nowhere to go, nothing to do...there's nothing registered on 
oh yes...well, you gotta be honest and straight...forget the bullshit nonsense, trying to put over somebody ...you got...in the wood business, you got ...what happens is...everybody advertises and they'll all advertise 15 dollars...they'll be 85 dollars when you're 100 that's one , because uncle...they're cutting on uncle's fence and they steal half of it you know, you almost have to..if you left a stick overnight you wouldn't have it in the morning and you see it go down past here in a trailer...car or half ton or such....and that'll be advertised for the cheap price ...wouldn't be enough to put you overnight hardly and they call that a cord of wood and you're no more face cord than...it's just stupid...you know what I mean, so that was one thing again it ...the next thing is...no tax...and when you get there and dump your load and you gotta say tax ...it takes...so, if you don't work the clientele...go into a man's place...be damned sure...no matter how he piles it ...there's gonna be lots of wood there for his order ...be sure it's split the way he wants it and if you promised maple or beech in there or whatever you promised, be sure it's there and if you do all that they'll phone you back in return...there's an odd son of a bitch who'll dump his load he has a bunch of drunken friends and they'll load 2 or 3 half tons up and phone you and say they're short half the load and if you don't bring it tonight..if you don't bring it we're gonna tell all the people around here and you're done bringin wood in this area ...you know what I mean ....and I go down and say lads...I'm gonna tell you a story...lads, you get no more wood out of me ...if you were short a wheelbarrow load, I could understand, but no, and of course a big fight and fuss and then there's an odd fight over payin you, but ...out of the new guys...an old customers ....cheque waiting on you everytime you go...knows he's got to pay and...every time...clientele 
that's the only thing...look after people...now something that happened to me a week or two ago...(wife)'s washing machine quit...only one thing to do...go and buy a new one ...so we went lookin for a damn washing machine...the first place was the brick ...well, they had exactly what she wanted...everything on it...great...nine hundred some dollars...no...maybe 7 ...goes over to..depot and they said 9 hundred...the identical same thing...and I said..well, thanks, we'll go lookin' ...just about to go out the door...regardl;ess...we will match anybody's price ...regardless...if you bring a bill...I said, mither, you got that thing in your purse, she said yes, I said you see that sign?...she sez ya, is ez ask about it...c'mere man, well they was talking to us...you see that sign over the door ..we'll match the bill...we just come from the brick and here's the paper that the brick has it all wrote out what they want...same thing as we're talking to you about...identical same number machine and everything else...oh, and uh, ...well, we'll have to match it, so they called the boss and ...yeah, match it, there's only one thing, l'll do better than that..he saz if you'll wait till Wednesday I'll deliver it and I'll hook it up for you, and I said, that'll be great, and for 10 or 20 dollars, if you want to get rid of your old washing machine the boys will pick it up while they're there and I said for god sake give them 20 dollars we've got to get somebody to draw it to the dump and pay them anyway...so ok, the machine comes ...well, you gotta put new hoses on or they won't guarantee the machine...we don't want you callin back in a week ...so ok..give me new hoses ..now this story I want to tell ya, I want to show you so ...I bought the new hoses for the machine and I got home here, our hoses just brand new as theirs was but we had to put them on and we unscrewed thm off and we tightened the old tap 
and it's 22 years since we moved here, or moved things in, so they were rusted and they took to leak on the floor so I said, lookit, there's only one thing to do with them old taps is to have them changed, so I phoned (plumber) to come and (he says) I wish I could help you out but I'm so far behind I couldn't get there for 2 weeks to save my life...you're gonna have to phone somebody else so I phoned 3 or 4 and got no answer ...I phoned (other plumber) that bought (plumber) out there...well yah, we'll be out soon..i'll have to call you back with the time...they were about 2 days getting here with about 6 different times ...it was the morning ahead of when the washer was gonna come..now I'm going to show you this...you won't believe it...just come here and see this...you see them 2 taps there...that goes through the wall there and they cut a piece of pipe out and up to there and the parts on the bill said 24 dollars and the bill was $\$ 558$...now how in hell...and (wife)'s all...oh, do this and do that and I said, what the hell are you going to do?...two feet of pipe...well what are you going to do about it ken...well I'll tell you what you're going to do, them bastards are (indistinct)..just go in there and pay the god damn thing ,...so I paid it...that's alright...just a few days ...the water acted up..(wife) was blamin' them but it wasn't it at all...22 years ago when we moved here they drilled my well...to the bottom...Dad twitched it and he said, it'll be about 65-66 feet and at 64 feet we'd piles and piles of water and I said run it down farther so we'd lots of headwater so he run it down 84 and I put in a new pump one of those ones that go on the bottom of the well and there's a thing and a motor and all that underneath here and everthing worked perfect but it...it acted up...so I phoned (plumber), and he said...now when I made the well old (cantankerous neighbour) was around here and he said"you can't get 
water and he had his couple old cars parked in the barns up here and he said "I still have rights" and all this and I said get them the hell out of here so I loaded the old cars and took them over and dumped them off in his yard then he didn't want them there...had to go pick them up and take them to the scrap...but anyway I was drillin my well and "you'll never get water" and " the water in that country's no good " and on and on and I thought, 'you old bastard, and I've heard all sorts of stories about him if I drill a new well and it's up, out of the ground, you're going to dump something down the well, and I was scared, you know, because anyways, all right , so there was an awful pile of fill put in so I just put a pail over the top and my well was down in there...so, (plumber)sez....you know there's a wire comes ...a wire from undergound...to the meter there and then around to the back to where it's hooked on to the thing...he sez, I gotta call a man to dictate where that wire is because I can't dig...I told him it was $5 \mathrm{ft}$ down but I was wrong...(wife) sez it's not 5 $\mathrm{ft}$ down, not at all. (Wife) walked out told him right where it was so he took his machine ...then took the shovel and it wasn't down 8 inches so anyways, alright he come and he said he's come and they he dug it out with a shovel....i thought he'd have to bring a backhoe but he dug it out with a shovel, but it was long...took him about 2 hours ...pulled the stuff out of the well and put me on a new one and put it back in and covered it up and I was telling him what I got charged for this so he said he was sorry he couldn't come and all that but he said, 'oh, I won't hit you so hard, but (son) got his done...it was $\$ 3000 \ldots$... don't know what this is gonna be ...it was just done yesterday like ...the bill won't be long comin...so got that to pay for but the trouble is your pension don't cover it...just keeps grindin into it you know...so, i'm 
80 some and I told (wife)...Stop...she's going to mexico on a trip with 7 girls..a bunch of her daughters and her friends and she's fussin...and I said...the hell with it because we're good for it...if our money is slow, we're gonna have to sell out and get the hell out of here anyways in the next five years so just don't worry about it, you know...we're alright, we've lots of money to go on...that's what I do for a livin...play with the cats and the ponies and the dog ...don't make any money but

Well, when I was telling you about this guy here with the pipe , that's why I told you that story...that lad will never get a call off me again...now, (owner of that company) owns a lot of stuff ...he didn't make that bill out but that's the carry on that's going on ...he took over that...and I don't know why...he's a commercial business...one time back when (daughter) got married..that would be 25 years ago ...i...she wanted to have the wedding at dads...at (local village), and she wanted this and that, so anyways she wanted it on grandpas lawn..she wanted to use (uncles)'s harness, my team and grandpas wagon to pull her in her wedding instead of cadillacs and all that ...so alright, but she wanted to have it at grandpas, so you had to..it was the $24^{\text {th }}$ of may weekend..you had to guarantee that the weather, so I got a notion to make a tent and I was working in the bush and I had an awful pile of logs ....cheap...so I had them all sawed and I made the frame of the building and tarped it all over and we had the wedding in it...it was a hundred and something feet long and it was 60 or 80 feet wide and I put it up right in his yard out close to the telephone wires at the highway, right straight back and he had a lovely uh..one of them trees that has white bosums on it, whadaya callit? ...stuff like that...a lovely tree...I covered right over the 
top of that that the head table would have this big tree with all the flowers ...and...that was a hell of a fuss...department of highways were gonna tear it down...they sent the police and everything else ...one policeman I knew real well...out he come and he sez..'you know... why I'm here?' and I said yes and he said, 'tell them all to go to hell' and he got in the car and left. I phoned Kingston and got hold of a girl up there and told her the situation and she said they're goin down here today, this is Thursday...I'll send them to Bancroft and I imagine they'll get around Monday or Tuesday, could you have it down?...i said I sure could. Monday morning, went to take it down and (owner of plumbing company) ...him that sent the bill, stopped in and said, 'how much do you want for this? I want to buy it for a ridin arena for the kids :' I told him a hell of a price...2000 some dollars, and (groom) has about 6 or 8 brothers and they all come and helped me nail it together one Saturday morning so it didn't cost me anything you know, except a bit of the red pine lumber so I got a good sale out of that case and he paid me cash for it, so...I give it back on this ...

I remember one time I was up in the ...around st catherines to Niagara falls area sellin cedar posts...and times were tough ...I had gone and gone and tried to sell...I was up there the last two weeks and never sold a dollars worth trying and (wife)workin at the (town) hospital makin money to keep me there..it was hard tough times ...I phoned home and I said...Hun...it was Thursday...I myswell come home, and she said for gawd sake come home or we'll have no money left...c'mon home and ta hell with it...we'll figure something out ...I sit down to have a coffee 
before I headed home, at this big motel ....a friend of mine come along...and sit down beside me..'well ... how's it goin?' I said 'turrible, I never seen any worse in my life, I said I just...not selling anything'...staying in motels and hotels up here...my wife phoned me to get in the car and come home so I'm just havin a coffee before I go home'...' well, I'm havin the same trouble...guess what happened to me...I was gonna phone you this morning but I knew it was no damn use...'...'why what's wrong?'... well, he sez, ' the government is putting a play pen in up at...at Niagara falls ...a big..yard affair or somethin' and they phoned for an awful pile of cedar...long cedar poles ...and...he said, I knew you could get them but I didn't have any money to pay you,...there was just no way...and I said, gawd, I wish I could work something out because I'm loaded with them...every dollar I own is tied up in them and I've had then awhile...beautiful poles...long ...and I have them up at (Ottawa valley town) ...all in a pile, ready to go...I wisht I could make a deal with you but he says, I got no money...he says, l'll tell you what happened to me...I bought ..i was dealin construction equipment and I wound up with five bulldozers and I can't sell one...they're just sittin there...there's one down a bit on repairs that needs work and there's a big international...a good dozer and there's a john deere almost new and there's another john deere there...a good machine ...a little older and he says...if I could sell them ...I'll take your poles, so I'm thinkin'...what the hell can I do with five bulldozers? So, I said ...Bill, let's try and see if we can't figure something out so anyways, I traded him the poles that I had in stock and it was the only one of a very few left ...and I'd get the five bulldozers but I had to do the truckin'...and put them up there and all that ...unload em, and bring back bulldozers ...so I picked up the phone, 
I phoned (wife) back...'oh, whadaya want now? Are you on your way home?'...I said, guess what, 'what now?' ...'you're the proud owner of five good big bulldozers '..she said 'WHAT ...are you gone crazy?' (laugh)...I said ...'but..it's somethin different...I still got no money but it's something different anyways'...'well I'll tell you something, you better find out what you're doing with them mister cuz you're in trouble '...I had the (construction company) over here and I knew they were looking for a good one and they'd cash money ..they had piles of money... (and then)a hutterite farm ...so I called them up and I sez, I got ,..i told 'em what I had ...it was john deere..it was perkins new shape and all that ...' well can I come and see it?' and I sez, no, you can't come and see it...I'll pick it up and take it over to you and see what you think of it whaddaya want for it...I wanted 25,000 for it ...so, well, bring it over and we'll try it ...so..took up a load of posts and I had a truck to pay too that day so I was hopin the deal would work...dumped them off, put on the dozer and went to the hutterites and put it off, and they just loved it, wrote me a cheque for it...home I come and another load up and kept getting the bulldozers ...and the big TD international...I got right down to it ...there was one I sold ...up to Kaladair...the next town back...northbrook ...went pretty well for parts and I got a good price and I sold the others and I got good money out of them ...real good money and I wound up with this great big red TD international, 2 motors in it..one pup motor you'd start to start the big motor and it was in brand new shape but old...and (wife) said to me, don't sell that bulldozer till we get...a laneway in here , cuz our lane way wasn't the way you knew it, it was around the hill ..alright, so I saved it for that and (neighbour) wanted some work done with it and is ent it over to go through the creek to 
(neighbour)'s and ...one track come off...so (neighbour) sez get on and I'll show you how to put it on...he snapped it on..he tightened it with the grease gun and we made it work and we got it home and we did the laneway ..and...it wasn't sellin'...there was a lad in Pembroke heard about it ...and...bring it up...he's sure he'd want it, but he didn't have much money...there was a lad owed him eleven thousand dollars and I, uh, ...he said if I can get that...I've got that and a bunch of cattle to ship to Toronto, so I said, I'm in the cattle business, I can take some cattle so up I went and the guy that owed him the money paid him ...he had that and he give me a bunch of cattle, what I needed and he'd cattle left...well, he said, you going to Toronto?... he said, you want to ship them for me...take them all...so I did and I brought him back his cheque , and he loved the bulldozer, so I wound up ...all in all...got rid of the posts, paid the truck, and went on with all the bullshit...I wound up with...oh, I mighta wound up...I wound up ....with.....maybe 16 or 18 thousand dollars ...to the good...I had 6 thousand dollars and done...and I got home and said 'there mom, there's the total the way it is...I got rid of my posts ...the dozers all sold ...the cattle deal went good and everything.... she said...did you read the paper?'...I said no...there's an advertisement...we need a furnace here, downstairs here in the house... a wood furnace and it's advertised down there near Rideau furry, and we should go and see it, so we got in the car to go down and ee the furnace and just before we got there we seen a brand new dodge truck sitting out at the road...a for sale sign on it...so, there's what you really need...you need that..if you're sensible you'd go in and see '...'I don't want to spend the money'...'you should go in'...so we stopped and knock on the door...yes, it's for sale ...and I said how much, and he said wait, I'm not sellin 
that, I want everything to go...and I said, well, what's everything...well, l've got a horse trailer here ...they lived out in ...lower $\mathrm{BC}$ or the states and they run a..they were from here around almonte and they went out there on their honeymoon and she got pregnant and she couldn't travel and they stayed there and they bought a drive in theatre and they spent their whole married life out there, but anyways, they wanted to settle back here so back they come ..they bought the new truck, put the horse trailer on it and all they were bringin, they put it in the horse trailer for pullin it down and halfways down somebody come through a stoplight and hit them dead on and smashed their new truck all to hell ...so, there was nothing left to fix so the insurance bought him a brand new half ton...he was in the hospital a couple of weeks ...and she took a motel till he got feelin like he could travel so he bought another brand new dodge truck and hooked on the horse trailer and headed for home ...she was drivin behind him with a big Chrysler car ...so I gotta sell everything...'what are you asking?' ..'I'll sell you everything for $\$ 12000 \ldots$...well I said, now just a minute...I'm not spending all my cash ...I'll tell you what I'll do...I'll give you 6000 cash for it all ...oh, there was two cutters that was in the trailer ...'oh, I can't that..no no...well now just a minute, I'm gonna ask wifey...you're the first man that offered me cash.' l've got the cash on me, you know what I mean, there's no cheque...just, I'll pay you. So, let me ask wifey so he goes into the house for a minute and comes out with his hand out ...shake hands, it's a deal, it's a deal...well I says, I'll pay you right ...no, you won't he says, I'll have this truck ...the safety check and papers all ready...you're the first man I've met..i've tried to sell that truck all summer..you're the first man l've met with cash...you meet me tomorrow at noon at 
the commerce bank in (town) and you count the money to the tiller...cuz I'm scared of your money, so that's good, so I met him there and the truck was parked there with the trailer on and the buggies in it , or the cutters...and went in and counted out to the tiller ...she said it's fine thanks and he handed me everything, ownership ...so, I was down the street aheading for home, proud of my new truck, I met (wife's) brother and he said we're in town lookin for a new half ton today and I said, well, I just bought one and he looked at it and he said, how much you take for it? I said, it's not for sale.. He says, i'll tell you what l'll do, that's exactly what I'm lookin for and I'll give you 12,000 cash and I said no, (wife) told me to keep this one.

\section{Participant 5, mid 60's, 'hippy' retired marijuana farmer}

Welcome to grade 2, 3 and $4 \mathrm{ok}$, so then my parents were smarter than the teachers or the system and they saw it and did the testing and everything and I got to go luckily to dr. (name), who's a world renowned person who understood this shit, who had a private school in (wealthy residential 'village' in city) where I went half days and public school the other half and that was thanks to my parents affordability and knowledge and that Hitler drove the polish jews out of Europe and they ended up at (university) as a prof and department head and then had her own private school so anyway, I got re-wired there and then in school I was more one of these hyperactive kids. I liked sports and adventure, and I was...busy...and that was 
all buckle down and then they all wanted it to be top down authority and I wanted it to be more of a...like, you give your respect where it's due cuz it's earned rather than because you're on that side of the desk and I'm on this, so..they created the outsider. G'day, I was just a nurtured little kid suckling and then all of a sudden I'm a fucking outsider of this whole thing and can't relate to any of it...family, school (laughs) Then I go to work and everybody job, almost per item, goes bankrupt or some fuckin thing fails so if you wannna ruin a company just hire me cuz I can do that in a year or two. It has nothing to do with me but that's my experience there

Out here, I was on my own but I had a good relationship with (ex-partner) so she came along for the ride but it wasn't her thing and then my grandmother gave me the money to buy a farm but when she saw it...she was from a farm, she said "I don't know what's going on with (participant) but that's not a fuckin' farm and I don't know what he's doing but here's a down payment" and I'm good at talking so I rousted up a bunch of people to contribute and we had a little commune there for a few years but it wasn't gonna work cuz they had legs in both worlds and I just committed to the one. Sold that...went on my own with (ex-partner)and been out here ever since.

The moving to the country was a good one. Making that decision, and sticking with it was another good one so that I'm one of the longest serving members of the...of the choice, and then uh, having the breakup of the family where the mother took the children and got the state to accept that, but I got to see them too but not on a full 
time basis and she was better prepared for that anyway and the fact that that was so bitter and protracted and went on for such a long time but we never involved the kids in it, but it was happening, so the weakening of both positions cuz of divided and then with the grandkid and the cottage that whole thing healing and then becoming confidant and friends and the thing is I looked at it as a big tree with two huge branches...an oak..i've got one out the back. So, one was suited to the school, the government jobs, the city, the system, the other was this guy you're talking about...the dinosaur guy who went...re-invented agriculture, who come from agriculture and when it wasn't workin was something else, you know what I mean, just kept on the creative side of re-invention, don't ever give up, come up with a better idea...see how that goes. So the big tree, two branches, nobody's right, bobody's wrong, one's reaching for sun this way, the other that way.1059 so that's good and then my lawyer can't believe it, cuz he was her lawyer to start and then she went for this viper guy and she lost everything but anyways I'm giving this place to her if I go first...he's like holy fuck, you're a nice man, so you know what I mean, in the end it'll be peace all around

So then the next one would be...the other big ones would be to be...stolen from...confidence, like either hidden steal or straight up steal and the other would be being tol...that's the sleazy underbelly at work tearing you down to take your food for their food play and the other would be the moral authority big footing you so that, no, you can't do this. I'm here to wipe the smile off of smiling XXX XXXX, that was the first investigator, the first bust thing, so it was this personal, vindictive 
hate for me, which just created my personal vindictive hate for them, but I'm bigger than that, I could give a fuck about them, I'm....oh, it's illegal is it? Well just let me finish that...oh, would you dispose of it for me, in other words (Gives 'up yours' hand signal), fuck you, because I don't believe in that law,

Who runs all the Petrocans...you know when I was in the (anti) uranium thing and (local First Nations leaders) and all these fake white Indians you know, I said, "I'm an Indian too, and the Indians are all around us too" and they said, oh really, where are you ... and I said, well I got relatives from the west ..."what are you? A Sioux or a Blood or a.."...No no, I'm from more local...my tribe owns all the Petrocans...we sell cigarettes too, I said. (laughs) Did that fuck their heads. I love doing that to people because it's such a crock of shit, eh? Isn't it? So we own all the Petrocans from Ottawa to Peterborough on 7 (highway)."

Like he was on the front lines over there...I remember him ...bald...and this was the way it was...put a saucer under the teacup cuz it all ended up in there. yah, because of bombs went off all around him and stuff..,bald cuz of the gas. So, anyway, that's probably why I can handle this police shit and everything, and guns and all...fuck...well, we're used to taking...we're not going to be intimida...we're not easily intimidated. Ok, so we're not out looking for anything neither.

He couldn't drink in his house cuz his wife wouldn't go for it ...Strachan, so she was a teetotaler. They said that the wife, she was small and busy...they said she never walked, she ran. ok so she's one of these little fuckin bunch like around here that 
have little doorways and busy and chew the trees down and make a shitload of babies and everything, so anyway, he would be at an auction or something and he would be known to have drinks and then I think some...one time he went on a bender for three days or something and I betcha that's when he got all the lying about his father killing himself and then his brothers, all those telegrams from Ontario that he probably burnt and he probably absorbed all that and went to drink for a bit...for the pain...just what I'm doing, so the...but the silence, eh? The proud Presbyterian and the...but he knew why he left Dad cuz Dad was out of control and he would have inherited all that fuckin...550 acres of fuckin' ...he was the oldest son...of cleared Stratford land. So he left...fuck off, I'm taking my little wife, my grandfather was one or two years old when they got on a train down through Chicago and that was to the red river...took the fuckin boat up to Winnipeg and then the first train into fuckin moose jaw ...or no, into, down through oxbow and into estevan and down that way. So, right early pioneer and so 1890 sort of..in southern Saskatchewan and then Saskatchewan became a...I betcha that he wasn't taking graft and that he...I woulda...but that's the (father's surname)to combine with the (other forebear surname). He came from...his father was probably a drinker but maybe he wasn't but his grandfather was, the one who came over, cuz that's, it's written right in the history books ...(forebear), how he set up crews to clear land and he was clearing land for the survey users on the survey crew for that county, perth county and stra...octon (?) township, so, then in clearing land he set up competitions of men, and the one who could do it first you would win a bottle/barrel of whiskey or something but you know woe behold the man that felled 
a tree on the other wrong side, and they come to realize that when spirits sagged or exhaustion set in then the whiskey would come out and go around and they'd keep going eh...so he came to realize the folly of that, so it's probably maybe later that it became...wow, and in the old country and he was a marksman because they said his table always had venison on it so he had a gun and he knew how to use it and early pioneers, because he probably was on the constabulary to keep the fuckin irish catholics down, eh? You know and he was in that township where the boyne happened, eh? He was from county monaghan right up against north Ireland so he was out there to do battle and he was sent there. That family in 1603 when james came on the throne of both England and Scotland..it wasn't a war zone...hadrian's wall, lowlands, islands and the border tribes thing, that was over and some of our family got totally exterminated, cuz of sides in this shit and this guy took a plea bargain because he was squeezed between the two crowns now and had a reputation, like me getting pinned, that we got an offer you can't refuse...we're sendin you and your whole family to fuckin Canada and you're gonna keep the peace for us over there and he did and then when the famine came, right in the beginning of the famine, he got the fuck out but there was a woman and a man and six kids and they all lived and they all got here and they all did that fuckin thing, so, he must have had money too. So, so he could shoot so he's probably killed people ...over there....and then I read a whole thing about the Donnelly thing and the Donnelly thing was just a county away. The same time period, even a little later...he would have known it all cuz it was right there in London. 
He would've known it all cuz he was so close to it, and Ireland and the whole diaspora, they were probably talking to each other all the time so that would have been a shakedown but they exploded where my family imploded...he committed suicide over this fight with the minister over withdrawing his dues at the church that he built and the manse that he built looks just like his house and the school and the graveyard that he gave and this guy looks like a police sargeant that was going after louis riel or something ...one of those really fuckin English sargeant major types and a Presbyterian...all the others were bearded like you ...fuckin philosopher kings or something ...so he was a proud man and in the end when he fuckin hangs himself they have to run up to the church where they're all in the church on a Sunday morning about this guffuffle...it was done...communication, it's like your boys ...they can...how do you choose to communicate? Are you gonna go shoot them now? Or, whaddaya you...burn his house? Those are hateful things...I've had them myself...I really fuckin wanted...and I've had them, and I've done some of this shit but the thing is, hey you're not going to get the results you want, but then this new urban ism's not the answer either. It's the other side of sneaky, you know...having one word meaning two things to two different people ...it's obfuscation...you know obscurity and there's too much of that going on and we're teaching it in school just like the manipulation game commercial. That fuckin MIT business school, that's all it is. It's just like where's the military come from, fort bennington, you know like in Georgia, like it's DUH! West Point...I'm just reading the New American Future, have you heard of that, Simon Schama? Fuck in excellent cuz it's snippets from now and all the way into the beginnings, eh? And the different contributions and the different 
stages and evolutions...it's a good backdrop to what's going on cuz it's grounded, eh..in some semblance of pastiche reality...in snippets like l'm giving you little history snippets here. So the (surname)'s ...he goes and fights and then he comes back and so my father, uh, they leave...he goes to the university of Saskatoon. Er...Saskatchewan, Saskatoon and he wanted to be an architect you know, passion and dream...look at (brother), he gets his stuff from there. I'm more like the tinsmith welder bunch, I can do this wood stuff but I don't care about fine little angles, like, so tight, I'm in to filling joints and stuff and makin it fit and not struggling with it cuz if you try and cut this too tight you can't get it in place, and stuff...so the thing is, he goes to school and becomes a chartered accountant cuz they're the (indistinct)...he and (daughter)...he would've been so proud of her and they would've understand each other in terms of ...how it works when you're inside trying to make a difference and do a good job and have pride in your work and have integrity cuz my dad could have been a millionaire many times over with his inside proprietary information on this shit, eh cuz he was with the auditor general for years as the head of this region right here...Toronto, Montreal, Ottawa, right up to Baffin Island, Frobisher bay and the gold mines all up through and everything, eh, so it was the main central...there was four areas I think...the prairies and both coasts and quebec...five, but he was the main one and fourty accountants under him so the fuckin guy did that...came from the prairies for opportunity, I got pictures of him on parliament hill lookin dapper as fuck going in with his white shoes and ...anyway...Mr. Professional and you should see his hand writing you know, so anyway, they would, they're more alike in terms of...but he's way more repressed 
than her, she's like my mother and she's very, she's actually as close to my mother as to her mother or closer so and she's very close to me, I talk to her all the time.

\section{Participant 6-mid 30's- Social worker}

I bounced around a lot as a kid...so I was constantly trying to fit in where I was at and it took a long time to sort of establish a sense of home. My dad was a presbyterian minister, so... it's very firmly engrained, you know, that you try and make this world a better place...you do what you can to help people in need, and celebrate...when people are joyful ...didn't help that my mom was a social worker...kind of condemned down this path from the get go ...that's really helped with these values.I'm suddenly realizing how conservative I am in some of my thoughts. Hunh! [laughs]That's a shock. I grew up as a big screaming lefty, so...[laughs] ...it's just that strong focus on family...until you talk about it you don't always realize how pinnacle and focal it is.

...I was going to re-educate the world. Teach them how to do things properly. I know better now [laugh]...when I was in my twenties, it would have been a big revolution [laugh]... then somewhere around my mid-twenties, it looked more like... in essence, helping teach some people to be less terrible to be less terrible to each other and helping people to...be less selfish and maybe, maybe more...group interested, ...but you know what, before you look at changing the entire scope of society you got to look at your own community and your own family and how that operates and I think 
that comes with maturity, whereas you want to change the world but sometimes you got to address your own backyard. Before you can fix the problems in the community, you got to make sure that your own household is running smooth. ...I went on exchange to (African state)...I was in my mid-twenties and wanting to change the world and then seeing that alright, some problems can't be fixed, at least not immediately and in the short term 